\title{
DETERMINAÇÃO DE ZONAS DE MANEJO E ESTIMATIVA DA PRODUTIVIDADE DE CULTURAS DE GRÃOS POR MEIO DE VIDEOGRAFIA AÉREA DIGITAL MULTIESPECTRAL
}

\author{
JOÃO CÉLIO DE ARAúJO
}

Tese apresentada à Escola Superior de Agricultura "Luiz de Queiroz", Universidade de São Paulo, para obtenção do título de Doutor em Agronomia, Área de Concentração: Irrigação e Drenagem.

PIRACICABA

Estado de São Paulo - Brasil

Junho - 2004 


\title{
DETERMINAÇÃO DE ZONAS DE MANEJO E ESTIMATIVA DA PRODUTIVIDADE DE CULTURAS DE GRÃOS POR MEIO DE VIDEOGRAFIA AÉREA DIGITAL MULTIESPECTRAL
}

\author{
JOÃO CÉLIO DE ARAÚJO
}

Engenheiro Agrônomo

Orientador: Prof. Dr. CARLOS ALBERTO VETTORAZZI

Tese apresentada à Escola Superior de Agricultura "Luiz de Queiroz", Universidade de São Paulo, para obtenção do título de Doutor em Agronomia, Área de Concentração: Irrigação e Drenagem.

PIR A C I C A B A

Estado de São Paulo - Brasil

Junho - 2004 


\section{Dados Internacionais de Catalogação na Publicação (CIP)}

DIVISÃO DE BIBLIOTECA E DOCUMENTAÇÃO - ESALQ/USP

\section{Araújo, João Célio de}

Determinação de zonas de manejo e estimativa da produtividade de culturas de grãos por meio de videografia aérea digital multiespectral.

101 p. il.

Tese (doutorado) - - Escola Superior de Agricultura Luiz de Queiroz, 2004.

Bibliografia.

1. Agricultura de precisão 2. Grãos 3.Sensoriamento remoto 4.Soja 5.

Videografia. I. Título

CDD 633.34

"Permitida a cópia total ou parcial deste documento, desde que citada a fonte - O autor" 
Aos meus familiares, em especial minha esposa Cristina, meus filhos Bruno e Carolina, meus pais João e Eliane e minhas irmãs Juliane e Janaína

OFEREÇO

À minha querida avó Helena (in memoriam), 


\section{AGRADECIMENTOS}

À Deus, pela saúde e perseverança;

A Coordenação de Aperfeiçoamento de Pessoal de Nível Superior (CAPES) pela concessão da bolsa de estudos;

Ao Prof. Dr. Carlos Alberto Vettorazzi, pela orientação, ensinamentos e amizade;

Ao Prof. Dr. José Paulo Molin, pelo apoio na realização do trabalho e amizade;

Ao Prof. Dr. Rubens Angulo Filho, pelas sugestões e amizade;

Aos Professores do Departamento de Engenharia Rural, pelos ensinamentos e pela oportunidade de cursar o programa de pós-graduação em Irrigação e Drenagem;

Aos amigos da ESALQ, alunos e funcionários, que ajudaram em vários momentos na realização deste trabalho, em especial ao amigo Luis Artur (in memorian); 


\section{SUMÁRIO}

Página

LISTA DE FIGURAS …........................................................ vii

LISTA DE TABELAS ...............................................................

LISTA DE ABREVIATURA E SIGLAS........................................ xii

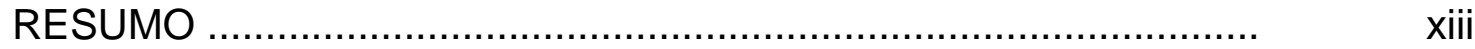

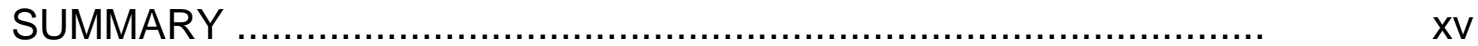

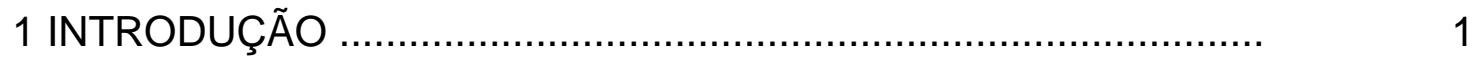

2 REVISÃO DE LITERATURA.....................................................

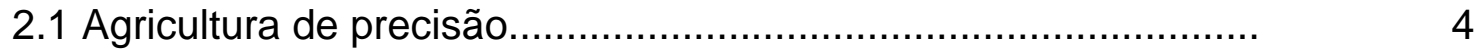

2.2 Mapas de produtividade - conceito e finalidade........................... 6

2.3 Sistema de informações geográficas...........................................

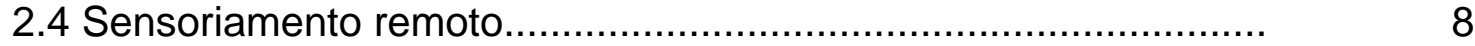

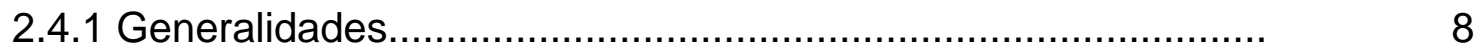

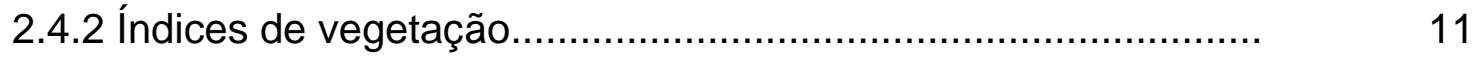

2.4.3 Classificação de imagens...................................................

2.4.4 Emprego do sensoriamento remoto aéreo na agricultura.......... 15

2.4.4.1 Fotografias aéreas.......................................................... 15

2.4.4.2 Videografia aérea........................................................... 19

2.5 Previsão de produtividade e fatores agronômicos......................... 22

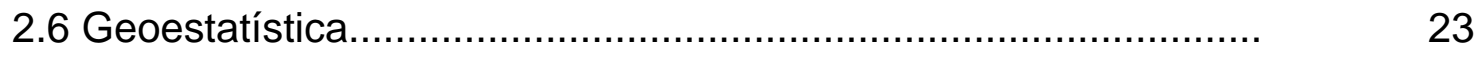

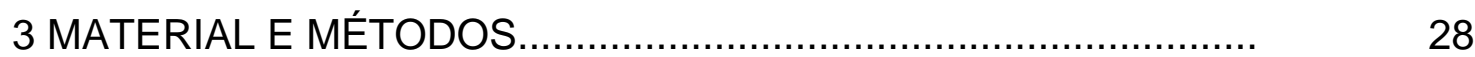

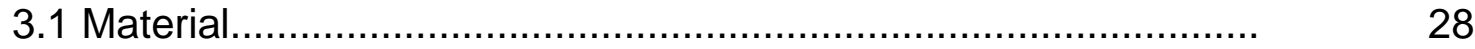

3.1.1 Caracterização das áreas de estudo...................................... 28 


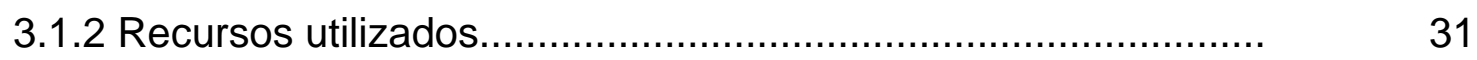

3.1.2.1 Câmera de vídeo........................................................... 31

3.1.2.2 Sistemas computacionais..................................................... 32

3.1.2.3 Medidor de índice de área foliar............................................ 33

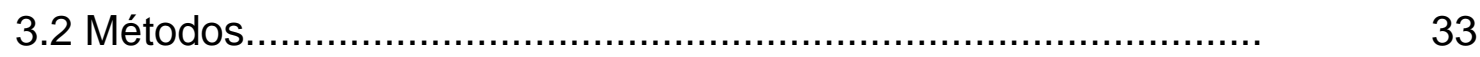

3.2.1 Processamento dos mapas de produtividade.......................... 33

3.2.2 Obtenção e tratamento das imagens........................................ 35

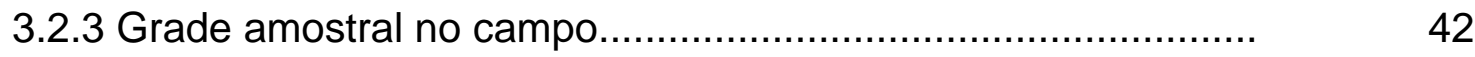

3.2.4 Determinação dos índices de vegetação.....................................

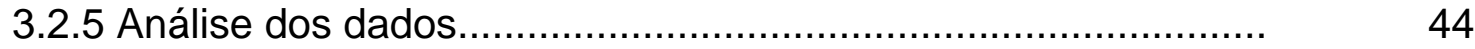

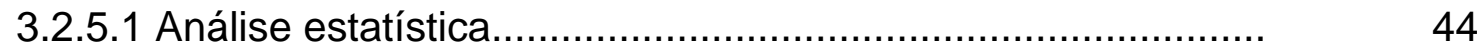

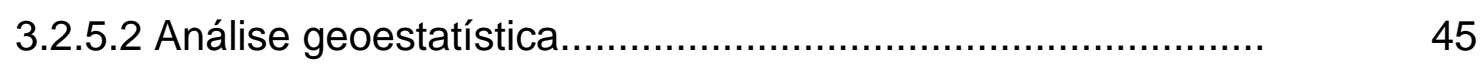

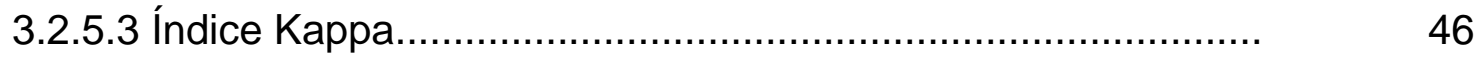

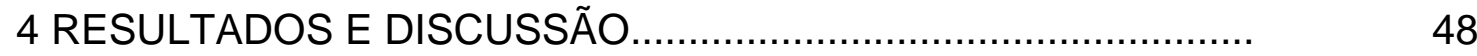

4.1 Imagens aéreas das culturas da soja e do trigo.......................... 48

4.2 Análise dos dados coletados em grade..................................... 49

4.2.1 Análise estatística.......................................................... 49

4.2.2 Análise geoestatística........................................................ 57

4.2.3 Mapas produzidos por meio de dados coletados em grade...... 61

4.2.4 Regressão entre mapas de variáveis coletadas em grade e

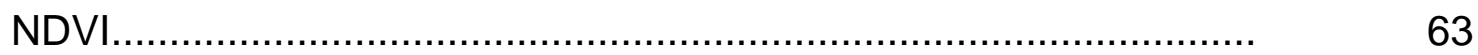

4.3 Análise entre mapas de produtividade e imagens NDVI.............. 67

4.4 Regressão entre variáveis, pixel-a-pixel..................................... 70

4.5 Variáveis classificadas.......................................................... $\quad 76$

4.5.1 Análise de concordância espacial entre as variáveis classificadas................................................................................. 80

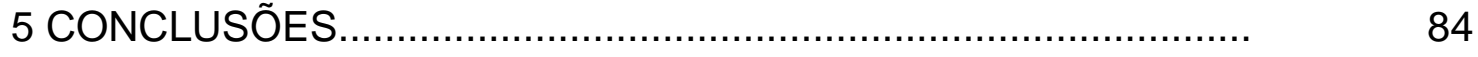

REFERÊNCIAS BIBLIOGRÁFICAS.............................................. 


\section{LISTA DE FIGURAS}

Página

1 Semivariograma teórico................................................................ 25

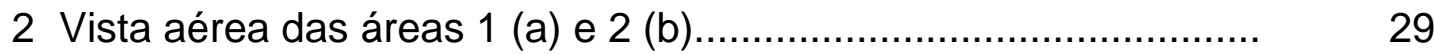

3 Visão tridimensional das áreas de estudo: área 1 (a) e área 2 (b). 30

4 Câmera de vídeo utilizada no trabalho......................................... 31

5 Esquema do posicionamento da câmera no assoalho do avião.... 36

6 Vista lateral (a) e do interior do avião (b), dos equipamentos utilizados para a obtenção das imagens...................................... 37

7 Processo de normalização radiométrica: extração dos valores

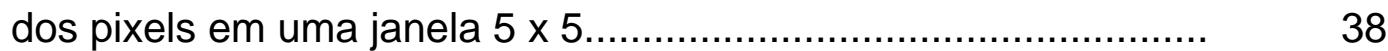

8 Mosaico sem a normalização radiométrica (a) e com a normalização radiométrica (b), evidenciando-se o efeito obtido....

9 Grade amostral de uma das áreas de estudo, com distância de

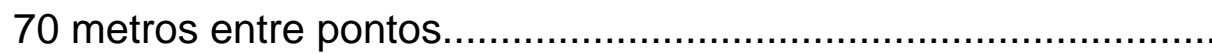

10 Imagens da área 1, referentes à cultura do trigo, nos espectros do vermelho (a) e do infravermelho próximo (b) e referentes à cultura da soja, nos espectros do vermelho (c) e do

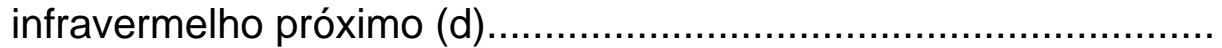

11 Imagens da área 2, referentes à cultura do trigo, nos espectros do vermelho (a) e do infravermelho próximo (b).

12 Histograma (a) e gráfico de probabilidade normal esperada (b) para os dados brutos de IAF. 
13 Histograma (a) e gráfico de probabilidade normal esperada (b) para os dados brutos de altura de plantas

14 Histograma (a) e gráfico de probabilidade normal esperada (b) para os dados brutos de número de plantas por metro linear.

15 Histograma (a) e gráfico de probabilidade normal esperada (b) para os dados refinados de IAF.

16 Histograma (a) e gráfico de probabilidade normal esperada (b) para os dados refinados de número de plantas por metro linear.

17 Semivariogramas de IAF (a); altura de plantas (b); número de plantas por metro linear (c)

18 Gráficos de validação cruzada para IAF (a); altura de plantas (b); e número de plantas por metro linear (c)

19 Índice de área foliar, para a área 1, dividido em cinco classes......

20 Altura de plantas, área 1, dividida em cinco classes.

21 Número de plantas por metro linear, área 1, dividido em cinco classes

22 Imagem NDVI para a área 1, cultura da soja, dividida em cinco classes

23 Produtividade da cultura da soja, na área 1, dividida em cinco classes

24 Produtividade da cultura do trigo, na área 1, dividida em cinco classes

25 Imagem NDVI para a área 1, cultura do trigo, dividida em cinco classes

26 Produtividade da cultura do trigo, na área 2, dividida em cinco classes

27 Imagem NDVI para a área 2, cultura do trigo, dividida em cinco classes 
28 Dados coletados em grade, classificados em duas categorias: IAF (a); altura de plantas (b); número de plantas por metro linear

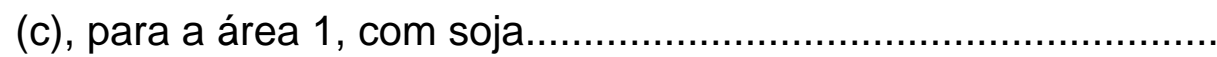

29 Produtividade (a); imagem no vermelho (b); imagem no infravermelho próximo (c); e imagem NDVI, para a cultura da soja, área 1, classificados.

30 Produtividade (a); imagem no vermelho (b); imagem no infravermelho próximo (c); e imagem NDVI, para a cultura do

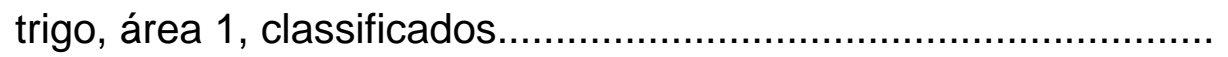

31 Produtividade (a); imagem no vermelho (b); imagem no infravermelho próximo (c); e imagem NDVI, para a cultura do

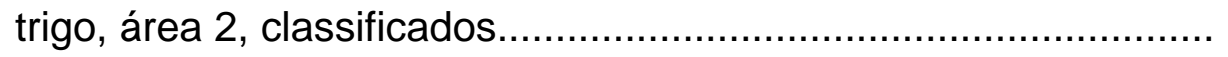

32 Mapa de correlação entre classes obtidas no processo de tabulação cruzada, para a produtividade da cultura da soja e o

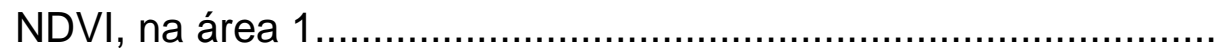




\section{LISTA DE TABELAS}

Página

1 Áreas de estudo e localização......................................................... 29

2 Especificações técnicas da câmera MS3100 (Duncan Technologies, Inc., 1999)...........................................................

3 Classificação qualitativa do índice Kappa.................................... 47

4 Resumo estatístico dos dados coletados em grade, na área 1, para a cultura da soja.......................................................... 50

5 Teste de Shapiro-Wilk para os dados brutos.............................. 54

6 Teste de Shapiro-Wilk para os dados refinados............................ 57

7 Resultados da análise geoestatística, para os dados coletados em grade .................................................................... 5

8 Resultados da análise de regressão linear entre mapas, pixel-a-

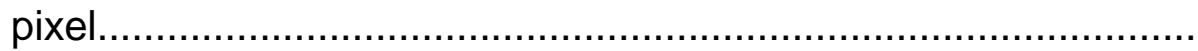

9 Comparação entre valores de $\mathrm{F}$ calculado e tabelado, referentes as regressões realizadas para os dados coletados em grade....... 65

10 Resultado da análise de regressão linear entre mapas, pixel-apixel, para a área 1, envolvendo dados obtidos a partir das

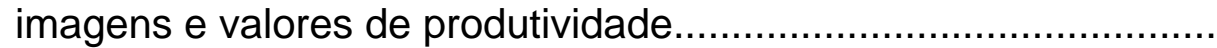

11 Resultado da análise de regressão linear entre mapas pixel-apixel para a área 2, envolvendo dados obtidos a partir das imagens e valores de produtividade 
12 Comparação entre valores de F calculado e tabelado, referentes

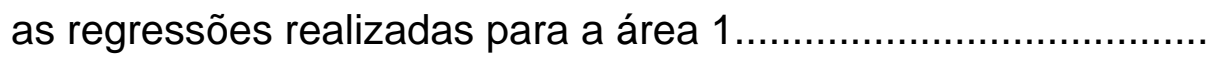

13 Comparação entre valores de F calculado e tabelado, referentes as regressões realizadas para a área 2 ........................................

14 Resumo estatístico das variáveis de imagem e produtividade

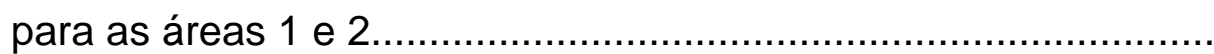

15 Índice Kappa para as variáveis obtidas em grade e imagem NDVI, para a área 1, cultura da soja..........................................

16 Índice Kappa entre as variáveis de imagem e produtividade

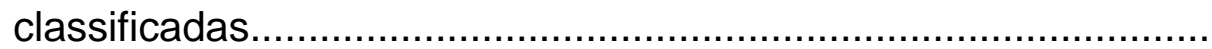




\section{LISTA DE ABREVIATURAS E SIGLAS}

$\begin{array}{ll}\text { AP } & \text { Agricultura de Precisão } \\ \text { CCD } & \text { Charge Coupled Device } \\ \text { DGPS } & \text { Diferential Global Positioning System } \\ \text { GPS } & \text { Global Positioning System } \\ \text { IAF } & \text { Índice de Área Foliar } \\ \text { IV } & \text { Índice de Vegetação } \\ \text { NDVI } & \text { Normalized Difference Vegetation Index } \\ \text { RGB } & \text { Red Green Blue } \\ \text { RS } & \text { Razão Simples } \\ \text { SIG } & \text { Sistema de Informações Geográficas } \\ \text { SR } & \text { Sensoriamento Remoto } \\ \text { UTM } & \text { Universal Transversa de Mercator }\end{array}$




\title{
DETERMINAÇÃO DE ZONAS DE MANEJO E ESTIMATIVA DA PRODUTIVIDADE DE CULTURAS DE GRÃOS POR MEIO DE VIDEOGRAFIA AÉREA DIGITAL MULTIESPECTRAL
}

\author{
Autor: JOÃO CÉLIO DE ARAÚJO \\ Orientador: Prof. Dr. CARLOS ALBERTO VETTORAZZI
}

\section{RESUMO}

O emprego de câmeras digitais multiespectrais torna possível a utilização de índices de vegetação, obtidos por meio de operações matemáticas entre bandas espectrais de uma mesma imagem. Estes índices podem ser empregados na estimativa de produtividade de culturas agrícolas e no delineamento de zonas de manejo, por apresentarem relação com o vigor da cultura. Algumas variáveis obtidas no campo, como o índice de área foliar (IAF), a altura de plantas e o número de plantas por metro linear, também podem ser empregadas na avaliação do vigor da cultura. O objetivo principal deste trabalho foi avaliar imagens obtidas por meio de videografia aérea digital multiespectral, quanto ao seu potencial na estimativa da produtividade e na determinação de zonas de manejo em culturas de grãos. As imagens foram adquiridas por meio de uma câmera de vídeo digital multiespectral (Duncantech MS3100). Também foram utilizados mapas de produtividade, referentes a duas áreas cultivadas, primeiramente com trigo, no inverno de 2001, e na seqüência com soja, no verão de 2002. Além disso, foi realizado um trabalho de campo, na cultura da 
soja, em uma das áreas de estudo, onde foram determinados, em uma grade amostral, o índice de área foliar, a altura de plantas e o número de plantas por metro linear. As imagens aéreas foram corrigidas geometricamente e normalizadas radiometricamente no software Idrisi32, após o que foi realizada uma regressão linear simples entre as imagens e os mapas de produtividade, pixel-a-pixel e com as imagens classificadas. Os dados coletados em grade foram analisados por meio da estatística descritiva e da geoestatística, sendo posteriormente interpolados, gerando os mapas de superfície das variáveis estudadas. Os mapas de superfície criados para as variáveis medidas no campo apresentaram elevada correlação entre sí. A imagem NDVI apresentou uma melhor relação com a estimativa de produtividade, quando comparada com as imagens das bandas espectrais individualizadas, do vermelho e do infravermelho próximo. Concluiu-se que as imagens aéreas digitais multiespectrais obtidas por videografia são eficientes na estimativa da produtividade de grãos quando existe elevada variabilidade nas imagens e as mesmas não apresentam valores discrepantes. Também proporcionam informações importantes ao delineamento de zonas de manejo. 


\title{
MANAGEMENT ZONES DETERMINATION AND YIELD ESTIMATE IN GRAIN CROPS THROUGH MULTISPECTRAL DIGITAL AERIAL VIDEOGRAPHY
}

\author{
Author: JOÃO CÉLIO DE ARAÚJO \\ Adviser: Prof. Dr. CARLOS ALBERTO VETTORAZZI
}

\section{SUMMARY}

The utilization of multispectral digital cameras makes it possible the use of vegetation indices, generated by means of mathematical operations between spectral bands from the same image. These indices can be used to estimate crop yields and delineate management zones due to the relation between them and crop vigor. Some variables, measured on the field, such as leaf area index (LAI), plants height and plants per linear meter, can also be used in the assessment of the crop vigor. The main objective of this work was to evaluate multispectral digital aerial videographic images regarding their potential in crop yield estimate as well as in management zones delineation. The images were acquired with a multispectral digital camera (Duncantech MS3100). Yield maps were also used, for two cropped areas, firstly with wheat, in the 2001 winter, and afterwards, with soybean, in the 2002 summer. Moreover, a field work was accomplished, for soybean, in one of the study areas. Three variables were measured, on a sampling grid: leaf area index, plants height and plants per linear meter. The aerial images were geometrically rectified and radiometrically normalized, in the software Idrisi32, and then a simple linear regression was performed between images and yield maps, pixel-by-pixel and with the classified 
images and maps. Data collected on the sampling grid were analyzed by means of descriptive statistics and also geostatistics. After an interpolation procedure, surface maps of these variables were generated. The surface maps generated for the variables measured on the field presented high correlation among themselves. The NDVI image showed a better relation with yield estimate than the individual spectral bands, red and near infrared. One can conclude that the multispectral digital aerial videographic images are efficient for grain crops yield estimates, when there is a high variability on the images, without outliers. These images can also provide important information to the management zones delineation. 


\section{INTRODUÇÃo}

A perspectiva de estimativa da produtividade por meio de um diagnóstico pontual das condições da cultura durante o ciclo da mesma, com uma metodologia que apresente uma visão global da área, com elevado rendimento, confiabilidade e acurácia dos dados levantados, é um tema que vem se desenvolvendo na atualidade, dentro da abordagem da Agricultura de Precisão.

Com o mercado globalizado e a competição na agricultura internacional cada vez mais acirrada, é imperativo o aumento da eficiência ao longo da cadeia produtiva agrícola. A maior eficiência permite tornar o produto nacional mais competitivo, minimizando perdas, aumentando lucros e auxiliando na preservação do meio ambiente.

A quantidade de informações e a qualidade das mesmas vêm se tornando cada vez mais o diferencial entre os produtores, pois para a tomada de decisões são necessárias informações advindas do conhecimento das áreas produtoras e dos fenômenos que estão ocorrendo durante o ciclo da cultura. Este gerenciamento, envolvendo o conhecimento "ponto-a-ponto" da área produtora, é tema abordado na Agricultura de Precisão.

Culturas como a soja e o trigo são commodities agrícolas e tendem a ser cultivadas em áreas cada vez maiores e por produtores cada vez mais tecnificados. A obtenção de informações de grandes áreas cultivadas está exigindo o emprego de tecnologia, deixando de lado a verificação apenas por meio de visitas ao campo, o que exigiria o emprego de muitas pessoas e demandaria muito tempo. 
A disponibilidade de informações precisas e em tempo hábil, relativa às áreas ocupadas com culturas anuais, é de grande importância também para a elaboração de estratégias referentes ao armazenamento, comercialização e suporte às decisões governamentais.

Nesse contexto, o Sensoriamento Remoto aparece como um instrumento com elevado potencial para a coleta de informações sobre as áreas cultivadas, de forma abrangente, confiável e ágil. O emprego da videografia aérea multiespectral pode tornar mais eficiente a obtenção dessas informações, pois permite a coleta de imagens com extrema agilidade. Nesse processo são utilizadas câmeras de vídeo, montadas no interior de aeronaves, permitindo a obtenção de imagens com alta qualidade, possibilitando a exploração de várias faixas do espectro eletromagnético de energia, abrindo o leque para a investigação da área agrícola.

O emprego da videografia aérea, no contexto da Agricultura de Precisão, tem-se mostrado eficiente principalmente pela disponibilidade em tempo quase real das imagens, diminuindo o custo operacional para a determinação da variabilidade espacial no campo e, também, possibilitando a tomada de decisões durante a própria safra.

A verificação quase imediata dos fenômenos que acometem as lavouras, como detecção de falhas, doenças, infestação por ervas-daninhas, ataque de insetos e outros, durante as etapas do ciclo das culturas julgadas mais relevantes, onde estas alterações possam acarretar prejuízos ao produtor, já é uma informação de grande relevância, pois o trabalho de campo seria direcionado para as áreas críticas.

A possibilidade do emprego de câmeras digitais multiespectrais torna possível a utilização de índices de vegetação, obtidos por meio de operações entre as bandas espectrais de uma mesma imagem. Estes índices podem ser empregados na verificação do estado da cultura em um determinado momento do ciclo, ou até mesmo para a estimativa da produtividade da mesma, um dos pontos mais pesquisados e buscados atualmente. 
Os mapas de produtividade das áreas, obtidos geralmente por colhedoras instrumentadas, proporcionam a verificação e a comprovação da qualidade dos métodos e técnicas utilizados na estimativa de produtividade.

A videografia aérea, aliada às técnicas de mapeamento empregadas na Agricultura de Precisão, inclusive mapas de produtividade das culturas, pode gerar um conjunto de informações que, potencialmente, responderão questões relativas à eficiência da técnica da videografia aérea na previsão de produtividade.

O objetivo geral deste trabalho foi avaliar imagens obtidas por meio de videografia aérea digital multiespectral, quanto ao seu potencial na determinação de zonas de manejo e na estimativa da produtividade de culturas de grãos.

Os objetivos específicos foram:

- Verificar as relações entre NDVI (Índice de Vegetação da Diferença Normalizada), IAF (Índice de Área Foliar), altura de plantas e número de plantas por metro linear;

- Verificar o potencial da videografia aérea digital multiespectral na estimativa da produtividade de grãos, a partir da análise de imagens nos espectros do vermelho e do infravermelho próximo e também de imagens NDVI;

- Verificar o potencial da videografia aérea digital multiespectral na geração de zonas de manejo em lavouras de grãos. 


\section{REVISÃO DE LITERATURA}

\subsection{Agricultura de precisão}

As técnicas de produção agropecuária têm sido desenvolvidas para serem implementadas em grandes áreas, assumindo que estas sejam unidades homogêneas. Técnicos e agricultores têm identificado, contudo, variações por vezes significativas nas características físicas, químicas e biológicas do solo, em micro e macro escalas, as quais chegam, em muitos casos, a comprometer os padrões de produção, aplicação de nutrientes, corretivos, agroquímicos e irrigação (Costa \& Santos, 1997).

Taylor et al. (1997) comentam que, na prática, a maioria desses fatores não são controláveis, como por exemplo, o tipo de solo. Para melhorar a eficiência da produção agrícola, é necessário melhorar a administração dessas diversidades. Blackmore \& Larscheid (1997) complementam afirmando que existem três tipos de variabilidade: espacial, temporal e preditiva. A variabilidade espacial é observada ao longo do campo e pode ser facilmente constatada em qualquer mapa de produtividade ou fertilidade. A variabilidade temporal é observada quando se comparam mapas de produtividade de diferentes safras. A variabilidade preditiva é a diferença entre a previsão de algum fator e o resultado real no campo.

Schueller (1992) definiu que a agricultura de precisão (AP) é um método de administração cuidadosa e detalhada do solo e da cultura, para adequar as diferentes condições encontradas em cada talhão de lavoura, tendo em vista a desuniformidade intrínseca dos solos. Molin (2000 a) ressalta que a 
mesma apresenta um elenco de tecnologias e procedimentos utilizados para que os sistemas de produção agrícola sejam otimizados, tendo como elemento chave o gerenciamento da variabilidade espacial da produção e os fatores a ela relacionados, sendo na verdade um sistema de gestão ou gerenciamento.

A AP surgiu visando a adequar a administração agrícola em relação às condições variadas encontradas nos campos. Isso se tornou possível recentemente, devido ao desenvolvimento de tecnologias que permitem monitorar e medir estas variações (Steven \& Millar, 1997).

Para Searcy (1995) a AP promove um novo significado ao gerenciamento da produção agrícola, onde o campo passa a ser visto como uma somatória de pequenas sub-áreas, tratadas individualmente e consideradas as menores unidades gerenciais a fim de que a rentabilidade econômica de cada uma delas seja incrementada.

Segundo Goering (1992) a AP tem sido cada vez mais utilizada, graças às motivações ambiental e econômica, além do impulso tecnológico. Blackmore (1994) relata que a AP traz muitos benefícios para a agricultura, principalmente a redução da poluição advinda da aplicação excessiva de produtos químicos.

As técnicas que envolvem a AP apresentavam problemas para a sua execução, devido às limitações dos sistemas terrestres de navegação (Goering \& Han, 1993). Em 1989, o Sistema de Posicionamento Global (GPS) tornou-se disponível, de forma limitada, à comunidade civil, e foi testado como meio de localizar equipamentos agrícolas no campo (Colvin et al., 1996).

O posicionamento por GPS é baseado na triangulação entre satélites, que possuem coordenadas conhecidas em suas órbitas, e um receptor. $O$ receptor determina a distância entre ele próprio e os satélites e calcula as coordenadas do ponto. Para aumentar a exatidão do sistema, pode ser utilizado um GPS com correção diferencial (DGPS) (Lange, 1996).

É hábito referir-se ao GPS como se fosse o único sistema de posicionamento e navegação por satélites disponível. A intensa evolução nessa área vem gerando outros sistemas e, com eles, uma série de outras siglas. $\mathrm{O}$ 
sistema de posicionamento global russo (GLONASS), herdado da antiga União Soviética, está numa fase de retomada de investimentos para que a constelação seja ampliada, hoje com "janelas" de ausência de sinal de até 8 horas diárias sobre a Rússia. Os representantes da União Européia anunciaram que o sistema de satélites de navegação global europeu, batizado de "Galileo", foi recentemente aprovado pelos seus países membros e deverá estar plenamente implementado com seus 30 satélites em 2008 (Molin \& Vettorazzi, 2002).

\subsection{Mapas de produtividade - conceito e finalidade}

Molin (2000 b) define que, de maneira simplificada, o mapa de produtividade é um conjunto de células que representam, cada uma, uma área de alguns metros quadrados, composta pela largura da plataforma da colhedora e a distância percorrida entre duas leituras. A montagem do mapa nada mais é do que a plotagem de cada uma destas células num sistema cartesiano, onde o eixo " $x$ " é a longitude e o eixo " $y$ " é a latitude. As células são representadas por diferentes cores ou tons de cinza, para diferentes valores de produtividade, obtidos na tabela de dados gerados no campo.

Os dados de produtividade são obtidos a partir de dispositivos específicos que equipam a colhedora: o sensor de velocidade monitora a velocidade da colhedora; o sensor de fluxo de massa indica o fluxo de grãos que a máquina colhe instantaneamente; o sensor de umidade determina a umidade da massa do grão; e um dispositivo associado à posição da plataforma liga e desliga a coleta de dados. Quando a plataforma é baixada os dados são coletados (Molin 2000 b). Para Wagner \& Schrock (1989) o sensor de fluxo de massa e o sistema de posicionamento são essenciais para a obtenção dos mapas de produtividade.

Han et al. (1994) comentam que vários fatores físicos são envolvidos no processo de obtenção dos mapas de produtividade, como por exemplo, o 
tamanho da colhedora, a capacidade de leitura, sistemas de medição de grãos e posicionamento.

O mapeamento de colheita é considerado, por muitos pesquisadores, como sendo uma parte essencial da AP (Makepeace, 1996). Balastreire et al. (1997) concordam que a elaboração de mapas de produtividade é importante para a AP, pois além de servirem como fonte de informações para a elaboração de um plano de recomendação, permitem uma visualização espacial detalhada das condições da área produtiva.

Para Han et al. (1994) o mapa de produtividade auxilia os processos de gerenciamento localizado. Queiroz et al. (2000) comentam que os mapas de produtividade são geralmente utilizados para verificar as respostas econômicas e o impacto ambiental que o sistema de manejo pode trazer.

Schuler et al. (1998) advertem que os mapas de produtividade são muito utilizados, mas as informações são disponíveis somente após os problemas já terem afetado a produtividade agrícola. Assim, os mesmos são úteis em análises posteriores à época de sua obtenção.

Doege (1999) comenta que o mapa de produtividade é um instrumento valioso na determinação da variabilidade espacial da produtividade, mas não permite determinar a causa desta variabilidade. Molin (2000 b) esclarece que, além da variabilidade espacial, a produtividade também apresenta a variabilidade temporal e um comportamento diferenciado para diferentes culturas.

\subsection{Sistema de informações geográficas}

Para o tratamento dos dados de natureza espacial, obtidos no campo ou remotamente, são empregados os conceitos e ferramentas do sistema de informações geográficas (SIG). Tozi (2000) definiu que o SIG é um conjunto de equipamentos, sistemas computacionais, dados e usuários, perfeitamente integrados, de forma a tornar possível a coleta, o armazenamento, o 
processamento e a análise de dados georreferenciados, além de proporcionar a produção de informações. Para Câmara (1995), o SIG constitui-se numa importante ferramenta de suporte à decisão de dados geográficos.

De acordo com Moreira (2001), qualquer SIG apresenta duas características principais: insere e integra num único banco de dados, informações espaciais provenientes de diversas fontes e oferece um mecanismo para combinar estas informações, por meio de algoritmos de manipulação e análise, bem como de consulta, de recuperação, de visualização e de impressão do conteúdo do banco de dados georreferenciados.

Há uma ampla gama de aplicações para os SIGs, dentre elas a agricultura. Existem ao menos três maneiras dos SIGs serem utilizados: como ferramenta para a produção de mapas; como suporte para a análise espacial de fenômenos e como banco de dados geográficos (Câmara, 1995).

Para Star \& Estes (1990), os SIGs também funcionam como meio para a integração de dados espaciais adquiridos em tempos diferentes e em diferentes escalas e formatos. Os autores esclarecem que os usuários de SIGs normalmente trabalham com medição, mapeamento, monitoramento $\mathrm{e}$ modelagem. Câmara (1995) comenta que, em um SIG, os dados espaciais são representados por pontos, linhas e polígonos, associados a atributos que os caracterizam.

\subsection{Sensoriamento remoto}

\subsubsection{Generalidades}

Para Rosa (1990) e Novo (1995) o sensoriamento remoto (SR) pode ser definido, de uma maneira ampla, como a forma de se obter, por meio do uso de sensores, informações de um objeto, ou alvo, sem que haja contato físico com o mesmo. Os dados podem ser adquiridos nos níveis: aéreo, terrestre e orbital, 
de acordo com a distância entre o objeto de interesse e o sensor (Mather, 1994).

Amaral (1992) explica que o SR começou a se destacar na década de 1990, como uma das mais poderosas ferramentas para o estudo e avaliação das mudanças espaço-temporais do meio físico, por meio de medidas das trocas energéticas no ambiente.

Segundo Novo (1995), a energia registrada pelo sensor é a integração da resposta espectral de diferentes objetos (ou alvos). Dessa maneira, para cada "pixel" da imagem, tem-se um valor de nível de cinza proporcional à intensidade de retorno da radiação ao sensor. Um pixel " $X$ " qualquer pode assumir um valor entre 0 e 255 para resolução radiométrica em imagens de 8 bits. Ripple (1994) afirma que o pixel é o menor elemento da imagem, também denominado de célula.

As imagens eletrônicas digitais envolvem um arranjo de "pixels", tendo cada "pixel" um número digital (nível de cinza) que representa o seu brilho em cada banda espectral (Lillesand \& Kiefer 1994).

Segundo Câmara (1995), a área do terreno representada por um "pixel", numa representação matricial, determina sua resolução. Cada "pixel" é referenciado por coordenadas relativas à linha e à coluna da matriz (a partir da origem). As imagens digitais são exemplos de dados espaciais representados no formato "raster". No formato vetorial, busca-se a representação mais exata possível das entidades geográficas, por exemplo, bases planialtimétricas digitais.

No formato matricial (ou raster), o espaço é dividido em células de tamanho fixo (pixels), configurando uma matriz; no formato vetorial, o espaço geográfico é considerado de forma contínua (Câmara, 1995).

Floyd Júnior (1996) comenta que existem, ao longo de todo o espectro eletromagnético, regiões chamadas janelas atmosféricas, onde a absorção atmosférica é relativamente pequena, e que se caracterizam por uma boa transmitância à radiação eletromagnética. Conseqüentemente, são essas 
regiões onde, praticamente, todas as atividades em SR podem ser realizadas com maior facilidade (Garcia y Garcia, 1997).

A tecnologia de SR traz algumas possibilidades vantajosas como: observação de grandes áreas; estudos de locais de difícil acesso e, principalmente, em pesquisas de aspectos dinâmicos, como uso do solo ou cobertura vegetal, onde é possível obter rapidamente informações a um custo relativamente baixo (Richards, 1993).

Crosta (1993) afirma que o SR representa uma das formas viáveis de identificação ambiental em escalas locais e globais, dada sua eficiência, rapidez e periodicidade, constituindo-se em uma ferramenta estratégica, diante da necessidade de identificar as mudanças globais que vêm ocorrendo na superfície do planeta.

Moran et al. (1997) ressaltam a importância do uso do SR das variáveis envolvidas na produção agrícola, como uma forma de viabilizar a AP.

Silva et al. (2000) comentam que a tecnologia do SR pode ser aplicada como suporte ao manejo e controle de doenças das plantas, uma vez que há diferenças nas respostas espectrais de uma planta sadia e uma planta doente. Fenômenos como pragas, doenças e infestação por plantas daninhas, devem ser monitorados, mas devem ser desenvolvidos métodos diretos para a mensuração e espacialização de tais fenômenos.

Segundo Santos et al. (2001 a) o SR, além de dispensar a coleta e o processamento de amostras em laboratório, permite levantamentos precisos e confiáveis, em curto espaço de tempo, independentemente do tamanho da área em questão. As imagens obtidas podem ser digitalizadas e processadas, de modo que, cada pixel da imagem, na tela do computador, exibe suas coordenadas geográficas. Com o auxílio de um receptor de GPS pode-se, facilmente, encontrar no solo qualquer ponto indicado pela imagem obtida. Com esse conhecimento, as decisões sobre as medidas de controle a serem adotadas podem ser tomadas mais racionalmente e poderão significar redução de custos econômicos e ecológicos. 
Thomson et al. (1990) comentam que o uso de imagens obtidas por SR para identificar e mapear ervas daninhas nos campos, requer técnicas especiais de diferenciação entre as ervas daninhas e as culturas. Um exemplo seria a identificação em períodos estratégicos, como no início do desenvolvimento da cultura, identificando ervas daninhas nas entrelinhas das culturas. Voll (2000) acredita que a interpretação de imagens aéreas, auxiliada por dados obtidos por veículos terrestres, operações de campo e de caminhamento, são uma possibilidade viável na detecção e mapeamento de ervas daninhas.

Segundo Blackmer \& Schepers (1996), a avaliação da variabilidade espacial de uma lavoura pode ser realizada com o mapa de produtividade ou imagem aérea da cultura, para mostrar ou localizar as áreas com problemas de produtividade. Com essas informações, correções podem ser realizadas no cultivo seguinte.

\subsection{2 Índices de vegetação}

Formaggio (1989) explica que, com a finalidade de relacionar parâmetros agronômicos com indicadores espectrais das condições vegetativas de culturas, ao invés de se usarem bandas individuais simplesmente, de imagens multiespectrais, a abordagem mais utilizada tem sido a que emprega índices de vegetação (IVs).

Os IVs são considerados as mais importantes aplicações das operações aritméticas com imagens, por auxiliarem no realce de variáveis, principalmente de vegetação (Crosta, 1993).

O IV resulta de transformações lineares obtidas em duas ou mais bandas espectrais, envolvendo soma, razão, diferença ou qualquer outra combinação (Wiegand et al., 1991). Estas transformações irão gerar uma nova imagem, denominada "imagem índice de vegetação" (Sassagawa, 1999).

A maioria dos IVs é obtida de medidas radiométricas sobre dosséis de vegetação, nas faixas espectrais do vermelho e do infravermelho próximo 
(Huete \& Jackson, 1989). Segundo Barret et al. (1989), há duas razões básicas para o uso destas faixas espectrais: a) estão presentes em quase todos os satélites de SR; e b) contêm mais de $90 \%$ da informação espectral da vegetação.

A quantidade de energia refletida pelo dossel da cultura, nos comprimentos de onda correspondentes ao vermelho e ao infravermelho próximo, é significativamente correlacionada com a atividade fotossintética das plantas (Holben et al., 1980; Daughtry et al., 1984).

Nas imagens, a vegetação aparece muito escura no espectro visível $(0,40$ - 0,73 $\mu \mathrm{m})$, devido à alta absorção da radiação nesta faixa de comprimentos de onda pelos pigmentos da folha (clorofila, xantofila, carotenos etc.). Há pequeno aumento na reflexão por volta de 0,55 $\mu \mathrm{m}$ (cor verde), uma vez que os pigmentos praticamente não absorvem esta cor. A amplitude espectral de 0,73 $\mu \mathrm{m}$ a 1,35 $\mu \mathrm{m}$ (infravermelho próximo) é caracterizada por uma alta reflexão e uma baixa absorção, causada pela estrutura celular da planta (Novo, 1995).

Tucker (1979) revisou os IVs formados por várias combinações das bandas do infravermelho próximo e do vermelho e mostrou que eles são úteis para monitorar a fitomassa fotossinteticamente ativa.

As técnicas que usam a radiação solar refletida (nas regiões espectrais do visível e do infravermelho próximo) têm sido mais úteis para se estimar propriedades das plantas, tais como a fitomassa e o índice de área foliar (IAF), propriedades que, por sua vez, podem ser usadas para avaliar o resultado de estresses e podem servir como variáveis de entrada para modelos de crescimento de plantas e para modelos de evapotranspiração (Formaggio, 1989).

Segundo Choudhury (1987), um dos IVs mais comumente utilizados é o Índice de Vegetação da Diferença Normalizada (NDVI), o qual é definido pela expressão (1). Vários IVs foram criados e modificados ao longo dos últimos 
anos. Dentre todos, o NDVI é o mais conhecido e serve de base para comparações de todos os novos índices que estão surgindo (Moura, 2000).

$$
N D V I=\frac{(I V P-V)}{(I V P+V)}
$$

Em que:

IVP = reflectância medida na faixa espectral do infravermelho próximo; $\mathrm{V}=$ reflectância medida na faixa espectral do vermelho.

Segundo Bauer et al. (1981), durante o ciclo de qualquer cultura anual há três fases bem nítidas quanto ao padrão geral de comportamento espectral. No início há grande influência do solo, depois há uma fase de resposta espectral da vegetação verde e, no final do ciclo, há resposta de vegetação senescente e do solo.

Zhang et al. (1998) realizaram um trabalho onde se discutiu o potencial de aplicação de imagens aéreas multiespectrais para monitorar e prever o rendimento das culturas do milho e da soja, em vários estágios de crescimento. Os mesmos concluíram que a melhor relação entre o NDVI e o rendimento da cultura foi obtida com a resolução espacial de $9 \mathrm{~m}$. Os resultados preliminares desse trabalho indicaram a possibilidade do uso do NDVI para estimar o rendimento potencial da soja e do milho. As imagens foram obtidas com uma câmera digital a uma altura aproximada de $2100 \mathrm{~m}$. Os autores obtiveram forte correlação entre as produtividades da soja e do milho e o NDVI obtido das imagens.

Lamb et al. (2000) utilizaram um sistema formado por 4 câmeras CCD (Charge Coupled Device), monocromáticas, com filtros, para estimar a biomassa de quatro estádios fenológicos de arroz. Os resultados iniciais obtidos foram promissores, devido às relações estabelecidas entre o NDVI e a 
biomassa medida no campo, o que permitiu a geração de um mapa de variabilidade de biomassa da área de estudo.

Em um trabalho com soja, Santos et al. (2001 b) obtiveram medidas de espectrorradiometria de campo, 112 dias após o plantio, nas regiões do visível e do infravermelho próximo do espectro eletromagnético, a fim de conhecer o padrão da resposta espectral de plantas atacadas por um fitonematóide. Os valores de NDVI foram relacionados com a densidade populacional dos nematóides, o peso da matéria fresca e o número de vagens por planta. Os resultados mostraram que existe uma clara relação entre os diferentes níveis de infestação da cultura da soja pelos nematóides e NDVI, de tal forma que os autores sugerem ser possível detectar e mapear áreas de soja infestadas por nematóides utilizando-se técnicas de SR.

\subsubsection{Classificação de imagens}

A classificação digital refere-se à interpretação de imagens auxiliada por computador (Eastman, 1997). É o processo de extração de informações em imagens para reconhecer padrões e objetos com o objetivo de mapear as áreas da superfície terrestre (Fonseca, 2000).

Durante a classificação de dados digitais, os alvos do universo real recebem a denominação genérica de classes temáticas. Em outras palavras, na classificação procura-se rotular cada "pixel" da imagem segundo a ocupação do solo, semelhante o que se faz na abordagem visual. Existem dois sistemas de classificação, a supervisionada e a não supervisionada (Moreira 2001).

Moreira (2001) explica que a classificação supervisionada utiliza algoritmos cujo reconhecimento dos padrões espectrais na imagem se faz com base numa amostra de área, fornecida ao sistema de classificação pelo analista. Já o uso de classificadores não-supervisionados é empregado quando o analista não possui conhecimento, a priori, da área de estudo, embora nada impeça que esta abordagem possa ser usada mesmo conhecendo-se a área. 
Fonseca (2000) comenta que o resultado final da classificação de uma imagem é uma imagem temática (mapa), onde os pixels classificados são representados por símbolos gráficos ou cores. Cada cor ou símbolo está associado a uma classe (área urbana, tipos de floresta, tipos de solo e outros) definida pelo usuário.

Neste trabalho foi utilizada a classificação não supervisionada na análise das imagens. Neste caso, segundo Eastman (1997), dentre os parâmetros básicos necessários para a classificação, podem ser citados o número de classes espectrais prováveis dentro da área de estudo e a distância mínima desejada entre os valores dos níveis digitais de duas classes, isto é, a diferença mínima de nível de cinza para considerar um pixel como pertencente a uma classe ou outra.

A partir desses parâmetros de entrada, pode ser realizado o agrupamento dos pixels homogêneos em " $n$ " classes espectrais (Moreira, 2001).

\subsubsection{Emprego do sensoriamento remoto aéreo na agricultura}

\subsubsection{Fotografias aéreas}

As imagens aéreas podem ser obtidas por meio de sistemas fotográficos e de vídeo. No caso das fotografias aéreas, Lueder (1959) comenta que as mesmas constituem um importante instrumento de apoio nos trabalhos de levantamentos de solo, que são fundamentais para o planejamento do uso da terra. Além de servirem como simples mapa-base de campo, podem ser utilizadas, por meio de interpretações, para fins pedológicos.

Segundo Spurr (1960), as fotografias aéreas são consideradas essenciais para o estudo da vegetação e os componentes em relação à paisagem na qual ela ocorre. 
Simakova (1964) cita que o uso de fotografias aéreas como instrumento de enriquecimento do conhecimento humano nasceu da necessidade de mapeamento de grandes áreas, com economia de tempo e redução de custos. Ricci \& Petri (1965) afirmam que a utilização dessa técnica teve início durante a Primeira Guerra Mundial.

Steiner (1970) comenta que as primeiras classificações de uso da terra baseavam-se em trabalhos de campo. Posteriormente, a partir de 1950, um grande número de pesquisadores, em várias partes do mundo, passou a se dedicar à identificação de culturas agrícolas por meio de fotografias aéreas.

Para Marchetti \& Garcia (1977), as fotografias aéreas de áreas agrícolas oferecem uma enorme quantidade de dados. Pode-se medir o tamanho de uma propriedade agrícola, estudar o uso atual da terra, determinarse o tipo e a qualidade dos solos, planejar o controle de erosão, programar reflorestamentos, planejar o uso da terra e tantas outras aplicações.

Marchetti \& Garcia (1977) acreditam que a fotografia aérea apresentase como o "único instrumento capaz de representar as formas e o arranjo espacial das plantas, individualmente ou em associações".

Blackmer \& White (1996) citam a fotografia aérea como um instrumento promissor para o monitoramento da variabilidade da produtividade na cultura do milho, tendo como base o nível de nitrogênio nas plantas.

Schepers (1996) comenta que as fotografias aéreas podem identificar as áreas com características questionáveis. Depois de identificadas, podem ser analisadas para se inferir sobre as causas dos problemas.

Blackmer \& Schepers (1996) utilizaram fotografias aéreas para a estimativa de um índice relacionado à biomassa, na busca de possíveis soluções para controlar a aplicação localizada de nitrogênio. Os autores testaram fotografias aéreas antes e depois da semeadura. Utilizaram também sensores óticos instalados sobre o veículo aplicador de nitrogênio para medir a luz refletida pelo milho. Concluíram que as fotografias aéreas podem ser utilizadas para a estimativa da fitomassa. 
Vellidis et al. (1997) estudaram a utilização de mapas de produtividade da cultura do algodão gerados a partir de fotografias aéreas. Os autores concluíram que este método apresenta grande potencial, por oferecer mapas de estimativa de crescimento da cultura. Embora os mapas não apresentassem magnitudes, eles mostraram claramente os padrões de produtividade resultantes. Pode-se utilizar esta informação para se alocar recursos e máquinas, determinar problemas de crescimento e melhorar a rentabilidade de operações da fazenda.

Taylor et al. (1997) citam que fotografias aéreas digitais foram usadas com sucesso para mapear a distribuição espacial do potencial de produtividade para grãos. A calibração foi realizada em uma equação derivada por meio de amostras de campo versus medidas de NDVI.

Carter (1999) estudou a detecção de anomalias no campo por meio do uso de imagens aéreas, estabelecendo um sistema de classificação, dividindoas em anomalias naturais e induzidas pelo homem. As anomalias específicas foram discriminadas entre umidade, nutrição, ervas daninhas e doenças. Quando o produtor consegue identificar as anomalias que estão incidindo sobre sua área de cultivo, são maximizadas as possibilidades de corrigir os problemas de uma maneira mais econômica e eficaz.

Adamsen et al. (1999) realizaram um estudo que verificou a viabilidade do emprego de imagens de um cultivo de trigo, obtidas por meio de uma câmera digital a 1,60 m acima da cultura, visando a avaliar o potencial das imagens para determinar o vigor das plantas, por meio de sua coloração e até mesmo identificar as plantas em senescência, pelas tonalidades amareladas. Foi utilizada uma câmera Olympus modelo D-300L, no espectro do visível, com aquisição das imagens em um horário controlado (entre 11:00 h e 11:30 h da manhã). Os autores concluíram que as imagens digitais permitiram quantificar a senescência da cultura do trigo.

Koller et al. (1999) utilizaram fotografias aéreas para acompanhar e modelar o crescimento da cultura do tomate. As imagens aéreas 
georreferenciadas permitiram a determinação de valores de NDVI, que se correlacionaram com a produtividade agrícola da cultura.

Daberkow et al. (1999) pesquisaram o potencial do uso de imagens obtidas por meio de fotografias aéreas em milho irrigado e constataram que a correlação entre imagens multiespectrais e a produtividade do milho mostrou-se baixa. Devido à baixa correlação entre as imagens e a produtividade, à incapacidade para identificar as causas de variação da produtividade agrícola, e o elevado custo do SR, os autores concluíram que sua utilização é problemática.

Staggenborg et al. (2000) realizaram um estudo que propunha determinar se a utilização de fotografias aéreas convencionais, com filmes de $35 \mathrm{~mm}$, a partir de pequenas aeronaves poderia, eficientemente, predizer a produtividade de grãos. As análises preliminares indicaram que as correlações diretas existentes entre a produtividade de grãos e os valores digitais das imagens foram baixas (coeficientes de determinação $\left(r^{2}\right)$ próximos a 0,01).

Araújo (2000) utilizou fotografias aéreas coloridas $35 \mathrm{~mm}$, para diagnósticos de lavouras, na determinação de variabilidade espacial para tratamentos localizados. O trabalho foi realizado em duas áreas piloto de agricultura de precisão, que dispunham de informações sobre o solo, incidência de pragas e doenças, além dos mapas de produtividade. As correlações para todas as áreas e todos os períodos analisados apresentaram valores baixos, havendo baixa correspondência entre os valores digitais das imagens e as produtividades das culturas.

Diker et al. (2001) usaram fotografias aéreas infravermelhas falsa-cor (35mm) para estimar a variabilidade da produtividade e monitorar 0 desenvolvimento espaço-temporal na cultura do milho irrigado em escala comercial. O melhor coeficiente de determinação, igual a 0,80, foi obtido entre 0 NDVI e a produtividade no estádio R5. Esse período coincide normalmente com o trigésimo-sexto dia após o princípio da polinização. Nessa etapa, os grãos encontram-se em fase de transição do estado pastoso para o farináceo. 
Concluíram que as variabilidades espacial e temporal do desenvolvimento das plantas e da produtividade podem ser estimadas por meio da integração do uso de imagens aéreas, SIG e observações de campo.

\subsubsection{Videografia aérea}

A videografia aérea, ou aerovideografia, é uma técnica que consiste na obtenção de imagens por meio de câmeras de vídeo, montadas no interior de aeronaves. A utilização da videografia vem crescendo rapidamente, nos últimos anos, principalmente nos Estados Unidos, devido em especial, à evolução dos equipamentos utilizados (Vettorazzi et al., 2000 a).

A grande vantagem da utilização de sistemas de vídeo está na agilidade de coleta, processamento e utilização dos dados. Este processo pode levar algo em torno de horas, ao invés de semanas ou até meses requeridos por outros sistemas (Everitt et al., 1991).

A videografia aérea tem sido usada no monitoramento agrícola, de recursos naturais, florestas e outros (King, 1995). Yang (1998) acredita que as grandes vantagens da videografia em relação às imagens de satélite e outros produtos de sensores remotos são a sua alta resolução espacial, disponibilidade imediata de dados para análise, baixo custo e facilidade de operação.

Segundo Vettorazzi et al. (2000 a), a videografia aérea pode ser considerada um instrumento útil àqueles envolvidos na assistência técnica a agricultores. Apresenta um grande potencial em diversas aplicações, como na detecção e no monitoramento de doenças, de pragas, de deficiências nutricionais, entre outras, e na avaliação do vigor geral da cultura; além disso, auxilia em levantamentos de solo. A possibilidade de classificação digital de imagens georreferenciadas abre perspectivas para o emprego da videografia aérea como técnica auxiliar para a AP. 
Segundo os autores, a videografia apresenta algumas vantagens em relação a outras técnicas de SR: (1) o equipamento é portátil, versátil, robusto e simples de operar; (2) apresenta custo operacional menor que os sistemas fotográficos convencionais; (3) permite ao operador observar em um monitor a imagem ao vivo, simultaneamente à aquisição, o que torna menos sujeito a erros comparado com a fotografia; (4) elevada velocidade de captura dos quadros, proporcionando versatilidade na escolha das melhores imagens; (5) pronta integração com sistemas de posicionamento (GPS) e com sistemas de informações geográficas (SIGs) e de processamento digital de imagens, devido ao formato eletrônico.

Everitt et al. (1991) afirmaram que a utilização de sistemas de imageamento de vídeo, ou videografia, para a avaliação de recursos naturais, tem aumentado nos últimos anos, principalmente pelo advento de novas tecnologias e avanços nos sistemas de gravação e processamento das imagens por computadores.

Anderson \& Yang (1996) realizaram um trabalho visando a avaliar o SR como um instrumento para determinar zonas de manejo. A videografia multiespectral foi utilizada para estratificar dois campos de sorgo em regiões ou zonas de resposta espectral homogênea. Foi adquirido um número limitado de amostras de solos e plantas para caracterizar as condições bióticas e edáficas de cada campo. O estudo indicou que o vídeo pode ser usado para estabelecer zonas de manejo. A análise estatística dos dados mostrou que $\mathrm{pH}, \mathrm{Ca}$ e $\mathrm{Fe}$ foram variáveis importantes e afetaram de forma significativa o rendimento da cultura. A estratificação, usando as imagens, reduziu o número de amostras para caracterizar o campo.

Carter \& Johannsen (2000) desenvolveram um trabalho com culturas de grãos, dentre elas o trigo (Triticum aestivum), onde empregaram imagens aéreas com resolução espacial de um metro e verificaram que as mesmas são eficientes na identificação de anomalias, como a ocorrência de doenças, 
problemas nutricionais, ervas daninhas, pragas, além de possibilitar o gerenciamento das tomadas de decisão.

Yang et al. (2000) utilizaram imagens digitais multiespectrais de vídeo para detectar as variabilidades espacial e temporal do desenvolvimento da cultura de sorgo (Sorghum vulgare) e na estimativa da produtividade da mesma. Foi utilizada uma área de 20,5 ha e foram obtidas imagens em cinco ocasiões durante o ciclo da cultura. A produtividade foi determinada por meio de monitor de colheita. As imagens revelaram claramente a variabilidade da cultura. $O$ índice de vegetação da diferença normalizada (NDVI), obtido por meio das imagens, correlacionou-se com o mapa de produtividade com um fator de correlação de 0,79. Os resultados indicaram que as imagens aéreas digitais podem ser utilizadas com sucesso na detecção da variabilidade do desenvolvimento e produtividade de grãos de sorgo.

Anderson et al. (2000) estudaram duas estratégias para a estimativa da produtividade da cultura do algodão. A primeira estratégia foi baseada na biomassa e a segunda na concentração de pigmentos nas folhas. Utilizaram imagens videográficas multiespectrais de 40 áreas de algodão irrigado. Foram utilizadas três câmeras da marca Cohu, ligadas a um computador. As imagens foram coletadas em três bandas espectrais: verde; vermelho; e infravermelho próximo. Os autores concluíram que a biomassa e a pigmentação das folhas são características relevantes quando usadas com imagens multiespectrais para a estimativa da produtividade na cultura do algodão.

Varner et al. (2000) trabalharam com a cultura da soja, em Illinois, EUA, para detectar ervas daninhas com videografia aérea. Algumas espécies de erva daninha foram semeadas propositalmente para garantir sua presença nas lavouras. A detecção das ervas daninhas foi realizada com uma câmera RDACS-/h3, multiespectral, utilizando os espectros do visível e do infravermelho próximo. Os autores concluíram que as respostas espectrais das ervas daninhas apresentaram-se diferentes quando comparadas com a da 
cultura da soja, possibilitando, portanto, a detecção das mesmas por meio da utilização de imagens.

\subsection{Previsão de produtividade e fatores agronômicos}

A previsão de safras, no Brasil, é feita por meio da estimativa anual da produção agrícola, utilizando-se questionários aplicados aos produtores e/ou às entidades relacionadas à atividade agrícola em cada região. Com isso, a obtenção de dados confiáveis por meio dessa metodologia é difícil, lenta e onerosa, tendo como conseqüência um alto grau de subjetividade nos resultados da estimativa da produção (Fontana et al., 2001).

Para Moura (2000), a cadeia produtiva da economia rural brasileira interconecta uma grande quantidade de interesses e atividades, abrangendo desde o preparo do solo, as pesquisas agronômicas, a estrutura de colheita e de transportes (inclusive as exportações) até a embalagem final e comercialização nas bolsas e redes de distribuição, constituindo-se no conceito de agronegócio.

No mês de fevereiro de 2004, o saldo comercial do agronegócio quase bateu em US\$ 2 bilhões. Foi de 36\% o aumento entre o saldo de fevereiro de 2002 (US\$ 1,4 bilhão) e o de 2004 (US\$ 1,9 bilhão), informa o Ministério da Agricultura. Do total das exportações brasileiras, quase $40 \%$ tem origem no agronegócio (Betting, 2004). O que dá uma noção da dimensão e potencialidade da agricultura nacional e da importância da previsão de safras.

As geotecnologias são instrumentos que podem otimizar a estruturação de sistemas mais eficientes e dinâmicos para estimativa da produção agrícola em níveis regional e nacional. Estas tecnologias permitem a obtenção de informações precisas, em tempo hábil e com baixo custo, sobre a extensão, as condições de desenvolvimento e o potencial de produção das culturas. Estas informações são de grande importância para a economia de um país, já que permitem um planejamento adequado da sua economia agrícola, minimizando o 
problema de escassez ou de excesso de produtos (Motta, 2001; Fontana et al., 2001).

Moura (2000) afirma que a estimativa de áreas favorece um reescalonamento no plantio das culturas, para que não haja superprodução de um único produto e a escassez de outros. Também contribui para o abastecimento dos mercados interno e externo, para o fomento de alguns produtos tidos como essenciais para a economia nacional, para a estimativa dos prejuízos decorrentes de pragas, doenças e de fenômenos da natureza (seca, inundação, dentre outros), que são comuns em países tropicais, como é o caso do Brasil.

O índice de área foliar (IAF), definido como a relação entre a área total de folhas e a área unitária de solo ocupada por elas, juntamente com a percentagem de cobertura do solo, são importantes indicadores do vigor e da produtividade das culturas, de uma maneira geral (Castro, 1999). Por exemplo, Humphries (1967) comenta que muitas pragas e doenças que atacam a cultura da batata (Solanum tuberosum L.), provocando danos que reduzem a área foliar, diminuem a translocação de fotoassimilados para os tubérculos e, conseqüentemente, afetam a produtividade.

Holben et al. (1980) chamaram a atenção para o fato de que a percentagem de cobertura do solo é um importante parâmetro de avaliação de cultura. Há um momento durante o desenvolvimento da cultura em que, apesar de não haver mais variação da percentagem de cobertura do solo, o IAF pode continuar a crescer. Esses autores observaram que houve baixa correlação entre IAF e percentagem de cobertura do solo quando a soja apresentava elevados valores de IAF.

\subsection{Geoestatística}

Para Vieira (2000), quando uma determinada propriedade ou parâmetro varia de um local para outro com algum grau de organização ou continuidade, 
expresso por meio de dependência espacial, a estatística tradicional deve ser complementada pela geoestatística. Por estatística tradicional entende-se aquela que se utiliza parâmetros como média e desvio padrão para representar um fenômeno e se baseia na hipótese principal de que as variações de um local para outro são aleatórias (Camargo, 1997). Fietz (1998) confirma, expondo que a estatística tradicional assume que a variabilidade do valor de um atributo do solo em torno da média independe da posição espacial dos valores amostrais.

Krige (1951), trabalhando com dados de concentração de ouro em minas, concluiu que somente a informação dada pela variância seria insuficiente para explicar o fenômeno em estudo. Para tal, seria necessário levar em consideração a distância entre as observações. A partir daí surge o conceito da geoestatística, que leva em consideração a localização geográfica das amostras e a dependência espacial entre os resultados.

Matheron (1971), baseado nas observações de Krige, desenvolveu a teoria das variáveis regionalizadas. Uma variável regionalizada é uma função numérica com distribuição espacial, que varia de um ponto a outro com continuidade aparente, mas cujas variações não podem ser representadas por uma função matemática simples.

Vieira et al. (1987) afirmam que vários trabalhos têm demonstrado que observações vizinhas, de variáveis do solo e de atributos das plantas, apresentam correlação ou dependência espacial. Isaaks \& Srivastava (1989) associam a estatística tradicional e a geoestatística, comentando que a primeira antecede a análise geoestatística, devido à necessidade da realização de uma criteriosa análise exploratória dos dados, objetivando a descoberta de dados discrepantes, que são valores discrepantes, sendo os mesmos analisados e posteriormente excluídos.

Vieira (2000) comenta que para determinar a necessidade do uso de ferramentas geoestatísticas utiliza-se o semivariograma, que é responsável por demonstrar a dependência espacial entre as variáveis. 
O semivariograma é o instrumento que determina a dependência espacial para as amostras, quando algum modelo é ajustado ao mesmo. $\mathrm{O}$ procedimento de ajuste do modelo não é direto e automático, como no caso de uma regressão, por exemplo, mas sim interativo, pois nesse processo o intérprete faz um primeiro ajuste e verifica a adequação do modelo teórico. Dependendo do ajuste obtido, pode ou não redefinir o modelo, até obter um que seja considerado satisfatório (Zanin et al., 1998).

Para Isaaks \& Srivastava (1989), são três os parâmetros principais na determinação de um modelo geoestatístico. O primeiro é o "alcance", distância dentro da qual as amostras apresentam-se correlacionadas espacialmente. $\mathrm{O}$ "patamar" é o valor do semivariograma correspondente a seu alcance, sendo que deste ponto em diante considera-se que não existe mais dependência espacial entre as amostras, porque a variância da diferença entre pares de amostras torna-se invariável com a distância. O terceiro é o "efeito pepita", onde à medida que a distância tende para 0 (zero), ocorre a aproximação de um valor positivo que revela a descontinuidade do semivariograma para distâncias menores do que a menor distância entre as amostras (Figura 1).

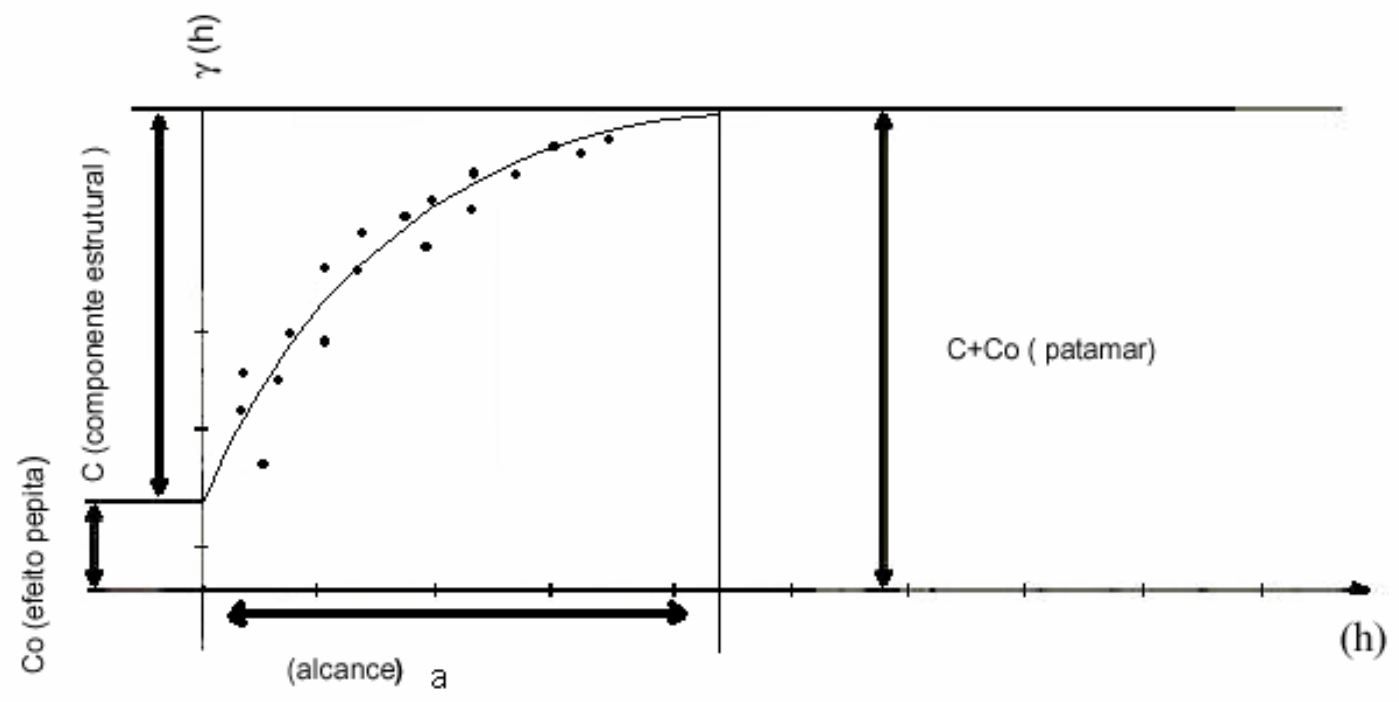

Figura 1 - Semivariograma teórico 
Fonte: Vieira (1995)

O uso da geoestatística na determinação dos semivariogramas e no ajuste dos modelos para os dados analisados, permite a interpolação dos mesmos, por meio do processo de krigagem. O processo de interpolação nada mais é do que, a partir de uma amostragem, realizar inferências sobre a população, ou seja, realizar inferências para os pontos não amostrados a partir dos dados coletados nos pontos amostrais (Vieira, 1995).

O termo krigagem é derivado do nome Daniel G. Krige, que foi o pioneiro na introdução do uso de médias móveis para evitar a superestimação sistemática de reservas de mineração (Delfiner \& Delhomme, 1975). A krigagem é considerada o melhor método de interpolação linear não tendencioso e com variância mínima, pois considera os parâmetros do semivariograma. Nenhum outro método de interpolação é baseado na variância mínima entre amostras (Isaaks \& Srivastava, 1989).

A diferença entre a krigagem e outros métodos de interpolação é a maneira como os pesos são atribuídos às diferentes amostras. No caso de interpolação linear simples, por exemplo, os pesos são todos iguais a 1/N (N = número de amostras); na interpolação baseada no inverso do quadrado das distâncias, os pesos são definidos como o inverso do quadrado da distância que separa o valor interpolado dos valores observados. Na krigagem, o procedimento é semelhante ao de interpolação por média móvel ponderada, exceto que os pesos são determinados a partir de uma análise espacial, baseada no semivariograma experimental. Além disso, a krigagem fornece, em média, estimativas não tendenciosas e com variância mínima igual a um (1) (Lajaunie, 1984).

Os métodos tradicionais de interpolação espacial, como triangulação, média local das amostras e método da distância inversa, estão amplamente disponíveis nos SIGs do mercado. No entanto, tais métodos possuem limitações na representação da variabilidade espacial, porque desconsideram a continuidade do fenômeno que se quer observar (Burrough et al., 1996). A 
incorporação de procedimentos geoestatísticos em SIGs, baseados em técnicas de krigagem, é importante, porque essa associação melhora os procedimentos tradicionais de tais sistemas devido à qualidade do estimador e, principalmente, pela informação de acurácia fornecida nesse modelo inferencial (Camargo, 1997). 


\section{MATERIAL E MÉTODOS}

\subsection{Material}

\subsubsection{Caracterização das áreas de estudo}

O trabalho foi realizado em duas áreas pertencentes a cooperados da Fundação $A B C$, que é uma empresa mantida por agricultores por meio das cooperativas Arapoti, Batavo e Castrolanda. A empresa presta assistência técnica e tem como objetivo o desenvolvimento de pesquisas voltadas à agricultura.

A região é conhecida por empregar alto nível tecnológico nas atividades agrícolas, apresentando uma produtividade de grãos superior à média nacional. É considerada também como pioneira na utilização do plantio direto em substituição ao convencional.

As áreas de estudo situam-se no município de Ponta Grossa, PR, na Região Centro-Leste do Estado. Quanto a geomorfologia e hidrologia, elas estão inseridas nos Campos Gerais, o qual está situado no Segundo Planalto Paranaense. No passado as áreas eram revestidas por extensos campos limpos, estepes de gramíneas baixas (Maack, 1981). Tradicionalmente utilizadas como pastagens naturais, estas áreas a partir de algumas décadas vêm sendo ocupadas por agricultura intensiva, com implantação de culturas anuais em larga escala.

O clima da região enquadra-se como mesotérmico úmido, do tipo subtropical úmido de altitude. A classificação, segundo Köppen (1948) é do tipo 
Cfb: sempre úmido, clima quente temperado, mês mais quente com temperatura média de $22^{\circ} \mathrm{C}$, onze meses com temperaturas médias maiores que $10^{\circ} \mathrm{C}$, com mais de cinco geadas noturnas por ano. A precipitação média anual é acima de $1.400 \mathrm{~mm}$, concentrando-se principalmente nos meses de janeiro e fevereiro e também em novembro e dezembro, porém com menor intensidade. Em suma, trata-se de um clima subtropical úmido com verões brandos e invernos com geadas freqüentes, sem estação seca definida (Maack, 1981).

A rotação de culturas é realizada principalmente entre as culturas da soja, milho e feijão no verão e trigo e aveia preta no inverno. Os dados foram coletados no mês de agosto de 2001 (cultura de inverno, trigo) e no mês de março de 2002 (cultura de verão, soja). As localizações e as vistas aéreas das áreas de estudo encontram-se respectivamente na Tabela 1 e na Figura 2. A altitude da área 1 varia de 778m a 806m e a altitude da área 2 de 869m a 910m (Figura 3).

Tabela 1. Áreas de estudo e localização

\begin{tabular}{lccc}
\hline Produtor & Área & Latitude & Longitude \\
\hline H. Borg (área 1) & 32 hectares & 24'50'52" S & $50^{\circ} 20^{\prime} 36^{\prime \prime} \mathrm{W}$ \\
J. Djkstra (área 2) & 16 hectares & 24'53'04" S & $50^{\circ} 16^{\prime} 35^{\prime \prime} \mathrm{W}$ \\
\hline
\end{tabular}

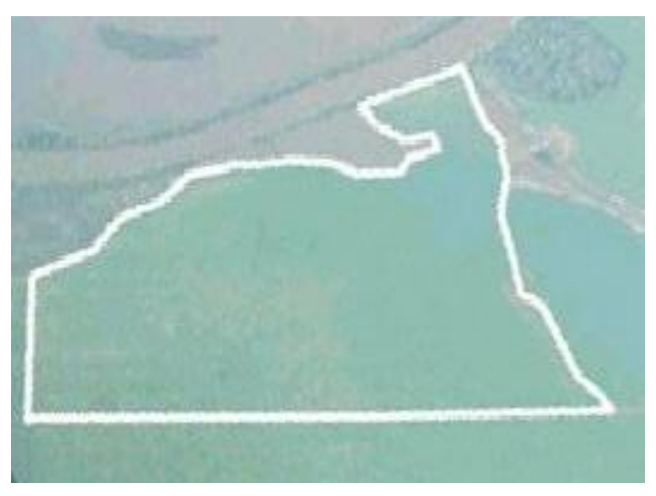

(a)

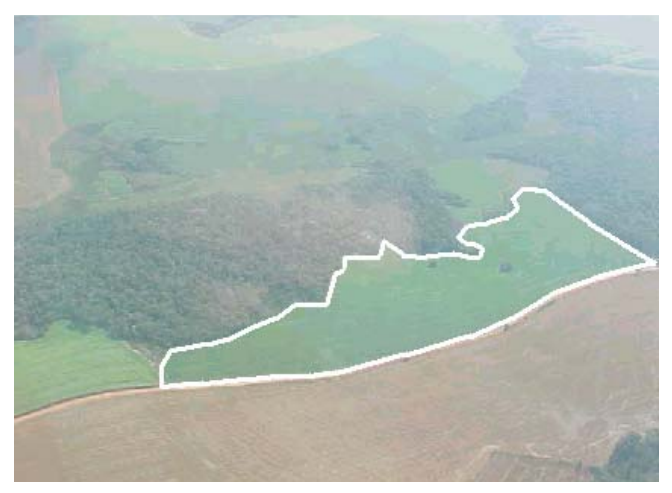

(b)

Figura 2 - Vista aérea das áreas 1 (a) e 2 (b) 


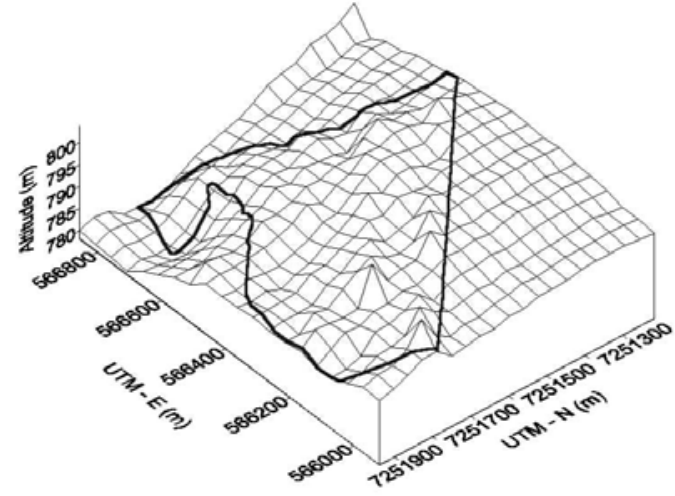

(a)

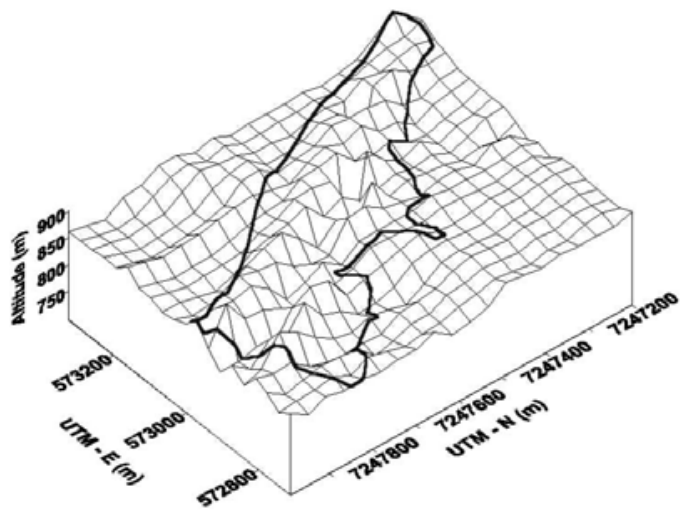

(b)

Figura 3 - Visão tridimensional das áreas de estudo: área 1 (a) e área 2 (b)

No inverno a área 1 foi cultivada com trigo da variedade CD-105, e a área $2 \mathrm{com}$ a variedade CV OR-1, ambos com 0,17m entre fileiras. Os mesmos foram semeados em maio de 2001 e colhidos em setembro do mesmo ano. No verão as duas áreas foram cultivadas com soja, da variedade FT-ABYARA, com espaçamento de $0,40 \mathrm{~m}$ entre fileiras, semeada em novembro de 2001 e colhida no final de fevereiro de 2002.

$\mathrm{Na}$ área 1 encontram-se Latossolos Vermelhos Distróficos típicos, com horizonte A moderado, textura média ou argilosa, em relevos planos a suave ondulados, Latossolos Vermelho-Amarelos Distróficos típicos de textura média em relevo plano a suave ondulado e os Cambissolos Háplicos de textura média a argilosa, caracterizando o restante da área de estudo.

$\mathrm{Na}$ área 2, dentre os solos de maior freqüência encontram-se os Latossolos Vermelhos e Vermelho-Amarelos e parte de Cambissolos. Os solos predominantes na área são os Latossolos Vermelhos Distróficos típicos, com horizonte A proeminente, textura argilosa, em relevo suave ondulado. 


\subsubsection{Recursos utilizados}

\subsubsection{Câmera de vídeo}

As imagens foram adquiridas por meio de uma câmera de vídeo digital multiespectral, pertencente ao Laboratório de Métodos Quantitativos do Departamento de Ciências Florestais, da Escola Superior de Agricultura "Luiz de Queiroz", ESALQ/USP. A câmera (Duncantech MS3100) (Figura 4) produz imagens com resolução espacial variável, de acordo com a altura de vôo. Neste trabalho foram geradas imagens com resolução espacial aproximada de um metro.

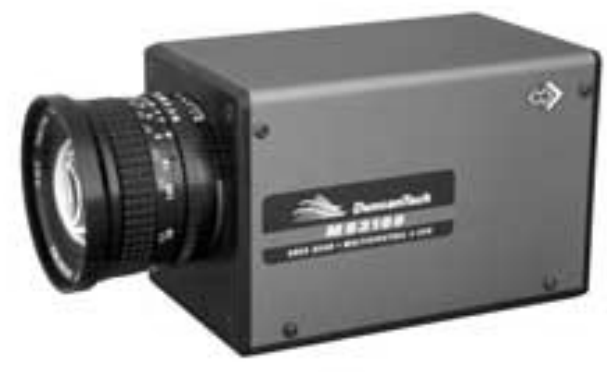

Figura 4 - Câmera de vídeo utilizada no trabalho

A câmera Duncantech modelo MS3100 captura imagens de alta resolução espacial (1392 x 1040 pixels) em três faixas co-registradas, que utilizam um prisma com três sensores de imagem CCD (Charge Coupled Device), que cobrem as regiões espectrais do azul (450 - $520 \mathrm{~nm}$ ), verde (520 $600 \mathrm{~nm})$, vermelho (630 - $690 \mathrm{~nm})$ e infravermelho próximo (760 - $1100 \mathrm{~nm})$. A câmera captura até 7,5 quadros por segundo e proporciona a exibição da composição colorida ou bandas individualizadas (Duncan Technologies, Inc. (1999). O ajuste do ganho e controles de tempo de exposição são independentes para cada canal. A Tabela 2 apresenta algumas especificações técnicas da câmera. 
Tabela 2. Especificações técnicas da câmera MS3100 (Duncan Technologies, Inc., 1999)

Dispositivo de imagem:

Elementos de imagem (pixels):

Tamanho do pixel:

Taxa de velocidade:

Taxa de obtenção dos quadros:

Resolução radiométrica:

Lentes

Seleção de ganho:

Seleção de offset:

Temperatura de operação:

Voltagem de operação:

Potência consumida:

Peso:

Funções programáveis:
Transferência CCD de 1/2 polegada

1392 (Horizontal) x 1040 (Vertical)

4,65 x 4,65 microns

$14318 \mathrm{MHz}$ (máximo)

7,5 quadros por segundo (máximo)

8 bits - 10 bits - 32 bits (máximo)

Canon ENG

Ganho independente por canal (0 - $36 \mathrm{~dB})$

Seleção independente por canal (0 - 127)

$0-50{ }^{\circ} \mathrm{C}$

12 VDC

10 Watts

$1,62 \mathrm{~kg}$

Offset , ganho, tempo de exposição

\subsubsection{Sistemas computacionais}

Os principais sistemas computacionais empregados no trabalho foram:

- Idrisi32 for Windows release 2, para o tratamento e a correção geométrica das imagens (Eastman, 1998).

- Aldus PhotoStyler 2.0, para a criação dos mosaicos não georreferenciados;

- SSToolbox 3.1, sistema personalizado para aplicações em AP, para o gerenciamento dos dados de produtividade das áreas;

- GS+ 3.11.20 Demo, análise geoestatística de dados (Gamma Design software, 1998); 
- Surfer 6.01, visualização de áreas em três dimensões (Golden Software, 1995) e;

- ArcView 3.2., gerenciamento de imagens e mapas de produtividade.

\subsubsection{Medidor de índice de área foliar}

Para a medição do índice de área foliar (IAF) foi empregado o equipamento LAI-2000 (LI-COR, 1992). O LAI-2000 utiliza um sensor de luz que mede a radiação difusa, simultaneamente, em cinco bandas angulares distintas $\left(0^{\circ}-13^{\circ}, 16^{\circ}-28^{\circ}, 32^{\circ}-43^{\circ}, 47^{\circ}-58^{\circ}\right.$ e $\left.61^{\circ}-74^{\circ}\right)$. O sensor é constituído de cinco fotodiodos, cujas superfícies ativas são arranjadas em anéis concêntricos. A imagem desta visão, quase-hemisférica, é projetada dentro destes anéis, permitindo, para cada intervalo angular, a medição da radiação na banda e no ângulo zenital conhecido. Um filtro óptico restringe a transmissão radiativa para comprimentos de onda menores que $490 \mathrm{~nm}$ (LI-COR, 1992).

Uma particularidade do LAI-2000 é a necessidade de se fazer uma leitura de referência externa ao dossel. Existe uma possibilidade de que as condições de iluminação do céu mudem entre a leitura de referência e a leitura abaixo do dossel, se o intervalo de tempo entre as medições for considerável (Xavier, 2002).

\subsection{Métodos}

\subsubsection{Processamento dos mapas de produtividade}

Os mapas de produtividade referentes às safras de trigo do ano de 2001 (áreas 1 e 2) e os mapas de produtividade referentes às safras de soja de 2002 (áreas 1 e 2), foram cedidos pela Fundação ABC. Os mapas foram gerados em formato digital compatível com a extensão shape. 
Esses mapas são considerados brutos, pois não apresentam valores interpolados, mas sim representando os valores pontuais colhidos. Os mapas brutos foram processados no software SSToolbox 3.1. Neste software, os valores foram interpolados por meio da opção "create surface using interpolation".

O método utilizado para o processo de interpolação foi o do Vizinho mais Próximo (Nearest Neighbor). O Método do Vizinho mais Próximo estima a função de distribuição cumulativa com base nas distâncias entre eventos em uma região de análise. Determina o valor de um ponto levando em consideração os valores mais próximos do ponto considerado. Este método é empregado nos casos onde os dados cobrem quase que por completo a área, apresentando apenas alguns valores perdidos, sendo efetivo para preencher os espaços vazios nos dados (Golden Software, 1995).

Os mapas de produtividade apresentam um grande número de pontos com os valores de produtividade, enquadrando-se no perfil de uso do parâmetro de interpolação escolhido, citado anteriormente. No processo de interpolação existe a opção de definição da área representativa de cada pixel no mapa de produtividade.

A área do pixel utilizado foi de $25 \mathrm{~m}^{2}$, coincidindo com o valor adotado para o pixel das imagens referentes à mesma área de estudo. Araújo (2000) utilizou pixels de $25 \mathrm{~m}^{2}$ para os mapas de produtividade, associando este valor a uma largura média aproximada de uma colhedora de grãos, com cerca de 5 metros.

No SSToolbox 3.1 existe a possibilidade de classificação da produtividade. No andamento do trabalho, a produtividade foi classificada em 2 e 5 classes, sendo a primeira apenas para a apresentação do mesmo e a segunda no processo de regressão linear entre variáveis classificadas.

A opção escolhida para a classificação dos mapas de produtividade no software SSToolbox 3.1 foi a "Natural Breaks". Está opção proporciona uma observação prévia do comportamento da distribuição da variabilidade espacial 
na área. Esta é uma classificação padrão do software ArcView 3.2, identificando os limites de cada classe, utilizando um modelo estatístico que se baseia na minimização da soma da variância dentro de cada classe.

O mapa de produtividade foi exportado, no formato shape, para o software Idrisi32, por meio da opção export do software SSToolsbox 3.1. Os mapas de produtividade, tratados no software Idrisi32 foram novamente classificados por meio da opção Reclass. Esta opção permite ao usuário atribuir novos valores aos pixels da imagem original. Por exemplo, pixels com valores variando de 20 a 30, recebem o valor 1 e assim sucessivamente.

O processo de classificação utilizado para os mapas de produtividade foi realizado no software Idrisi32. Primeiramente foi obtido o histograma para cada mapa de produtividade envolvido no trabalho, por meio da opção Histo deste software. De posse dos histogramas, foram observados os valores máximos e mínimos das produtividades. O valor utilizado como limiar entre as classes foi o valor médio da produtividade para cada mapa.

Foi estabelecido como padrão, trabalhar-se com duas classes. Uma com valores inferiores ao valor médio, classe 1, e outra com valores iguais e superiores a média, classe 2. Este procedimento de classificação também poderia ser utilizado para trabalhos com maior número de classes.

Optou-se por duas classes, uma de baixa e outra de alta produtividade, facilitando a visualização das mesmas no campo e o entendimento das áreas analisadas.

\subsubsection{Obtenção e tratamento das imagens}

Para que a câmera permanecesse na posição vertical em relação ao solo, foi necessária a construção de um suporte de metal, onde a mesma foi parafusada. O suporte foi posicionado no assoalho do avião (Figura 5). 


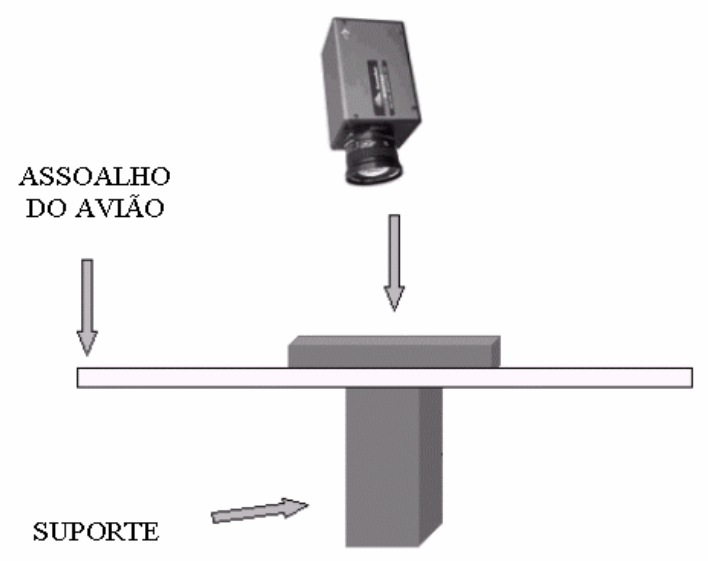

Figura 5 - Esquema do posicionamento da câmera no assoalho do avião

As imagens foram obtidas entre $2000 \mathrm{~m}$ e $3000 \mathrm{~m}$ de altura, de maneira a obter pixels com as dimensões apropriadas ao estudo. As imagens referentes à cultura do trigo foram tomadas em agosto de 2001 e as da soja em fevereiro de 2002. A época escolhida para os sobrevôos foi a do máximo desenvolvimento vegetativo das culturas, período precedente ao florescimento, sendo no caso da soja o estádio R1 e do trigo o estádio 10.5 (Embrapa, 2003).

Essas épocas foram consideradas de maior relevância para a estimativa da produtividade e também para a determinação do NDVI. Yang et al. (2000) afirmam que dados obtidos por imagens aéreas digitais, usualmente são utilizados para a identificação do desenvolvimento espacial e temporal das plantas analisadas na agricultura de precisão. As imagens adquiridas no período próximo ao máximo desenvolvimento vegetativo das culturas de grãos mostram padrões mais estáveis e mais representativos. Além disso, é a melhor época para a estimativa da produtividade.

O avião utilizado foi um Cessna 180, mono-motor, com um orifício no assoalho, característica fundamental para a realização do trabalho, por proporcionar que a câmera permanecesse o mais verticalizada possível em relação ao solo durante a tomada das imagens. A câmera foi ligada a um computador com 80 Gbytes de capacidade de armazenamento, proporcionando 
uma maior autonomia de coleta de imagens durante o vôo, sendo que cada imagem apresentou um tamanho de 4,3 Mbytes.

Para o acompanhamento em tempo real das imagens capturadas foi utilizado um monitor ligado ao computador (Figura 6), que também foi fundamental no acionamento do software de comando da câmera.

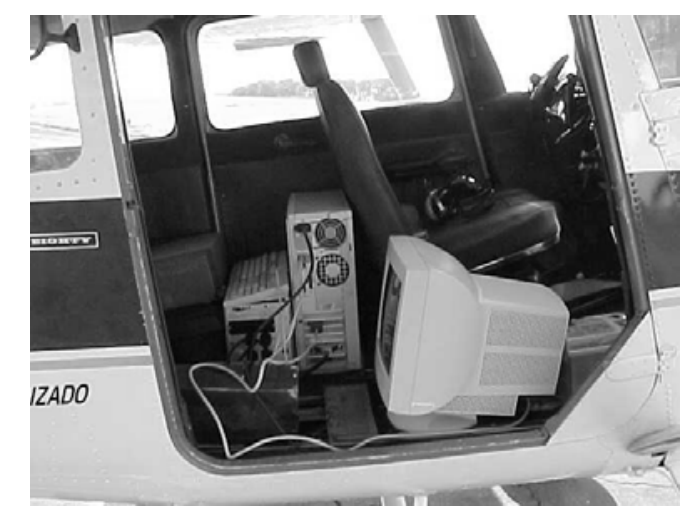

(a)

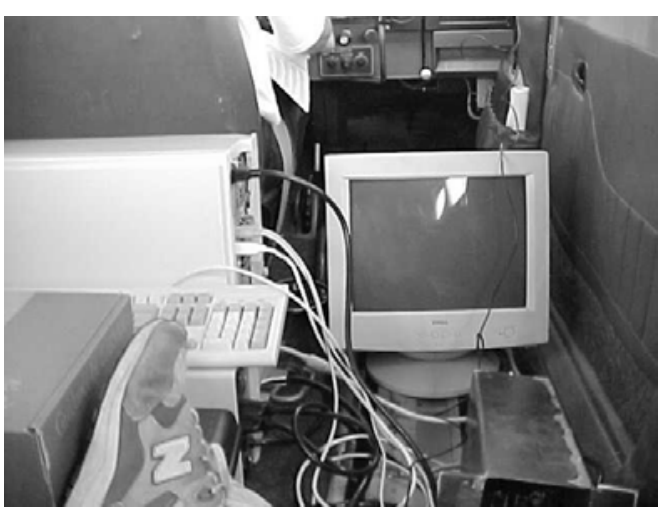

(b)

Figura 6 - Vista lateral (a) e do interior do avião (b), dos equipamentos utilizados para a obtenção das imagens

Devido à altura de vôo empregada e a dimensão das áreas trabalhadas, houve casos em que toda a área a ser imageada não ficou inserida em um único quadro, sendo necessária a realização da mosaicagem. A mosaicagem é a fusão entre imagens sucessivas.

Para a realização da mosaicagem são necessárias a correção geométrica e a normalização radiométrica das imagens, promovendo a união entre as imagens sem que haja a percepção visual desta união. A correção geométrica e a normalização radiométrica serão descritas mais adiante.

O produto obtido a partir da cobertura videográfica é uma composição colorida falsa cor (RGB) e, utilizando o software Aldus PhotoStyler, estas imagens foram separadas em três bandas (verde, vermelho e infravermelho próximo) e convertidas para imagens com 256 níveis de cinza (8 bits). 
O pré-processamento das imagens é necessário para a transformação dos dados digitais brutos em dados corrigidos, para serem processados posteriormente e, assim, obterem-se as informações necessárias contidas nas imagens.

Para Quintanilha (1990), a imagem digital é uma função bidimensional da intensidade de luz refletida ou emitida por uma cena, representada por $f(x, y)$, onde of correspondente a cada $(\mathrm{x}, \mathrm{y})$ refere-se à intensidade da radiação nesse ponto. Essa intensidade é numericamente representada na imagem por um valor inteiro, não-negativo e finito (nível de cinza).

A normalização radiométrica tem por finalidade a eliminação das distorções decorrentes do fato de que as imagens foram obtidas sob condições diferentes de luminosidade, devido ao deslocamento da posição de tomada das imagens, alterando os níveis de cinza de um mesmo alvo de uma imagem para a seguinte. A finalidade da normalização foi simular condições semelhantes de luminosidade para imagens sucessivas.

A normalização radiométrica neste trabalho foi realizada manualmente, por meio da verificação dos valores de nível de cinza em 3 janelas de 25 pixels (5 x 5), com coordenadas conhecidas e idênticas, na área comum para as duas imagens a serem mosaicadas, conforme ilustra a Figura 7.

\begin{tabular}{|c|}
\hline \begin{tabular}{|l|l|l|l|l|}
52 & 54 & 63 & 68 & 66 \\
53 & 55 & 65 & 65 & 68 \\
51 & 54 & 64 & 68 & 68 \\
54 & 55 & 63 & 64 & 62 \\
59 & 60 & 62 & 65 & 63 \\
\end{tabular} \\
\hline DOS PIS \\
\hline \begin{tabular}{l|l|l|l|}
50 & 52 & 61 & 6 \\
51 & 52 & 62 & 6 \\
48 & 52 & 62 & 6 \\
54 & 55 & 61 & 6 \\
59 & 58 & 60 & 6 \\
\end{tabular} \\
\hline
\end{tabular}

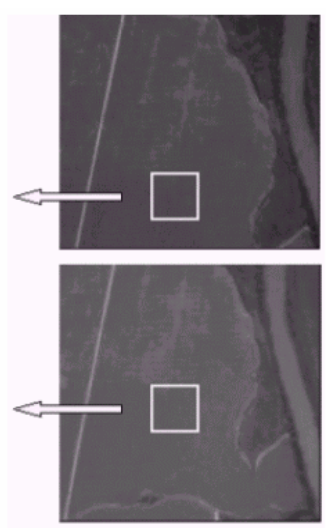

Figura 7 - Processo de normalização radiométrica: extração dos valores dos pixels em uma janela de $5 \times 5$ 
Com os valores dos pixels conhecidos, foi determinada a variação numérica entre os mesmos para cada ponto. A média de variação dos três quadros foi utilizada como parâmetro de variação dos valores dos pixels entre as duas imagens e este valor foi adicionado ou subtraído de uma delas. As alterações nos valores dos pixels foram realizadas no software Idrisi32 com a opção Scalar. A título de exemplo, a Figura 8 ilustra o resultado da normalização radiométrica realizada na área 2, com a imagem da cultura do trigo no infravermelho próximo.

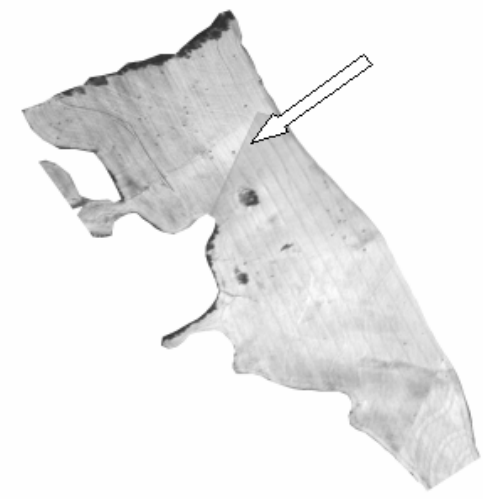

(a)

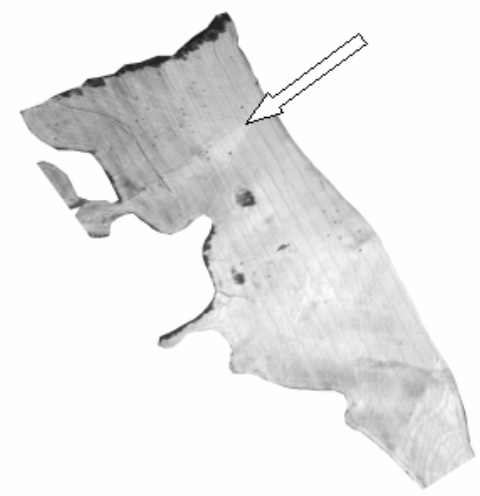

(b)

Figura 8 - Mosaico sem a normalização radiométrica (a) e com a normalização radiométrica (b), evidenciando-se o efeito obtido

A correção geométrica das imagens foi realizada por meio das coordenadas de alvos (placas de $1 \mathrm{~m}^{2}$ ), dispostos em pontos estratégicos da área. Os mesmos foram georreferenciados por GPS com correção diferencial em tempo real.

Farret \& Gioto (1997) afirmam que a melhor geometria para os pontos de apoio no processo de correção geométrica de imagens aéreas é aquela baseada na distribuição dos mesmos nos cantos da imagem, contrariando hipóteses de que pontos de apoio próximos ao centro da imagem levariam a melhores resultados. 
Segundo Novo (1995), a correção geométrica, ou georreferenciamento, tem como objetivo reorganizar os pixels da imagem em relação a um determinado sistema de projeção cartográfica.

O georreferenciamento foi realizado com os mosaicos prontos, que foram exportados para o software Idrisi32. No georreferenciamento o usuário identifica os alvos dispostos na área e registra as coordenadas de imagem dos mesmos. As coordenadas de imagem e suas correspondentes reais formam um arquivo de correspondência por meio da opção Edit, com os pares de pontos que representam o mesmo lugar no antigo e no novo sistema de coordenadas.

O arquivo de correspondência criado contém primeiramente as coordenadas de imagem e na seqüência as coordenadas reais obtidas no campo. A opção Resample é selecionada e o software processa equações que descrevem as relações entre os dois sistemas de coordenadas. Com essa operação o arquivo é convertido para o novo sistema de referência por meio de uma transformação do tipo Rubber sheet.

O software, na alocação dos pixels, realiza uma interpolação pelo método do Vizinho mais Próximo, descrito anteriormente. Novo (1995) comenta que em casos onde as imagens de entrada contêm valores quantitativos, esta é a técnica que deverá ser utilizada, devido a não alteração dos valores originais de cinza.

O modelo matemático utilizado foi o polinomial que, de acordo com Rosa (1990), possui como principal fundamento os pontos de controle definidos como uma característica detectável na imagem, com localização geográfica precisamente conhecida e invariável com o tempo. Ainda segundo o autor, o desempenho destes pontos no georreferenciamento depende do seu número, distribuição e acurácia de localização.

Com esse modelo matemático foi gerado o erro médio quadrático, denominado RMS - Root Mean Square, que quantifica a variabilidade das medidas em relação aos seus verdadeiros valores. A diferença entre estes 
valores é elevada ao quadrado e somada; o resultado da soma é dividido pelo número de pontos para se obter então um desvio quadrado (Eastman, 1997).

Cada ponto é mostrado individualmente e numerado de acordo com a ordem em que aparece no arquivo de correspondência. Estes resíduos expressam quanto cada ponto de controle se desvia da equação de melhor ajuste. A equação de melhor ajuste descreve a relação entre o sistema de referência arbitrário da imagem e o novo sistema de referência ao qual ela está sendo reamostrada, e essa relação é calculada a partir dos pontos de controle (Eastman, 1997).

O RMS total descreve o erro de posicionamento característico de todos os pontos de controle em relação à equação. Ele descreve a probabilidade com o qual uma posição mapeada poderá variar da sua localização verdadeira. 0 erro RMS é diretamente comparável ao conceito de desvio padrão. De acordo com Eastman (1997), o RMS para imagens deve ser menor que a metade da resolução espacial da imagem a ser corrigida. No caso deste trabalho foram utilizadas imagens com $1 \mathrm{~m}$ de resolução espacial, portanto admitindo-se 0,5m de limite máximo para o erro RMS.

A partir das bandas individuais georreferenciadas e normalizadas, foram geradas imagens representativas do índice de vegetação da diferença normalizada (NDVI), por meio do procedimento descrito na seqüência.

Foi aplicada uma "máscara" às imagens (NDVI, vermelho e infravermelho próximo), isolando a área de estudo do restante da imagem. As "máscaras" das duas áreas de estudo foram desenvolvidas pelo mesmo procedimento. O processo foi realizado no software Idrisi32, onde os mapas de produtividade da área de interesse foram classificados por meio da função Reclass. Os valores correspondentes à área de interesse assumiram o valor "um" e os correspondentes à área externa assumiram o valor "zero", formando assim a "máscara" utilizada no trabalho.

A utilização da "máscara" foi possível por meio da opção Overlay, que é utilizada para efetuar operações matemáticas entre imagens. A "máscara" é 
multiplicada por uma das imagens produzidas. Os valores dos pixels da imagem multiplicados pelos valores iguais a zero da "máscara" formam conseqüentemente, uma nova imagem formada apenas pela área de interesse.

As classificações das imagens foram realizadas pelo mesmo processo empregado nos mapas de produtividade, descritos anteriormente. É importante reconhecer que no caso das imagens os agrupamentos que a classificação não supervisionada produz não são classes de informação, mas categorias espectrais com padrões de reflectância similares (Eastman, 1997).

\subsubsection{Grade amostral no campo}

$\mathrm{Na}$ área 1, para a cultura da soja, paralelamente à obtenção das imagens foi realizada uma missão de campo em janeiro de 2002, tendo sido levantados o IAF (índice de área foliar), a altura das plantas e o número de plantas por metro linear.

Visando a racionalizar o trabalho foi elaborada uma grade amostral no software SSToolbox 3.1, com um espaçamento entre pontos de $70 \mathrm{~m}$, para a referida área de estudo (Figura 9). Os pontos amostrais foram percorridos no campo com auxílio de um DGPS conectado a um computador de mão e um software de navegação, ambos cedidos pelo projeto de Agricultura de Precisão do Departamento de Engenharia Rural da ESALQ.

Um dos problemas encontrados na determinação da variabilidade espacial de fatores agrícolas refere-se ao tamanho da grade a se amostrar. Quanto menor a malha, melhor a precisão dos mapas gerados, entretanto uma malha muito pequena reflete em custos elevados, maior disponibilidade de mão-de-obra e maior número de análises. A grade empregada neste trabalho foi a mesma utilizada em outras análises pela equipe da Fundação $A B C$.

No contexto da AP, a determinação dessa variabilidade é fundamental na atividade de aplicação localizada de insumos e defensivos agrícolas. Segundo Antuniassi (2000), a determinação do posicionamento dos alvos para 
a definição dos locais onde serão realizadas as aplicações é uma das etapas mais importantes dos sistemas de aplicação localizada.

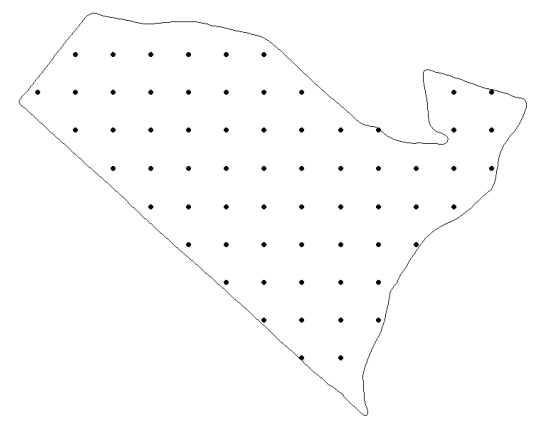

Figura 9 - Grade amostral de uma das áreas de estudo, com distância de 70 metros entre pontos

O índice de área foliar (IAF) em campo foi estimado com o aparelho LAI-2000 (LI-COR, 1992). A cultura analisada foi a soja, onde foram coletados 65 pontos em uma grade amostral, no verão de 2002, correspondendo ao período de maior desenvolvimento vegetativo da cultura. A análise do trigo, no inverno seguinte, não foi realizada devido a problemas operacionais.

Para a operacionalização do equipamento foi realizada uma leitura de referência sobre o dossel, para a calibração do aparelho, e oito no interior do mesmo. Este procedimento foi realizado por duas vezes em cada ponto amostral, conforme orientação do manual do aparelho (LI-COR, 1992). As condições de iluminação do céu são alteradas a todo o momento, devido ao deslocamento do sol e das nuvens. Este fato pode acarretar em uma estimativa errônea do IAF. Visando a evitar este tipo de problema as leituras foram realizadas em um dia nublado.

As leituras foram realizadas no ponto determinado pelo GPS, a uma altura aproximada de $0,1 \mathrm{~m}$ do solo, com variações de posição, ao lado da 
planta e nas entrelinhas. A área percorrida em cada ponto amostral foi estabelecida por 3 linhas (espaçamento de $0,4 \mathrm{~m}$ entre linhas) de cultivo por $1,5 \mathrm{~m}$, perfazendo uma área de $0,6 \mathrm{~m}^{2}$.

\subsubsection{Determinação dos índices de vegetação}

Existem vários índices de vegetação, sendo que o NDVI e o índice Razão Simples (RS) são amplamente utilizados em trabalhos relacionados à AP. Segundo Jackson \& Huete (1991), do ponto de vista matemático estes dois índices são equivalentes e contêm as mesmas informações. Neste trabalho foi utilizado exclusivamente o NDVI.

O índice de vegetação da diferença normalizada (NDVI) é determinado por processos matemáticos realizados entre bandas das imagens multiespectrais. O software Idrisi32 apresenta uma opção denominada Vegindex, sendo que a seleção da mesma ativa uma janela que permite a seleção de diversos índices de vegetação, sendo o NDVI uma delas.

A opção NDVI exige a entrada da imagem nas bandas do vermelho, do infravermelho próximo e o nome do arquivo de saída. A imagem do NDVI apresenta uma legenda dos valores encontrados na operação, sendo que os números gerados variam de (-1 a 1$)$. Os valores negativos de NDVI foram descartados, por não se referirem à vegetação, considerando a faixa compreendida entre ( 0 a 1 ), onde os valores mais próximos a um correspondem a um alto vigor vegetativo.

\subsubsection{Análise dos dados}

\subsubsection{Análise estatística}

A análise de regressão simples entre mapas e imagens foi desenvolvida no software Idrisi32. O mesmo apresenta um conjunto de opções estatísticas, 
dentre elas a determinação do coeficiente de correlação (r) e do coeficiente de determinação $\left(r^{2}\right)$ para as análises realizadas, além do ajuste do modelo de regressão e a análise de variância utilizada para o teste do ajuste da equação. Veiga \& Sáfadi (1999) afirmam que a análise de variância é utilizada na verificação da significância ou não da equação de regressão obtida.

A análise estatística descritiva foi utilizada para os dados coletados em grade, pois os mesmos foram interpolados por meio de uma krigagem, onde os modelos e os parâmetros empregados foram obtidos por meio de análise geoestatística, descrito na seqüência.

\subsubsection{Análise geoestatística}

O processo geoestatístico foi desenvolvido visando à elaboração dos mapas das variáveis analisadas em grade. Vieira (2000) previne que para uma adequada análise geoestatística é imprescindível efetuar uma cuidadosa análise descritiva dos dados. A eliminação desta etapa pode levar a uma análise geoestatística não condizente com a realidade de campo.

$\mathrm{Na}$ análise descritiva é observado o comportamento dos dados, por meio de histogramas, gráficos box-plot e outras ferramentas estatísticas (Banzatto \& Kronka, 1995). Este processo permite verificar o comportamento e a presença de dados discrepantes, dados que não se enquadraram entre os limites inferior e superior, considerados dados discrepantes. Estes dados foram retirados para não influírem nos resultados da análise geoestatística.

Os limites inferior e superior foram calculados adotando-se o critério de Hoaglin et al. (1983), determinados por meio de uma operação aritmética utilizando como parâmetros os resultados obtidos na estatística descritiva. O limite inferior (LI) foi calculado pela subtração entre o quartil inferior (QI) e a amplitude interquartílica (Al) multiplicada por 1,5 (LI = QI - (1,5.Al)). O limite superior (LS) foi calculado pela adição do quartil superior com a amplitude interquartílica multiplicada por 1,5 (LS = QI + (1,5.Al)). 


\subsubsection{3 Índice Kappa}

Um método eficiente de comparação entre mapas no formato raster é fazer uma sobreposição e uma avaliação pixel-a-pixel, de modo a identificar as áreas de concordância entre os dois mapas. Para expressar o grau de concordância entre os mapas classificados num único valor usou-se o índice Kappa (Landis \& Koch 1997).

No software Idrisi32, a opção Crosstab executa um cruzamento entre duas imagens, no qual as categorias de uma imagem são comparadas às categorias da outra. O resultado desta operação é uma relação de medida de associação entre as imagens.

Neste trabalho o índice Kappa foi determinado no software Idrisi32 por meio da opção Crosstab. Esta função exige a entrada das duas imagens classificadas a serem analisadas. Logo após, opta-se pela opção Both crossclassification and tabulation e fornece-se a nome do arquivo de saída. Esta operação resulta em uma tabela que apresenta o índice Kappa e um mapa de associação entre as classes. O índice Kappa assume um valor máximo igual a 1 (um), onde os valores mais elevados representam maior correspondência entre as classes dos dois mapas considerados.

A Tabela 3 apresenta o grau de concordância entre imagens, em função do valor do índice Kappa. 
Tabela 3. Classificação qualitativa do índice Kappa

\begin{tabular}{cc}
\hline Índice Kappa & Grau de concordância \\
\hline$<0,00$ & Péssimo \\
$0,00-0,20$ & Mal \\
$0,21-0,40$ & Razoável \\
$0,41-0,60$ & Bom \\
$0,61-0,80$ & Muito Bom \\
$0,81-1,00$ & Excelente
\end{tabular}

Fonte: Landis \& Koch (1977) 


\section{RESULTADOS E DISCUSSÃO}

\subsection{Imagens aéreas das culturas da soja e do trigo}

A Figura 10 apresenta as imagens aéreas obtidas das culturas do trigo e da soja, respectivamente, para a área 1. Foram obtidas imagens nos espectros do vermelho e infravermelho próximo.

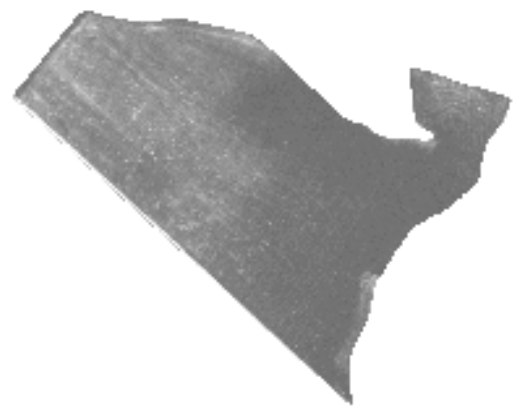

(a)

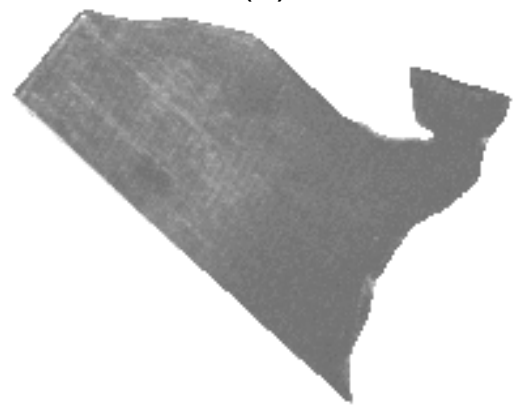

(c)

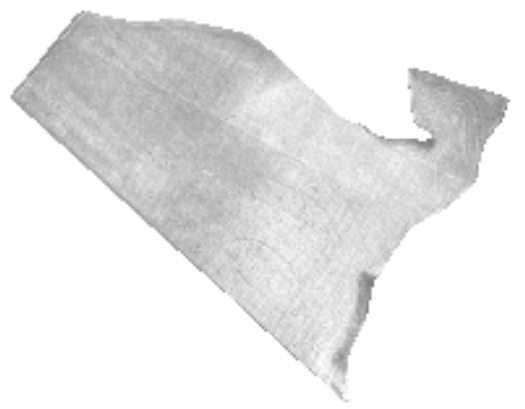

(b)

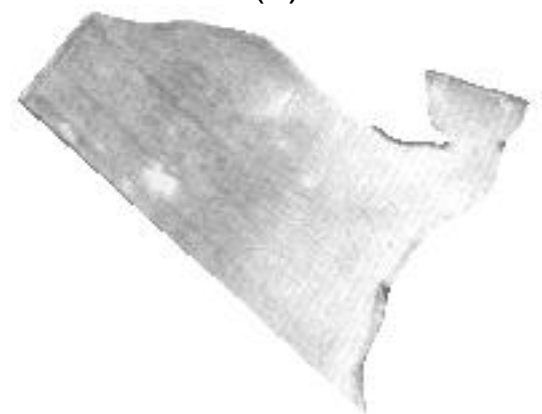

(d)

Figura 10 - Imagens da área 1, referentes à cultura do trigo, nos espectros do vermelho (a) e do infravermelho próximo (b) e referentes à cultura da soja, nos espectros do vermelho (c) e do infravermelho próximo (d) 
No caso da área 2, foram realizados vôos nos dois períodos, referentes às culturas do trigo e da soja. A Figura 11 apresenta as imagens aéreas da cultura do trigo, para a área 2, nos espectros do vermelho e do infravermelho próximo.

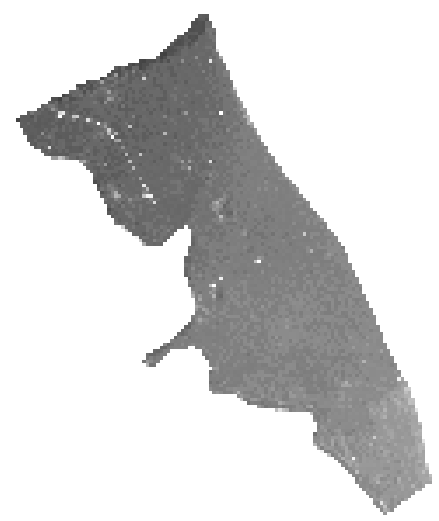

(a)

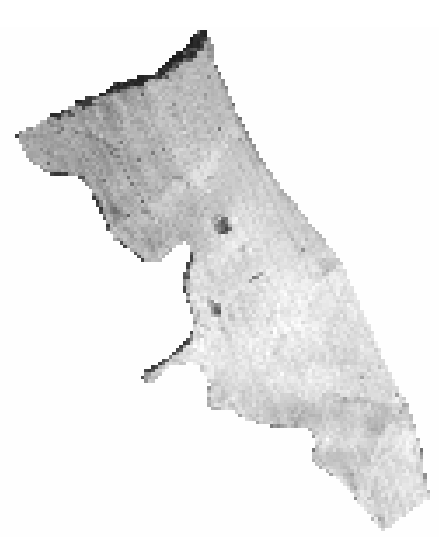

(b)

Figura 11 - Imagens da área 2, referentes à cultura do trigo, nos espectros do vermelho (a) e do infravermelho próximo (b)

Por motivos técnicos, as imagens nos espectros do infravermelho próximo e do vermelho referentes à cultura da soja tiveram de ser descartadas. As imagens apresentaram valores de pixel iguais a 255 e 11, respectivamente, para toda a área de interesse. Este fato tornou impossível a análise destes produtos.

\subsection{Análise dos dados coletados em grade}

\subsubsection{Análise estatística}

Foi efetuada uma análise estatística descritiva para os dados coletados em grade. A mesma foi realizada dadas as prerrogativas da análise 
geoestatística, que apregoa que a eliminação desta etapa pode levar a uma análise geoestatística não condizente com a realidade no campo.

Os dados coletados em grade são correspondentes aos valores de IAF, altura de plantas e número de plantas por metro linear. Esta coleta de dados foi realizada na área 1 , para a cultura da soja, e o resumo estatístico destes dados é apresentado na Tabela 4.

Tabela 4. Resumo estatístico dos dados coletados em grade, na área 1, para a cultura da soja

\begin{tabular}{lccc}
\hline & IAF $\left(\mathbf{m}^{\mathbf{2}} \cdot \mathbf{m}^{-2}\right)$ & $\begin{array}{c}\text { Plantas por } \\
\text { metro linear }\end{array}$ & $\begin{array}{c}\text { Altura de } \\
\text { plantas (cm) }\end{array}$ \\
\hline Número de observações & 65 & 65 & 65 \\
Média & 2,75 & 11,67 & 0,41 \\
Mínimo & 0,9 & 4,66 & 0,21 \\
Máximo & 6,61 & 36,33 & 0,65 \\
Quartil inferior & 1,73 & 10,33 & 0,34 \\
Quartil superior & 3,55 & 12,33 & 0,46 \\
Variação entre quartis & 1,82 & 2,00 & 0,12 \\
Variância & 1,57 & 12,75 & 0,86 \\
Desvio padrão & 1,25 & 3,57 & 0,09 \\
Limite inferior & 0,00 & 7,33 & 0,15 \\
Limite superior & 6,28 & 15,33 & 0,65 \\
Curtose & 0,43 & 36,30 & $-0,127$ \\
Coeficiente de Variação (\%) & 45,45 & 30,59 & 22,64 \\
\hline
\end{tabular}

Pode-se verificar na Tabela 4, que os coeficientes de variação das variáveis analisadas apresentam-se elevados, retratando uma grande dispersão dos dados, principalmente para os valores de IAF e número de plantas por metro linear. Na Figura 12, o histograma e o gráfico de probabilidade normal esperada retratam as distribuições dos dados brutos de IAF. 


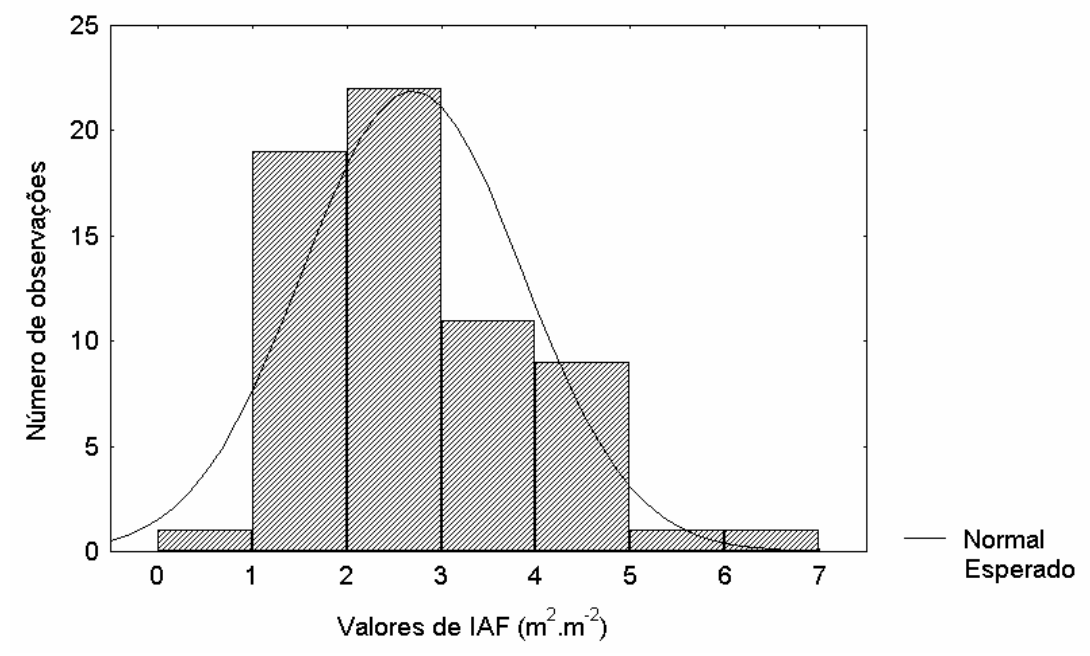

(a)

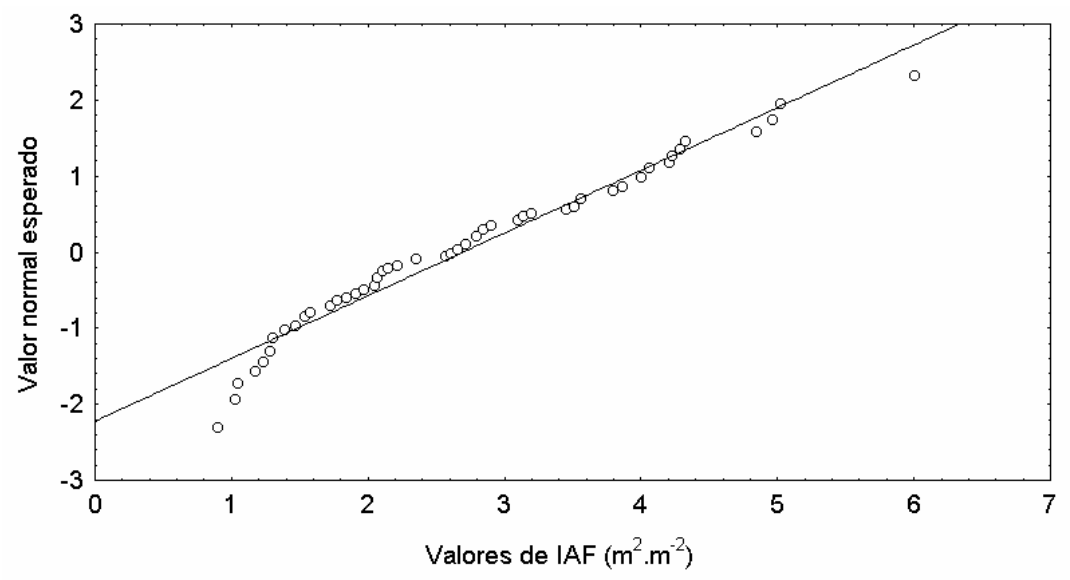

(b)

Figura 12 - Histograma (a) e gráfico de probabilidade normal esperada (b) para os dados brutos de IAF

Observa-se que a distribuição dos valores de IAF (Figura 12) apresenta uma ligeira assimetria para a esquerda e uma curtose elevada, com o pico da curva elevado em relação à curva de distribuição normal. As Figuras 13 e 14 ilustram os histogramas e os gráficos de probabilidade normal referentes aos valores encontrados para a altura de plantas e para o número de plantas por metro linear, respectivamente. 


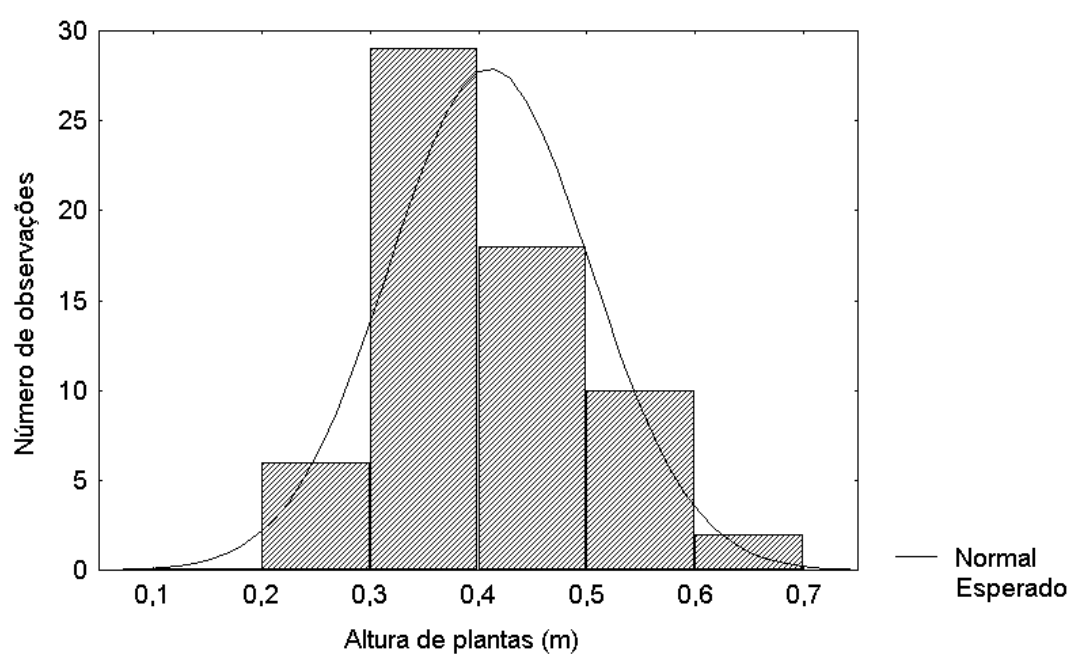

(a)

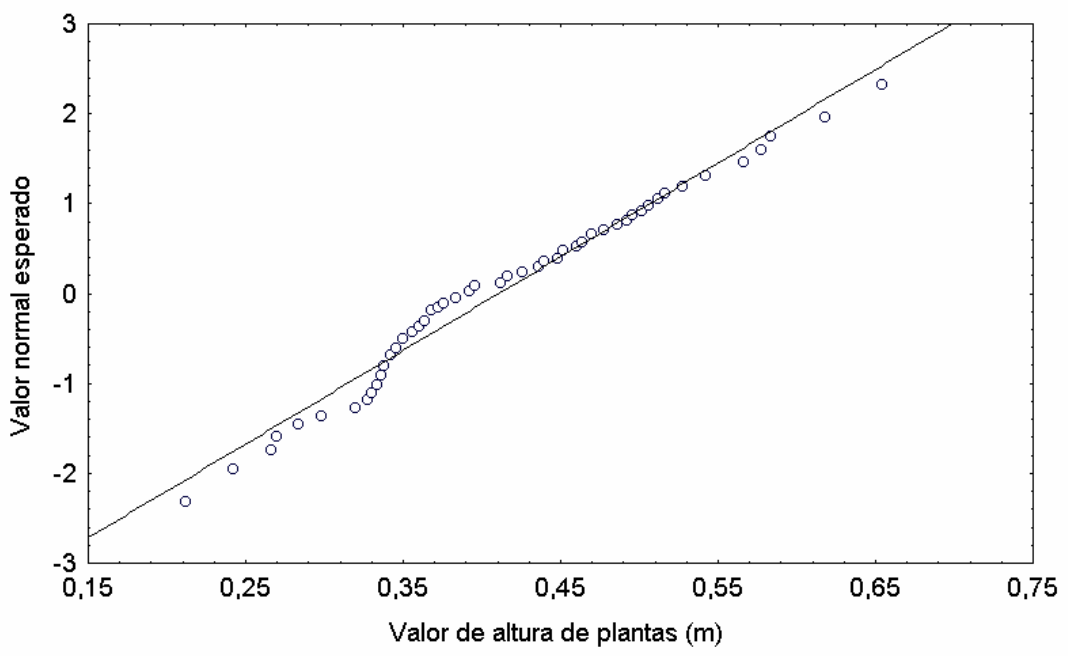

(b)

Figura 13 - Histograma (a) e gráfico de probabilidade normal esperada (b) para os dados brutos de altura de plantas 


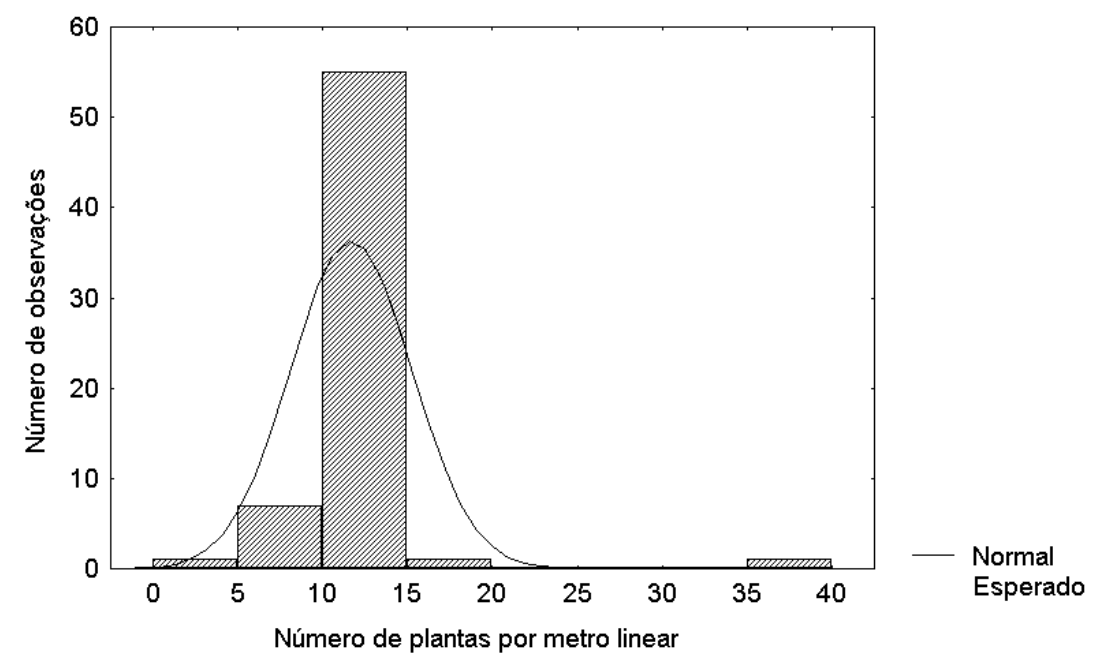

(a)

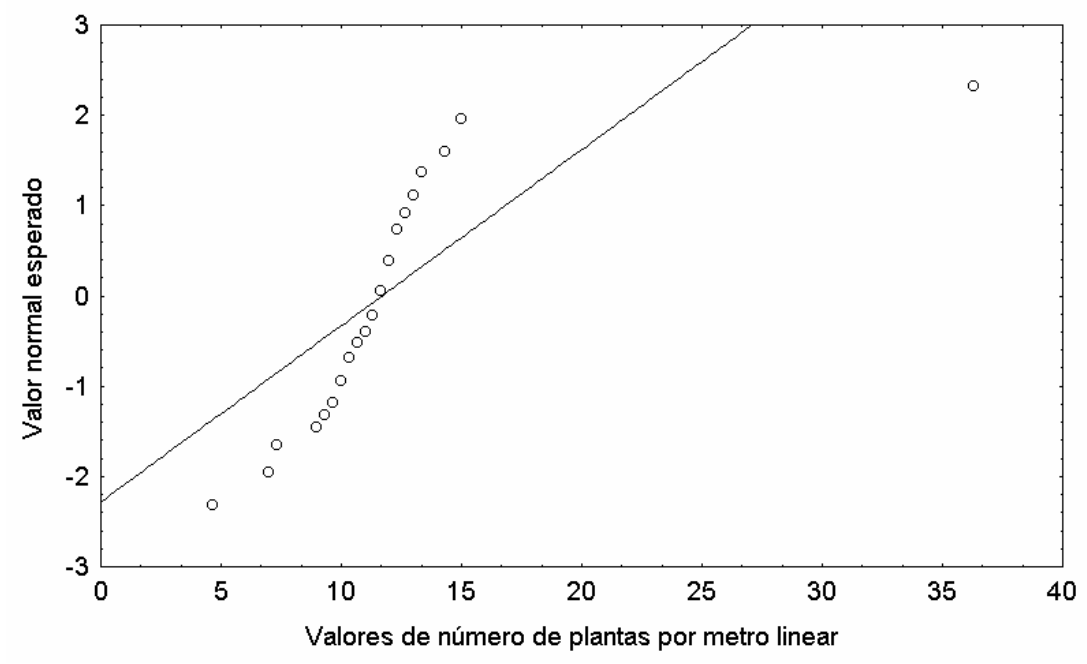

(b)

Figura 14 - Histograma (a) e gráfico de probabilidade normal esperada (b) para os dados brutos de número de plantas por metro linear

Em relação à altura de plantas (Figura 13), o histograma apresentou uma distribuição mais simétrica, com o valor de curtose mais próximo a zero em relação às outras variáveis. Para os dados referentes ao número de plantas por metro linear (Figura 14), ocorreu um acentuado deslocamento da curva de distribuição para a esquerda (assimetria) e o valor da curtose muito elevado, com o pico da curva mais acentuado em relação à curva normal. Para Banzatto 
\& Kronka (1995), curvas com distribuição normal apresentam curtose próxima a zero.

O teste de Shapiro-Wilk (Tabela 5) foi determinante no processo de verificação da distribuição normal dos dados. Os dados correspondentes à altura de plantas foram os que apresentaram maior tendência à distribuição normal ( $W=0,969)$, na seqüência vieram os valores de IAF $(W=0,93)$, ambos considerados elevados, e por último o valor referente ao número de plantas por metro linear $(W=0,571)$.

Tabela 5. Teste de Shapiro-Wilk para os dados brutos

\begin{tabular}{lll}
\hline Variáveis & \multicolumn{2}{c}{ Shapiro-Wilk (W=\%) } \\
\hline IAF & $\mathrm{W}=0,939$ & $\mathrm{P}<0,005$ \\
Altura de plantas & $\mathrm{W}=0,969$ & $\mathrm{P}<0,247$ \\
Plantas por metro linear & $\mathrm{W}=0,571$ & $\mathrm{P}<0,003$ \\
\hline
\end{tabular}

Este cenário mostra a possível necessidade de eliminação de dados discrepantes, em busca de uma análise geoestatística confiável, principalmente para os dados de plantas por metro linear. Os dados que excederam os limites inferior e superior (Tabela 4) foram eliminados. Estes limites foram calculados de acordo com critérios mencionados anteriormente. Depois de retirados os dados discrepantes foi repetido o procedimento de determinação do histograma e do gráfico de probabilidade normal para os dados refinados de IAF (Figura 15) e número de plantas por metro linear (Figura 16). 


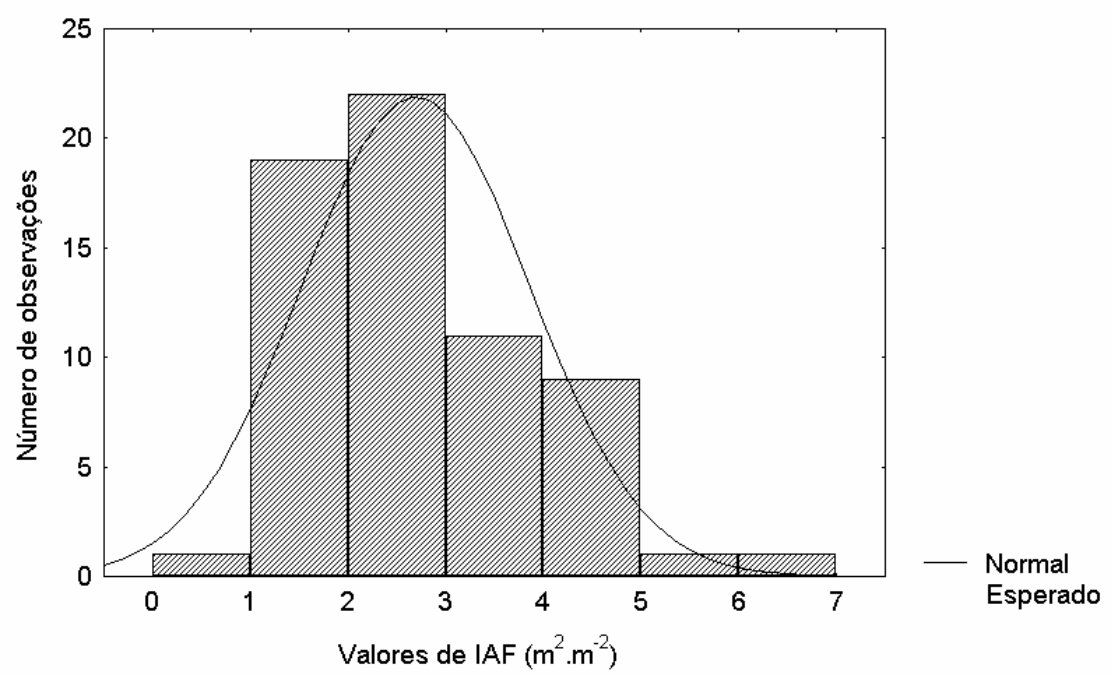

(a)

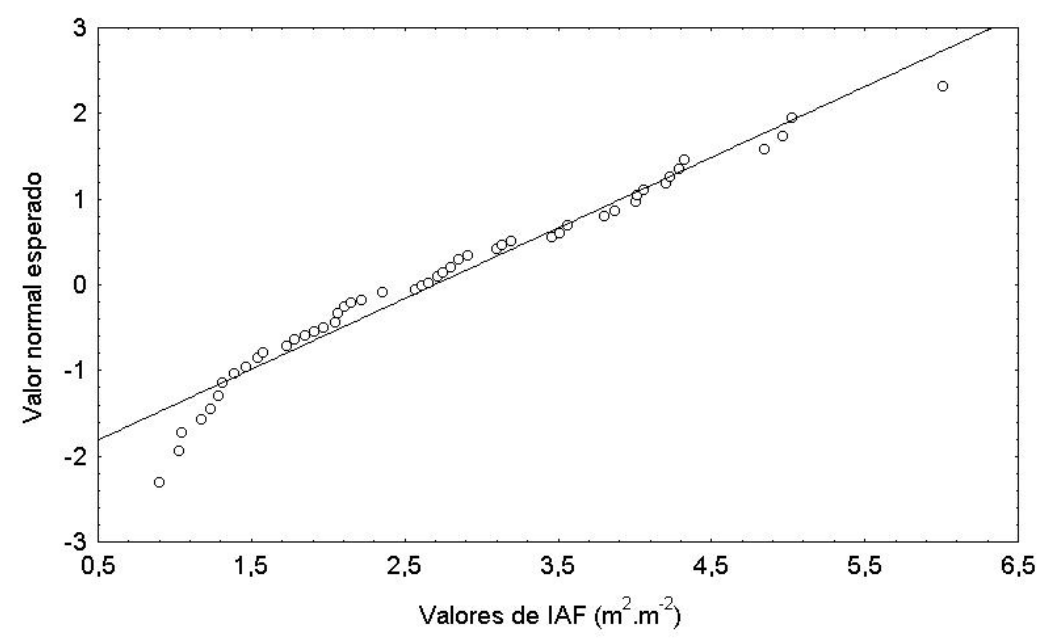

(b)

Figura 15 - Histograma (a) e gráfico de probabilidade normal esperada (b), para os dados refinados de IAF

A variável altura de plantas não necessitou eliminação de pontos e, conseqüentemente, não exigiu a elaboração de um novo histograma. Foram suprimidos três pontos amostrais dos valores de número de plantas por metro linear e um ponto amostral dos valores de IAF. 


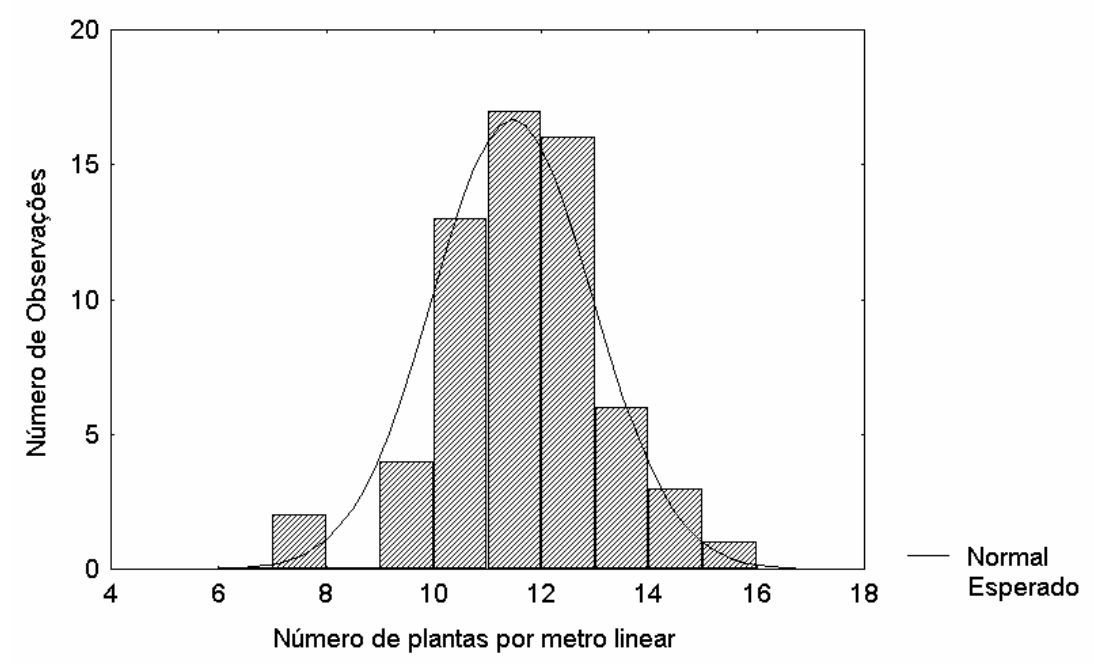

(a)

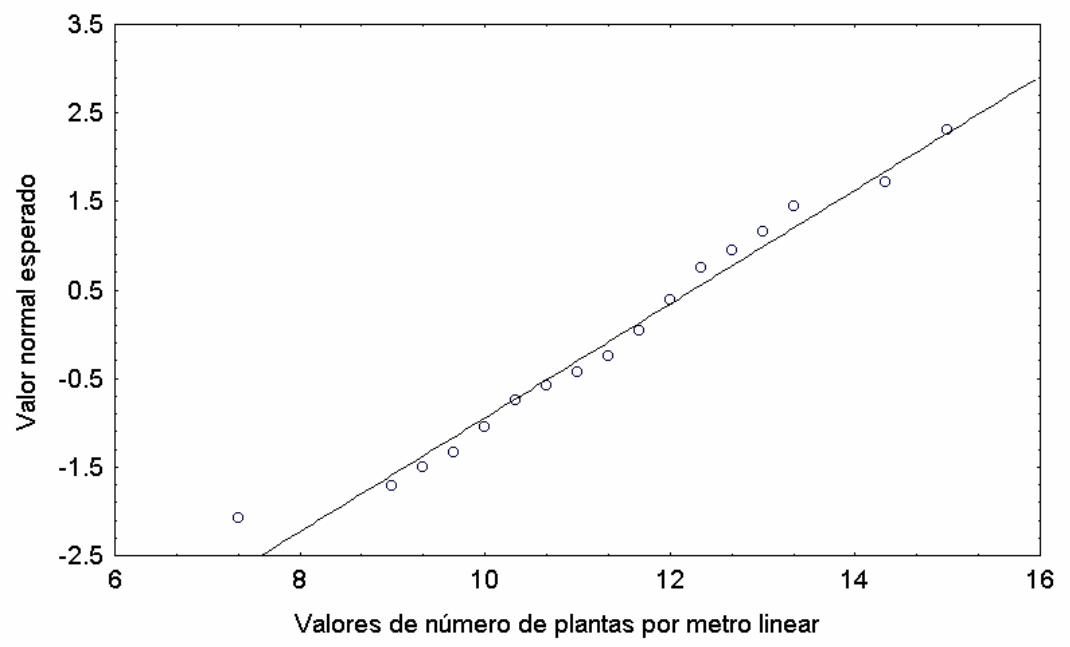

(b)

Figura 16 - Histograma (a) e gráfico de probabilidade normal esperada (b), para os dados refinados de número de plantas por metro linear

Este procedimento permitiu a utilização dos dados sem a necessidade de transformação dos mesmos e com perda de poucos pontos amostrais. 0 valor mais discrepante de curtose que se referia ao número de plantas por metro linear (valor de 36,30 - Tabela 4), passou para 0,9818, próximo a zero. Verifica-se pela Tabela 6 que os dados refinados apresentaram valores maiores 
em relação ao teste de Shapiro-Wilk, permitindo a realização da análise geoestatística com confiabilidade.

Tabela 6. Teste de Shapiro-Wilk para os dados refinados

\begin{tabular}{lll}
\hline Variáveis & \multicolumn{2}{c}{ Shapiro-Wilk (W=\%) } \\
\hline IAF & $\mathrm{W}=94,9$ & $\mathrm{P}<0,022$ \\
Altura de plantas & $\mathrm{W}=96,9$ & $\mathrm{P}<0,247$ \\
Plantas por metro linear & $\mathrm{W}=96,5$ & $\mathrm{P}<0,192$ \\
\hline
\end{tabular}

\subsubsection{Análise geoestatística}

A análise geoestatística foi realizada para a determinação de parâmetros para o processo de interpolação dos dados em grade. A Tabela 7 apresenta o modelo, o valor do efeito pepita, o valor do patamar, o valor do alcance e o valor da validação cruzada (VC). Vieira (2000) esclarece que a VC é a análise de erro de estimativa, onde são correlacionados os valores estimados pelos modelos produzidos com os valores observados no campo.

Tabela 7. Resultados da análise geoestatística, para os dados coletados em grade

\begin{tabular}{lccccc}
\hline Variável & Modelo & $\begin{array}{c}\text { Efeito Pepita } \\
\mathbf{C}_{\mathbf{0}}\end{array}$ & $\begin{array}{c}\text { Patamar } \\
\left(\mathbf{C}_{\mathbf{o}}+\mathbf{C}\right)\end{array}$ & $\begin{array}{c}\text { Alcance } \\
\text { A (m) }\end{array}$ & VC (\%) \\
\hline IAF & esférico & 0,001 & 1,749 & 392,7 & 99 \\
Altura de plantas & esférico & 0,100 & 112,5 & 401,7 & 98 \\
Plantas/m linear & esférico & 0,001 & 2,728 & 390,0 & 96 \\
\hline
\end{tabular}

Altura de plantas: altura de plantas $(\mathrm{m})$; Plantas/m linear: número de plantas por metro linear; IAF: índice de área foliar $\left(\mathrm{m}^{2} \cdot \mathrm{m}^{-2}\right)$.

Para as três variáveis analisadas foi encontrada dependência espacial entre as observações. Coincidentemente, o modelo que melhor se ajustou para 
as três variáveis analisadas foi o esférico. Os semivariogramas das três variáveis, IAF, altura de plantas e número de plantas por metro linear, apresentaram validações cruzadas superiores a 96\%. As Figuras 17 e 18 apresentam, respectivamente, os semivariogramas e os gráficos de VC para as variáveis analisadas.

Os valores de alcance $(A)$ permitem determinar a distância limite entre dependência e independência entre as amostras. Medições localizadas a distâncias maiores que A, têm distribuição espacial aleatória e por isto são independentes entre si (Vieira, 2000). Os valores encontrados nas análises realizadas variaram entre 390 metros a 401,7 metros, demonstrando que as variáveis estudadas apresentaram dependência espacial a grandes distâncias.

Os valores correspondentes ao efeito pepita (Co), foram de 0,001 para o IAF e para o número de plantas por metro linear. Para a variável altura de plantas o valor encontrado foi de 0,1. Todos os valores foram próximos a zero. Segundo Trangmar et al. (1985), um efeito pepita próximo a zero indica que o erro experimental é praticamente nulo e que não existe variação significativa a distâncias menores que a amostrada.

Os valores correspondentes ao patamar $(\mathrm{Co}+\mathrm{C})$ foram de 1,749, 112,5 e 2,728, respectivamente para o IAF, altura de plantas e número de plantas por metro linear. Vieira (2000) explica que este valor corresponde ao ponto onde a curva se estabiliza, sendo aproximadamente igual à variância dos dados.

Vieira (1995) afirma que quanto menor a proporção do efeito pepita para o patamar, maior será a semelhança entre os valores vizinhos e a continuidade do fenômeno, sendo menor a variância da estimativa e, portanto, maior confiança nas estimativas. 


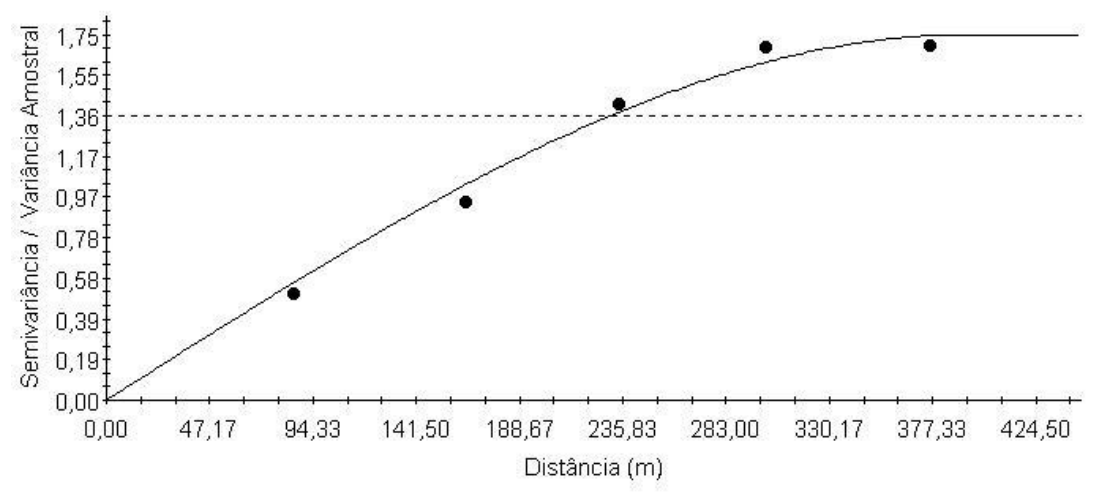

(a)

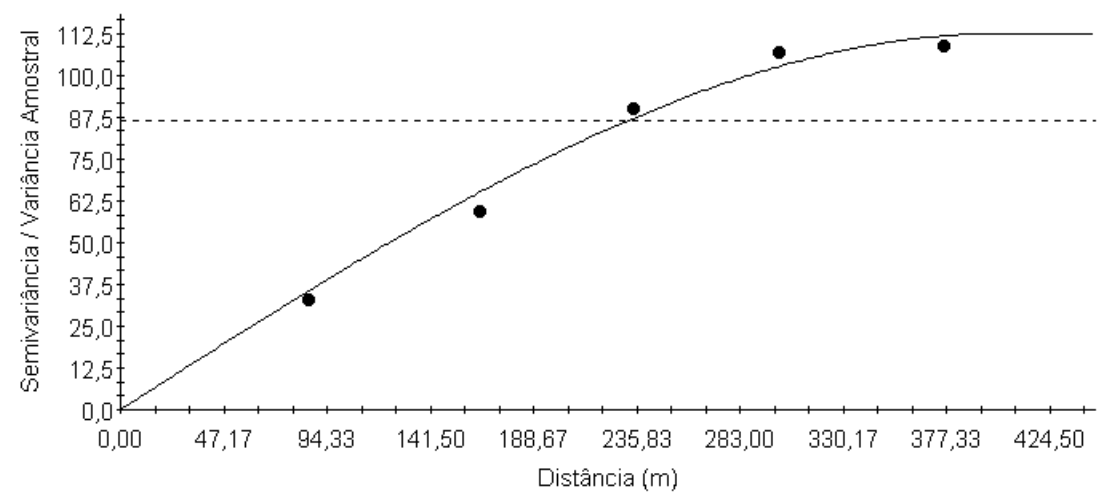

(b)

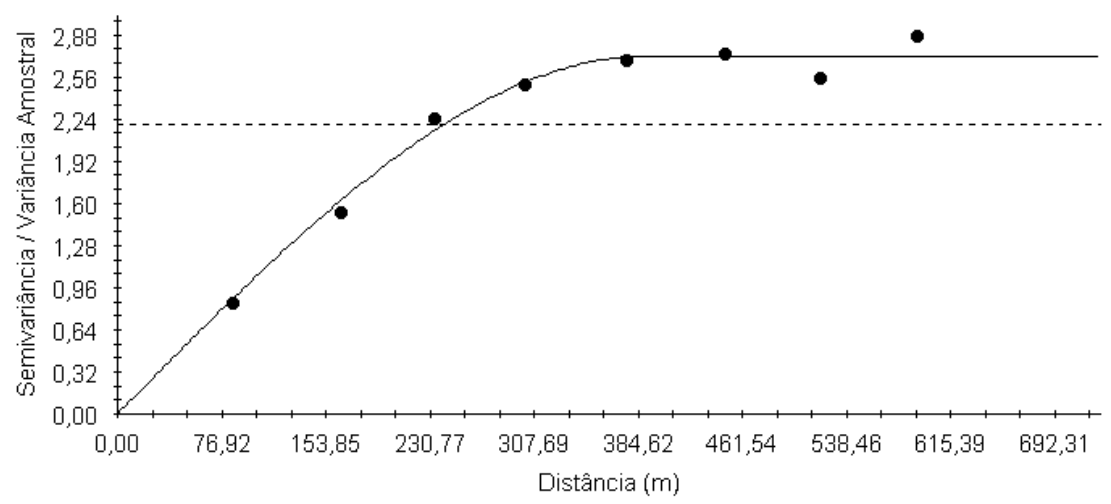

(c)

Figura 17 - Semivariogramas de IAF (a), altura de plantas (b); e número de plantas por metro linear (c) 


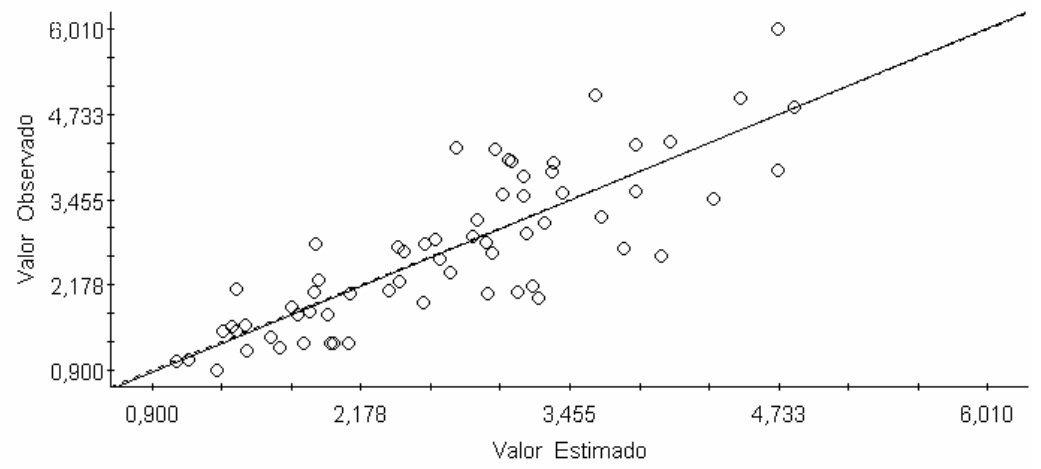

Coeficiente de determinaçã̃o $=99 \%$

(a)

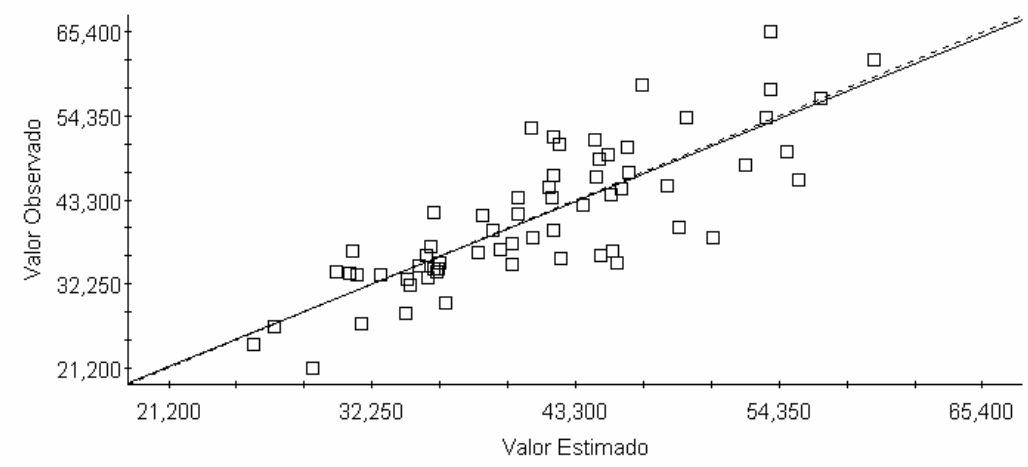

Coeficiente de determinaçẫo $=98 \%$

(b)

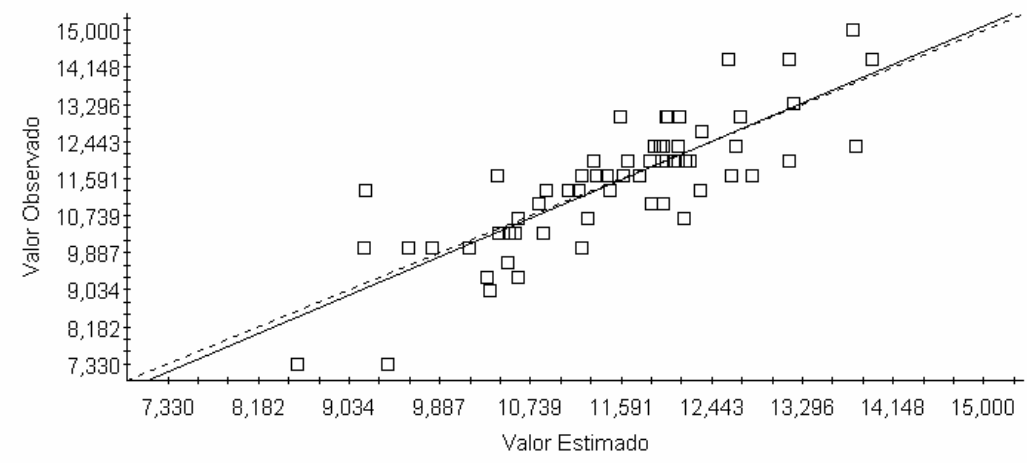

Coeficiente de determinaçẫo $=96 \%$

(c)

Figura 18 - Gráficos de validação cruzada para IAF (a); altura de plantas (b); e número de plantas por metro linear (c) 


\subsubsection{Mapas produzidos por meio de dados coletados em grade}

Com o uso da interpolação pela técnica da krigagem, embasada pelos parâmetros obtidos em cada semivariograma na análise geoestatística, os valores de IAF, altura de plantas e número de plantas por metro linear, coletados em grade, geraram os mapas de superfície para cada variável (Figuras 19, 20 e 21), posteriormente reclassificados em cinco classes, para facilitar a visualização da distribuição dos valores. Este número de classes foi utilizado por ser um padrão encontrado em vários trabalhos de agricultura de precisão, por exemplo (Araújo, 2000; Sharp et al., 2004; Yang, 2000).

Com este recurso pode-se verificar a distribuição espacial das variáveis na área de estudo. A análise das superfícies geradas possibilitou a distinção de regiões com menor e maior variabilidade das variáveis analisadas, permitindo a divisão da área em subáreas, além de proporcionar o zoneamento de cada variável, permitindo as análises de correspondência entre as variáveis (zonas de valores altos ou baixos).

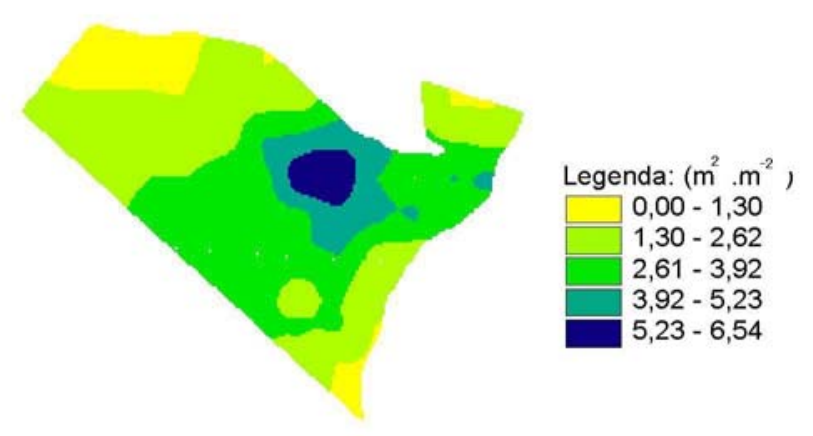

Figura 19 - Índice de área foliar, para a área 1, dividido em cinco classes 
As leituras de IAF variaram de zero a $6,54 \mathrm{~m}^{2} \cdot \mathrm{m}^{-2}$, onde a classe 2 variou de $1,3 m^{2} \cdot m^{-2}$ a $2,62 m^{2} \cdot m^{-2}$ e a classe 3 variou de $3,92 m^{2} \cdot m^{-2}$ a $5,23 m^{2} \cdot m^{-2}$. As mesmas apresentaram visualmente maior área de abrangência. Visualmente a classe cinco, variando de $5,23 \mathrm{~m}^{2} \cdot \mathrm{m}^{-2}$ a $6,54 \mathrm{~m}^{2} \cdot \mathrm{m}^{-2}$, foi a menor em relação à área de abrangência.

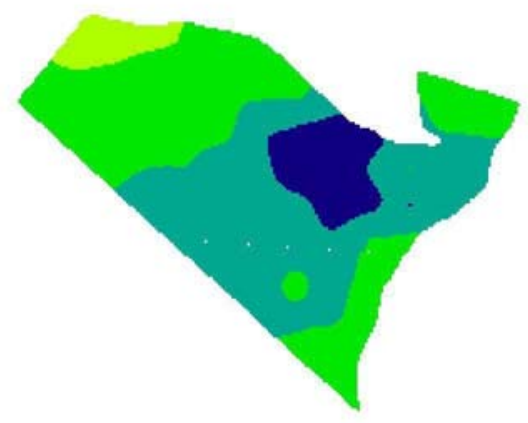

Legenda: $(m)$

$0,0-0,13$

$0,13-0,26$

$0,26-0,39$

$0,39-0,52$

$0,52-0,65$

Figura 20 - Altura de plantas, área 1, dividida em cinco classes

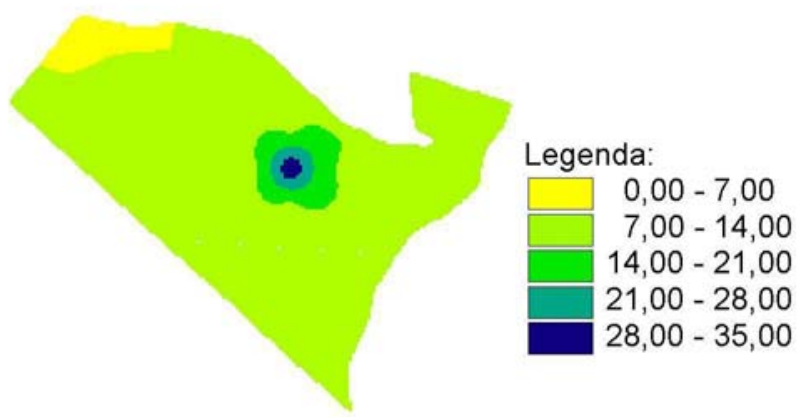

Figura 21 - Número de plantas por metro linear, área 1, dividido em cinco classes 
Analisando a superfície formada pela variável número de plantas por metro linear (Figura 21), percebe-se que em toda a área os valores variaram de zero a 35 plantas por metro linear. A classe estabelecida entre 7 e 14 plantas foi a que se destacou, cobrindo grande parte da área. Uma região mais centralizada cobriu as três classes restantes, onde houve uma variação de 14 a 35 plantas por metro linear. Esta região correspondeu visualmente à região de maiores valores de IAF (Figura 19) e de altura das plantas (Figura 20).

Ocorreu também nos três casos uma correspondência visual entre as classes com valores mais baixos (áreas com menor vigor da cultura). Esta constatação permitiu estabelecer visualmente áreas onde a cultura da soja apresentou-se mais e menos vigorosa.

\subsubsection{Regressão entre mapas de variáveis coletadas em grade e NDVI}

No software Idrisi32 foi realizada a análise de regressão linear simples entre os mapas gerados com dados coletados em grade e a imagem NDVI (Figura 22), esta última devido à associação teórica com o IAF.

O estabelecimento da correspondência entre as variáveis por meio de uma análise computacional corroborou e apresentou a mesma tendência encontrada na análise visual. Os resultados das regressões lineares realizadas para as variáveis, pixel-a-pixel, considerando-se os valores obtidos de $r^{2}$ (coeficiente de determinação) e r (coeficiente de correlação linear espacial), são apresentados na Tabela 8. 
Tabela 8. Resultados da análise de regressão linear entre mapas, pixel-a-pixel

\begin{tabular}{ccccc}
\hline \multicolumn{2}{c}{ Variável } & Equação & $\mathrm{r}^{2}(\%)$ & $\mathrm{R}$ \\
Independente & Dependente & & \\
\hline Altura & Plantas & Altura $=10,9526+2,5621$. Plantas & 71,09 & 0,84 \\
Altura & IAF & IAF $=-2,5872+0,1304$.Altura & 96,80 & 0,98 \\
Plantas & IAF & IAF $=-1,2152+0,3389$. Plantas & 70,80 & 0,84 \\
NDVI & IAF & IAF $=$ 0,6062+3,8805.NDVI & 14,07 & 0,37 \\
NDVI & Altura & Altura $=24,544+29,6773 . N D V I$ & 14,43 & 0,38 \\
NDVI & Plantas & Plantas $=7,5239+7,4428 . N D V I$ & 8,38 & 0,28
\end{tabular}

Altura: altura de plantas $(\mathrm{m})$; Plantas: número de plantas por metro linear; IAF: índice de área foliar $\left(\mathrm{m}^{2} \cdot \mathrm{m}^{-2}\right)$; NDVI: índice de vegetação da diferença normalizada.

$\mathrm{Na}$ análise de regressão foram realizadas as análises de variância dos modelos de regressão estabelecidos para cada variável analisada. Veiga \& Sáfadi (1999) afirmam que alguns critérios estatísticos são utilizados para se avaliar a qualidade do ajuste do modelo proposto. Dentre eles destaca-se a análise de variância. A análise de variância é uma técnica utilizada para se testar o ajuste da equação como um todo, ou seja, um teste para verificar se a equação de regressão obtida é significativa ou não.

Cada modelo gerado foi analisado por meio da análise de variância e foram comparados os valores de $\mathrm{F}$ calculados, com os valores de $\mathrm{F}$ tabelados, em função de $F(1,13096)$ igual ao valor de 6,63 , avalizando ou não o uso das regressões lineares estabelecidas para as variáveis (Tabela 9). 
Tabela 9. Comparação entre valores de F calculado e tabelado, referentes as regressões realizadas para os dados coletados em grade

\begin{tabular}{cccc}
\hline \multicolumn{2}{c}{ Regressão } & F Calculado & F Tabelado (1\%) \\
\hline Altura & Plantas & 32206,96 & 6,63 \\
Altura & IAF & 401261,68 & 6,63 \\
Plantas & IAF & 31842,16 & 6,63 \\
NDVI & IAF & 2143,59 & 6,63 \\
60 & Altura & 2209,88 & 6,63 \\
NDVI & & & \\
NDVI & Plantas & 1198,64 & 6,63
\end{tabular}

Altura: altura de plantas $(\mathrm{m})$; Plantas: número de plantas por metro linear; IAF: índice de área foliar $\left(\mathrm{m}^{2} \cdot \mathrm{m}^{-2}\right)$; NDVI: índice de vegetação da diferença normalizada.

O resultado da estatística $\mathrm{F}(\mathrm{Pr}>\mathrm{F}$ ) muito maior que 6,63 (Tabela $\mathrm{F}$ ) permite aceitar, a 1\% de significância, a hipótese HA, que afirma a existência da relação de dependência entre as variáveis, por sua vez rejeitando a hipótese H0, referente à não existência de relação de dependência entre as variáveis. Concluiu-se que, estatisticamente, existem fortes evidências de relação causaefeito entre a variável dependente e a independente para todas as análises de regressão realizadas e apresentadas na Tabela 8.

Segundo Jacob et al. (1999), na regressão espacial, a estatística F (Pr>F) é sempre muito maior do que sua probabilidade da tabela de distribuição $F$ (tabela), assim, o modelo é sempre aceito.

Teoricamente existe uma correspondência entre as variáveis IAF (Figura 19) e NDVI (Figura 22), sendo a primeira obtida no campo e a segunda obtida por meio de imagens aéreas da área. O NDVI apresentou valores de zero a 0,72 , sendo que, quanto mais próximo da unidade, maior o vigor da cultura. 


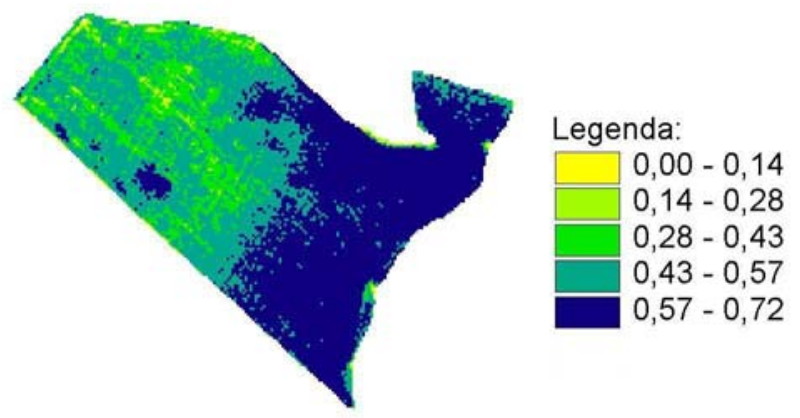

Figura 22 - Imagem NDVI para a área 1, cultura da soja, dividida em cinco classes

Observa-se visualmente que a área que apresenta maiores valores de IAF corresponde à área de maiores valores de NDVI. A análise de regressão realizada no software Idrisi32 resultou nos valores de (r) 0,37, 0,38 e 0,29 para NDVI correlacionado com IAF, altura de plantas e número de plantas por metro linear, respectivamente. Segundo Peterson et al. (1997) estes valores são considerados significativos, porém baixos.

Xavier (2002) encontraram valores de $r$ próximos a 0,7, analisando imagens NDVI obtidas por meio do satélite Landsat-7 e IAF obtido pelo equipamento LAI-2000. Os valores de $r$ encontrados entre o NDVI e o IAF, considerados baixos, podem estar relacionados à grade amostral utilizada no trabalho (70m entre pontos), considerando que ocorre grande irregularidade na área estudada em relação às características analisadas. Em regiões com desenvolvimento vegetativo visivelmente maior existiam pequenas manchas pouco desenvolvidas e, em alguns casos, coincidentes com os pontos amostrais, caracterizando erroneamente a área de abrangência do ponto amostral. 


\subsection{Análise entre mapas de produtividade e imagens NDVI}

A Figura 23 ilustra a produtividade para a cultura da soja, referente à área 1. A mesma apresenta uma variação de produtividade entre $1,38 \mathrm{t} / \mathrm{ha} \mathrm{e}$ 6,54 t/ha, distribuída em cinco classes.

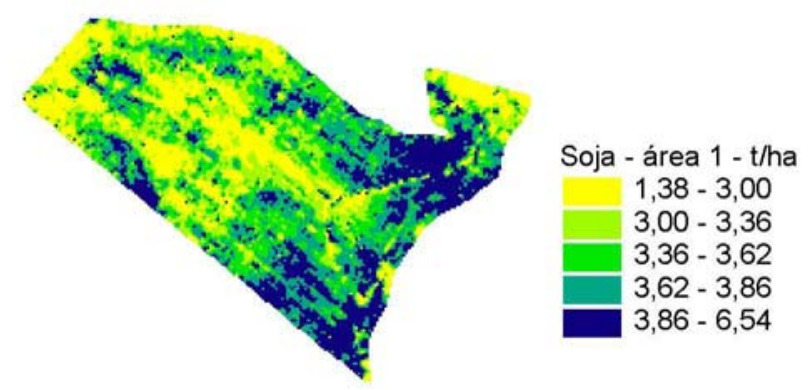

Figura 23 - Produtividade da cultura da soja, na área 1, dividida em cinco classes

Visualmente definem-se áreas correspondentes, comparando-se as imagens de produtividade (Figura 23) e de NDVI (Figura 22). Alguns pontos com menor valor de NDVI relacionam-se com alguns pontos de menor produtividade para a cultura da soja.

Esta constatação também foi verificada, com um grau mais acentuado, quando da realização de uma análise visual entre a produtividade da cultura do trigo, área 1 (Figura 24) e o NDVI (Figura 25), obtido para a referida cultura e área.

O mapa de produtividade para a cultura do trigo (Figura 24), referente à área 1, apresenta uma variação de produtividade entre 0,72 t/ha a 4,75 t/ha, 
distribuída em cinco classes. A imagem NDVI apresenta-se classificada em cinco classes, estabelecendo uma variação do índice NDVI de zero a 0,6.

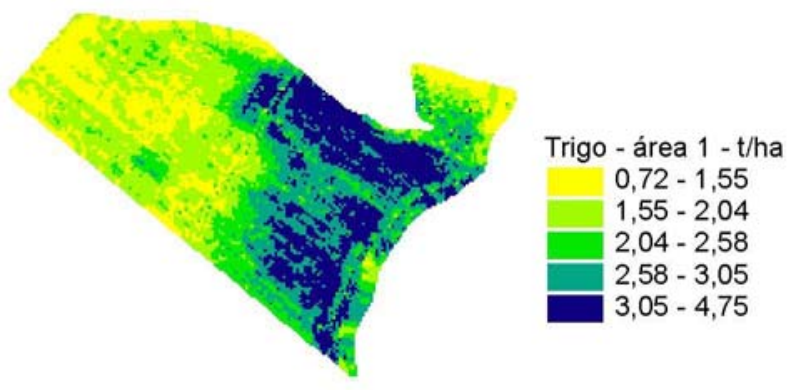

Figura 24 - Produtividade da cultura do trigo, na área 1, dividida em cinco classes

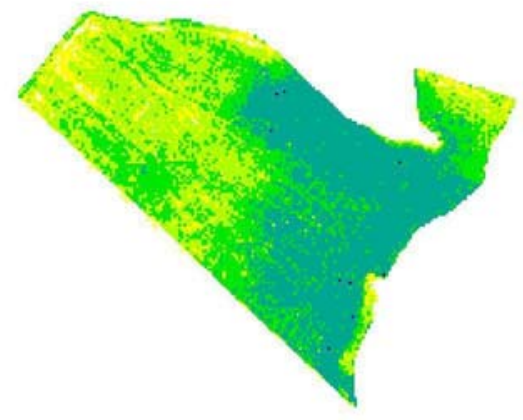

Legenda:

$0,00-0,12$

$0,12-0,24$

$0,24-0,36$

$0,36-0,48$

$0,48-0,60$

Figura 25 - Imagem NDVI para a área 1, cultura do trigo, dividida em cinco classes 
Percebe-se que nesta análise existe uma correspondência visual clara entre a área correspondente à maior produtividade (3,05 t/ha a 4,74 t/ha) e a classe que representa os maiores valores de NDVI $(0,48$ a 0,60$)$. Da mesma forma os pontos de menor produtividade correspondem visualmente aos pontos onde os valores de NDVI foram menores.

O estudo realizado na área 2 envolveu apenas a cultura do trigo. $\mathrm{O}$ mapa de produtividade da mesma (Figura 26) foi dividido em cinco classes, representando a variação de produtividade entre 0,51 (t/ha) a 4,60 (t/ha).

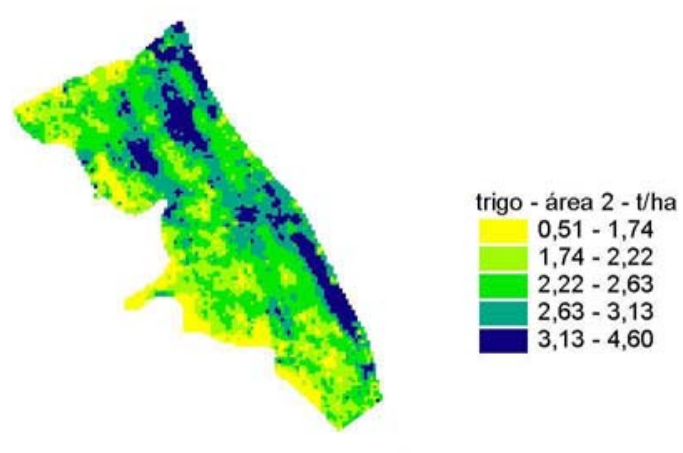

Figura 26 - Produtividade da cultura do trigo, na área 2, dividida em cinco classes

Como no caso da produtividade do trigo (Figura 26), o NDVI para a mesma cultura (Figura 27) também foi classificado em cinco classes, que apresentaram variação de zero a 0,78. 


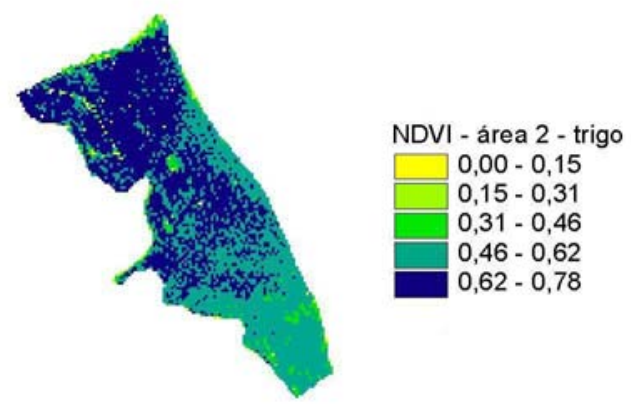

Figura 27 - Imagem NDVI para a área 2, cultura do trigo, dividida em cinco classes

Diferentemente dos outros dois casos, quando se procedeu à análise visual para esta área não foi observada a coincidência entre pontos de maior produtividade com pontos de maior valor de NDVI. Como a análise visual é muito subjetiva, procedeu-se à análise de regressão entre as variáveis.

\subsection{Regressão entre variáveis, pixel-a-pixel}

As análises de regressão linear entre as variáveis foram realizadas considerando os valores pixel-a-pixel, empregando os valores de produtividade, níveis de cinza na imagem do infravermelho próximo, níveis de cinza na imagem do vermelho e valores correspondentes ao NDVI. A produtividade foi definida, em todas as situações, como variável dependente e as demais como variáveis independentes.

A Tabela 10 apresenta os resultados das análises de regressão linear simples, com os valores dos coeficientes de determinação $\left(r^{2}\right)$ e os valores de correlação (r), para as culturas da soja e do trigo referentes a área 1. 
Tabela 10. Resultado da análise de regressão linear entre mapas, pixel-a-pixel, para a área 1, envolvendo dados obtidos a partir das imagens e valores de produtividade

\begin{tabular}{ccccc}
\hline \multicolumn{2}{c}{ Variável } & Equação & $\mathbf{r}^{2}(\%)$ & $\mathbf{r}$ \\
Independente & Dependente & & & \\
\hline INFRA & Soja & Soja $=1,5488+0,0093$. INFRA & 29 & 0,50 \\
VER & Soja & Soja $=4,5805-0,0188$.VER & 18 & 0,42 \\
NDVI & Soja & Soja $=2,2261+2,269$. NDVI & 25 & 0,54 \\
INFRA & Trigo & Trigo $=2,5715-0,08$. INFRA & 35 & 0,59 \\
VER & Trigo & Trigo $=2,5562-0,095$. VER & 33 & 0,57 \\
NDVI & Trigo & Trigo $=0,939+3,9321 . N D V I$ & 67 & 0,82
\end{tabular}

INFRA: valores de nível de cinza para imagem do infravermelho próximo; VER: valores de nível de cinza para imagem do vermelho; NDVI: valores de NDVI; Trigo: produtividade do trigo (t/ha); Soja: produtividade da soja (t/ha).

Foram encontrados valores significativos de $r$ para as regressões realizadas entre o NDVI e as produtividades da soja e do trigo para a área 1. A área 1 apresentou coeficiente de correlação (r), entre produtividade e NDVI, de 0,82 e 0,54 para as culturas do trigo e soja respectivamente. Yang et al. (2000) trabalharam com imagens aéreas obtidas em cinco períodos durante o ciclo da cultura da soja e o mapa de produtividade da cultura. A partir das imagens foram gerados índices de vegetação (NDVI) que, correlacionados com a produtividade, geraram um coeficiente de determinação de 0,63 , na média dos cinco períodos.

Steven \& Millar (1997) encontraram valores similares, onde o valor de $r$ variou de 0,552 a 0,774 quando correlacionaram imagens do satélite SPOT com mapas de produtividade de grãos. Ainda focando a área 1, observou-se que a cultura do trigo apresentou melhor resposta (maiores valores de r), em relação à cultura da soja. Observou-se no mapa de produtividade do trigo (Figura 24) 
uma definição mais clara das classes de produtividade, quando comparado com o mapa de produtividade da cultura da soja (Figura 23), onde as classes apresentaram-se mais dispersas.

Em todas as análises realizadas os valores de $r$ foram maiores para a área 1. Na área 2, não foi possível a obtenção de imagens apropriadas ao estudo referentes à cultura da soja, como já comentado, devido a problemas com a câmera. A Tabela 11 apresenta os resultados das análises de regressão linear simples com os valores dos coeficientes de determinação $\left(r^{2}\right)$ e os valores de correlação (r), para a cultura do trigo referente à área 2. A área 2 apresentou coeficiente de correlação (r) entre produtividade e NDVI de 0,15.

Tabela 11. Resultado da análise de regressão linear entre mapas pixel-a-pixel para a área 2, envolvendo dados obtidos a partir das imagens e valores de produtividade

\begin{tabular}{ccccc}
\hline \multicolumn{2}{c}{ Variável } & Equação & $\mathbf{r}^{\mathbf{2}} \mathbf{( \% )}$ & $\mathbf{r}$ \\
Independente & Dependente & Trigo $=2113,827+1,6403$. INFRA & 1,0 & 0,10 \\
\hline INFRA & Trigo & Trigo $=2627,2854-3,9191$. VER & 0,9 & 0,09 \\
VER & Trigo & Trigo $=1880,251+921,693$. NDVI & 2,5 & 0,15 \\
NDVI & Trigo & Th
\end{tabular}

INFRA: valores de nível de cinza para imagem do infravermelho próximo; VER: valores de nível de cinza para imagem do vermelho; NDVI: valores de NDVI; Trigo: produtividade do trigo (t/ha).

A área 2 apresentou coeficientes de determinação muito baixos para as duas bandas individualizadas (vermelho e infravermelho próximo). O NDVI apresentou a mesma tendência de estabelecer maior valor do coeficiente de correlação da regressão realizada com a produtividade, mas o valor encontrado foi considerado muito baixo em relação aos valores encontrados na área 1.

As análises com o NDVI apresentaram os maiores valores de $r$ quando comparadas com as bandas isoladas do infravermelho próximo e do vermelho. 
Excetuando-se as imagens NDVI, os maiores coeficientes de determinação foram encontrados para as imagens isoladas do espectro do infravermelho próximo e, por fim, do vermelho.

Segundo Veiga \& Sáfadi (1999), uma questão bastante estudada, por dificuldades inerentes ao assunto, trata-se do ajuste do modelo de regressão. Em todas as áreas em que se aplica a regressão, procura-se um modelo que explique a variação da variável dependente, com um ajuste que permita fazer previsões ou explicar o fenômeno em questão. Alguns critérios são utilizados para se avaliar a qualidade do ajuste do modelo proposto, dentre eles destacase a análise de variância.

Foram realizadas as análises de variância para as regressões entre as variáveis analisadas e os valores de $F$ (Tabelado) e $F$ (Calculado), foram dispostos nas Tabelas 12 e 13.

Tabela 12. Comparação entre valores de $\mathrm{F}$ calculado e tabelado, referentes as regressões realizadas para a área 1

\begin{tabular}{cccc}
\hline \multicolumn{2}{c}{ Regressão } & F Calculado & F Tabelado (1\%) \\
\hline INFRA & Soja & 5377,37 & 6,63 \\
VER & Soja & 2877,997 & 6,63 \\
NDVI & Soja & 4368,68 & 6,63 \\
INFRA & Trigo & 7150,88 & 6,63 \\
VER & Trigo & 6578,21 & 6,63 \\
NDVI & Trigo & 26756,38 & 6,63 \\
\hline
\end{tabular}

INFRA: valores de nível de cinza para imagem do infravermelho próximo; VER: valores de nível de cinza para imagem do vermelho; NDVI: valores de NDVI; Trigo: produtividade do trigo (t/ha); Soja: produtividade da soja (t/ha).

O valor de $\mathrm{F}$ (Tabelado) foi determinado segundo Banzato \& Kronka (1995), para os valores de $F(1,13096)$ e $F(1,6333)$ para as áreas 1 e 2 , 
respectivamente, gerando o valor 0,63 para ambas as áreas, a 1\% de significância.

Tabela 13. Comparação entre valores de F calculado e tabelado, referentes as regressões realizadas para a área 2

\begin{tabular}{cccc}
\hline \multicolumn{2}{c}{ Regressão } & F Calculado & F Tabelado (1\%)* \\
\hline INFRA & Trigo & 68,049 & 6,63 \\
VER & Trigo & 58,859 & 6,63 \\
NDVI & Trigo & 163,971 & 6,63 \\
\hline
\end{tabular}

INFRA: valores de nível de cinza para imagem do infravermelho próximo; VER: valores de nível de cinza para imagem do vermelho; NDVI: valores de NDVI; Trigo: produtividade do trigo (t/ha); Soja: produtividade da soja (t/ha).

As análises de regressão realizadas entre os mapas de produtividade e as bandas espectrais geraram números opostos entre as duas áreas analisadas no trabalho. Esta discrepância gerou questionamentos a respeito do porque deste fato. Visando ao entendimento da mesma, foi realizada a análise estatística descritiva (Tabela 14) para todos os elementos envolvidos no processo de regressão para as duas áreas.

Os coeficientes de variação (CV) para as variáveis NDVI das culturas do trigo e da soja, na área 1, foram superiores ao valor do coeficiente de variação do NDVI referente à cultura do trigo na área 2. Verificou-se a tendência de maior coeficiente de determinação na regressão com as produtividades das culturas para as variáveis NDVI que apresentaram o maior CV. Esta característica permitiu inferir que a imagem obtida por meio de videografia aérea digital multiespectral correlaciona-se significativamente com a produtividade, quando existe uma variabilidade evidente nas variáveis estudadas. 
Tabela 14. Resumo estatístico das variáveis de imagem e produtividade para as áreas 1 e 2

\begin{tabular}{lcccccccc}
\hline Variáveis & Média & Mediana & Mínimo & Máximo & Variância & $\begin{array}{c}\text { Desvio } \\
\text { padrão }\end{array}$ & Curtose & CV \\
\hline VE_1_T & 64,70 & 60,00 & 40,00 & 181,00 & 288,66 & 16,99 & 7,32 & 26,26 \\
IV_1_T & 131,42 & 131,00 & 69,00 & 179,00 & 255,82 & 15,99 & $-0,29$ & 12,17 \\
NDVI_1_T & 0,34 & 0,36 & $-0,29$ & 0,60 & 0,02 & 0,15 & 0,63 & 43,59 \\
PROD_1_T & 2,30 & 2,26 & 0,77 & 4,75 & 0,51 & 0,71 & $-1,27$ & 30,95 \\
IV_1_S & 204,37 & 202,00 & 99,00 & 255,00 & 913,83 & 30,23 & $-1,07$ & 14,79 \\
VE_1_S & 60,54 & 58,00 & 40,00 & 192,00 & 137,13 & 11,71 & 14,80 & 19,34 \\
NDVI_1_S & 0,54 & 0,56 & $-0,17$ & 0,72 & 0,01 & 0,11 & 2,71 & 21,31 \\
PROD_1_S & 3,46 & 3,52 & 1,39 & 6,54 & 0,26 & 0,51 & 0,37 & 14,71 \\
PROD_2_T & 2,39 & 2,37 & 0,52 & 4,60 & 0,31 & 0,55 & 0,25 & 23,14 \\
NDVI_2_T & 0,60 & 0,63 & $-0,91$ & 0,78 & 0,01 & 0,10 & 22,87 & 16,33 \\
VE_2_T & 48,30 & 49,00 & 10,00 & 208,00 & 189,71 & 13,77 & 9,53 & 28,52 \\
IV_2_T & 197,67 & 205,00 & 23,00 & 255,00 & 1249,68 & 35,35 & 5,17 & 17,88 \\
\hline
\end{tabular}

E_1_T: Imagem no espectro do vermelho - área 1 - trigo; IV_1_T: Imagem no espectro do infravermelho próximo - área 1 - trigo; NDVI_1_T: Imagem NDVI - área 1 - trigo; PROD_1_T: Produtividade do trigo - área 1; IV_1_S: Imagem no espectro do infravermelho próximo - área 1 - soja; E_1_S: Imagem no espectro do vermelho área 1 - soja; NDVI_1_S: Imagem NDVI - área 1 - soja; PROD_1_S: Produtividade da soja - área 1PROD_2_T: Produtividade do trigo - área 2; NDVI_2_T: Imagem NDVI área 2 - trigo; VE_2_T: Imagem no espectro do vermelho - área 2 - trigo; IV_2_T: Imagem no espectro do infravermelho próximo - área 2 - trigo.

A análise realizada para a área 2 demonstrou um valor de curtose elevado para a variável NDVI, para a cultura do trigo, em relação à mesma variável da área 1, para as culturas da soja e do trigo. Por esta constatação pode-se inferir que houve a ocorrência significativa de valores discrepantes na imagem NDVI, referente à área 2.

Constatou-se, também, que em todas as imagens obtidas no espectro do vermelho, houve valores de curtose superiores aos das imagens do espectro 
do infravermelho próximo. Este fato permite supor um possível problema de calibração da câmera nessa faixa espectral, que teria gerado dados discrepantes. Associando-se a questão da baixa variabilidade das imagens obtidas na área 2 com o possível problema de calibração da câmera na faixa espectral do vermelho, explicam-se os baixos coeficientes de determinação entre a produtividade e as imagens obtidas nesta área.

\subsection{Variáveis classificadas}

As variáveis analisadas anteriormente foram também classificadas em duas categorias, conforme procedimento descrito anteriormente no item 3.2.2. A análise pixel-a-pixel é interessante para tratamentos localizados, ou seja, tratamentos em zonas de manejo com equipamentos que aplicam produtos em taxas variadas. Já para a destinação (em termos de uso e cobertura do solo) de diferentes partes da área de trabalho, torna-se mais viável a estratificação da mesma em um número menor de subáreas, visando a auxiliar a logística da atividade agrícola.

Sob esta ótica, segmentou-se a área em duas classes e foram então realizadas análises de concordância espacial entre as variáveis. Na Figura 28, são apresentados os mapas dos dados coletados em grade, classificados em duas categorias, para a cultura da soja. Nas Figuras 29, 30 e 31 são apresentadas as variáveis classificadas em duas produtividades, para a área 1, cultura da soja; área 1, cultura do trigo; e área 2, cultura do trigo, respectivamente. A classe 1 representa os valores abaixo da média e a classe 2 valores acima da média (incluindo os valores médios), para todas as variáveis analisadas. 


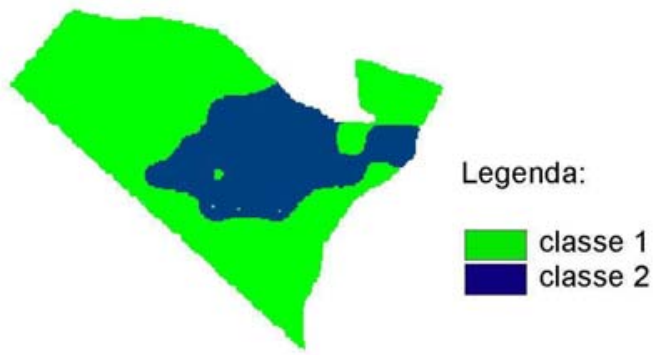

(a)

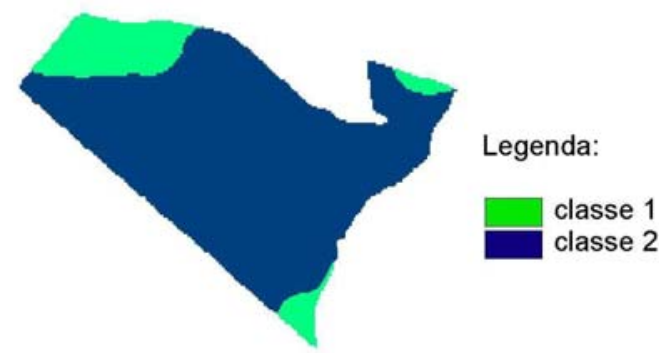

(b)

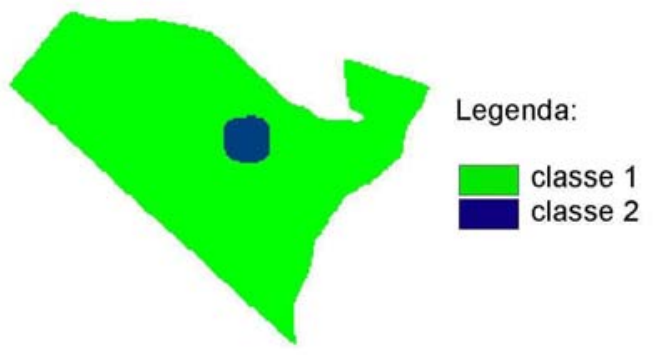

(c)

Figura 28 - Dados coletados em grade, classificados em duas categorias: IAF (a); altura de plantas (b); número de plantas por metro linear (c), para a área 1, com soja 


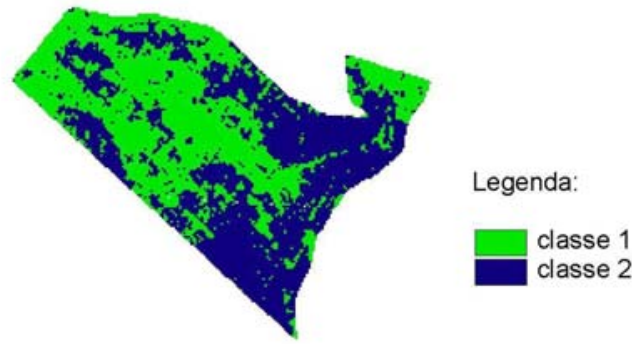

(a)

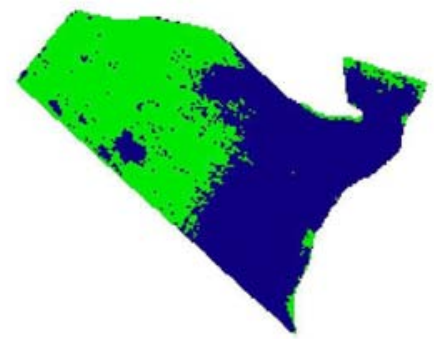

Legenda:
\begin{tabular}{|l}
\hline classe 1 \\
classe 2
\end{tabular}

(c)

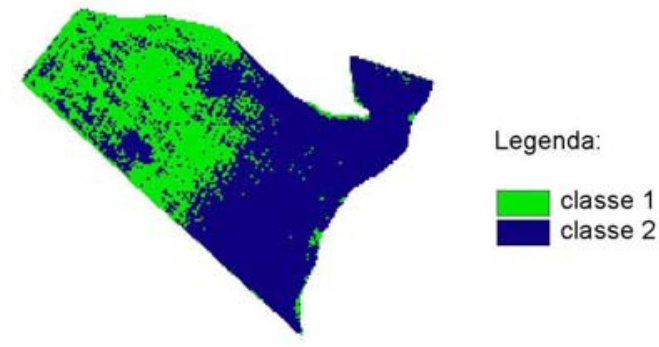

(b)

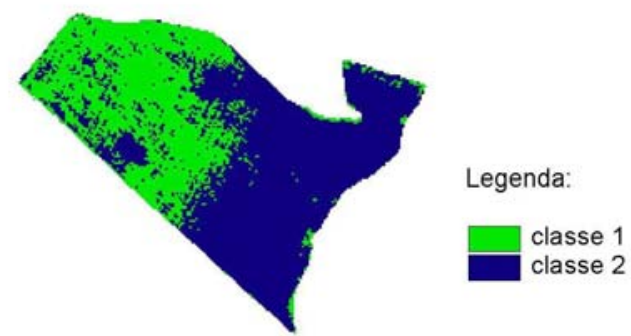

(d)

Figura 29 - Produtividade (a); imagem no vermelho (b); imagem no infravermelho próximo (c); e imagem NDVI, para a cultura da soja, área 1, classificados

Verificou-se, analisando visualmente, uma forte correlação entre a classe de menor produtividade (classe 1), com a classe de menor valor de NDVI (classe 1), para as variáveis da área 1, cultura da soja (Figura 29). 


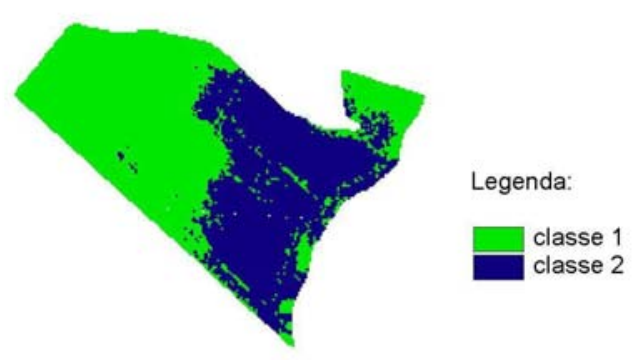

(a)

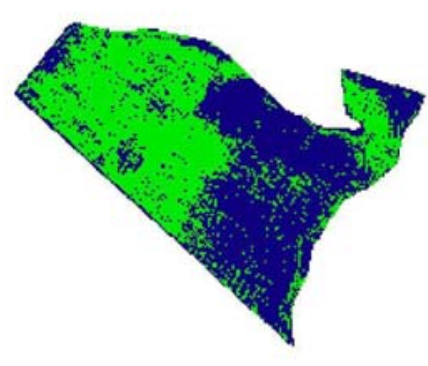

Legenda:

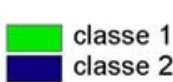

(c)

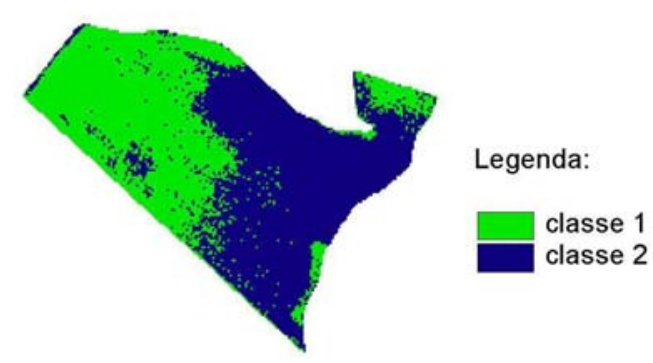

(b)

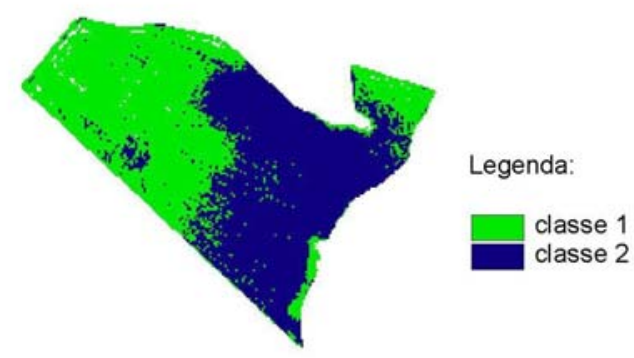

(d)

Figura 30 - Produtividade (a); imagem no vermelho (b); imagem no infravermelho próximo (c); e imagem NDVI, para a cultura do trigo, área 1, classificados

A área 1, com a cultura do trigo (Figura 30), apresentou similarmente à cultura da soja (Figura 29), uma forte correlação visual entre as classes 1 e 2, para as variáveis produtividade e imagens NDVI, vermelho e infravermelho próximo.

A classificação realizada na área 2 (Figura 31), como no caso da correlação visual das imagens originais (sem classificação), não apresentou tendência para nenhuma combinação realizada entre as variáveis. 


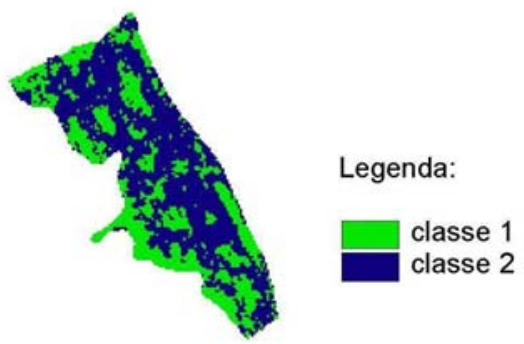

(a)

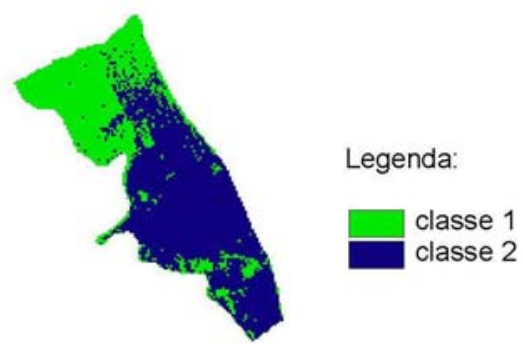

(c)

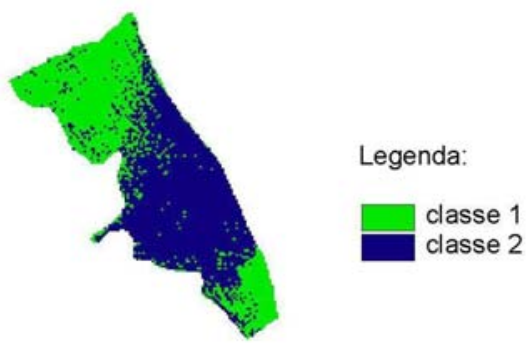

(b)

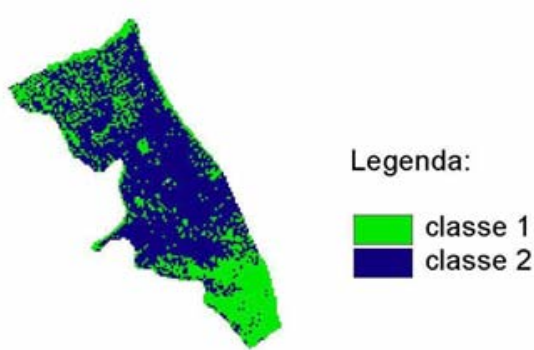

(d)

Figura 31 - Produtividade (a); imagem no vermelho (b); imagem no infravermelho próximo (c); e imagem NDVI, para a cultura do trigo, área 2, classificados

\subsubsection{Análise de concordância espacial entre as variáveis classificadas}

Se recorrermos somente à análise visual para comparar os mapas e imagens produzidas, reparamos em algumas semelhanças, mas não é possível distinguir com objetividade o grau de similaridade entre as classes. Logo, a informação obtida é muito geral e subjetiva, pois é baseada no contraste visual. 
Visando evitar esta subjetividade, foi utilizado o índice Kappa de concordância espacial.

Para verificar o grau de correspondência entre os dados coletados em grade, classificados em duas classes e a imagem NDVI, classificada da mesma forma, procedentes da área 1, cultura da soja, procedeu-se à verificação da concordância entre as mesmas (Tabela 15).

Tabela 15. Índice Kappa para as variáveis obtidas em grade e imagem NDVI, para a área 1, cultura da soja

\begin{tabular}{ccccc}
\hline & NDVI & IAF & Altura & Plantas \\
\hline NDVI & 1,0 & 0,52 & 0,57 & 0,58 \\
IAF & & 1,0 & 0,63 & 0,78 \\
Altura & & 1,0 & 0,55 \\
Plantas & & & 1,0 \\
\hline
\end{tabular}

NDVI: índice de vegetação da diferença normalizada; IAF: índice de área foliar $\left(\mathrm{m}^{2} \cdot \mathrm{m}^{-2}\right)$; Altura: altura de plantas $(\mathrm{m})$; Plantas: número de plantas por metro linear.

Nesta análise verificaram-se valores altos de concordância entre as variáveis analisadas, principalmente entre o IAF e o número de plantas por metro linear, com valor de índice Kappa igual a 0,78, qualitativamente considerado muito bom, segundo a Tabela 3. Nesta mesma qualificação encontra-se também a concordância entre IAF e altura de plantas. As demais comparações encontram-se na faixa correspondente a concordâncias consideradas boas, variando o valor de índice Kappa de 0,52 a 0,58.

Na Tabela 16 são apresentados os valores de índice Kappa para a comparação entre os mapas de produtividade das áreas 1 e 2, correspondentes as culturas da soja e do trigo, e os valores de nível de cinza das imagens aéreas em bandas individualizadas do vermelho e infravermelho próximo e da imagem formada pelo NDVI. 
Tabela 16. Índice Kappa entre as variáveis de imagem e produtividade classificadas

\begin{tabular}{lccc}
\hline & \multicolumn{3}{c}{ Produtividades } \\
& Soja & \multicolumn{2}{c}{ Trigo } \\
& Área 1 & Área 1 & Área 2 \\
\hline VER & 0,622 & 0,845 & 0,432 \\
INFRA & 0,635 & 0,718 & 0,447 \\
NDVI & 0,646 & 0,854 & 0,493
\end{tabular}

INFRA: valores de nível de cinza para imagem do infravermelho próximo; VER: valores de nível de cinza para imagem do vermelho; NDVI: valores de NDVI; Trigo: produtividade do trigo (t/ha); Soja: produtividade da soja (t/ha).

O NDVI novamente mostrou-se mais eficiente em relação às bandas individuais, de acordo com os valores do índice Kappa, quando comparado com a produtividade das culturas analisadas.

A área 2 apresentou valores de índice Kappa considerados bons. A área 1 , cultura da soja, apresentou valores considerados muito bons e para a cultura do trigo houve uma variação entre valores Kappa considerados muito bons a excelentes. Em todos os casos o NDVI apresentou valores de índice Kappa superiores ao vermelho e ao infravermelho próximo. A cultura do trigo, referente à área 1, foi a que apresentou maiores valores de índice Kappa.

Mesmo sendo análises distintas, o índice Kappa e a regressão pixel-apixel, apresentaram a mesma tendência, sendo mais elevada para a área $1 \mathrm{com}$ cultura do trigo, área $1 \mathrm{com}$ cultura da soja e área 2 com cultura do trigo, respectivamente.

A Figura 32 ilustra a correlação entre as classes obtidas no processo de tabulação cruzada entre a produtividade da cultura da soja e o NDVI, na área 1, por meio do mapa gerado nesta operação. 


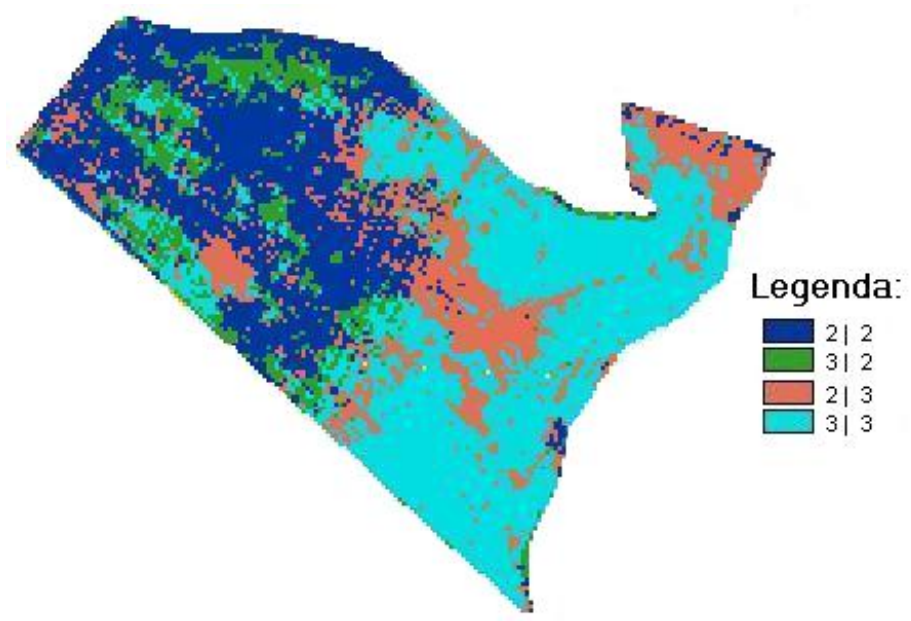

Figura 32 - Mapa de correlação entre as classes obtidas no processo de tabulação cruzada, para a produtividade da cultura da soja e o NDVI, na área 1

Este mapa apresenta um índice Kappa de 0,646, mostrando as coincidências entre as superfícies formadas pelas classes estabelecidas. Podese observar a boa correspondência visual, principalmente entre as classes 2 e 3, mas verifica-se que os valores encontrados na Tabela 16 de índice Kappa, é mais esclarecedor. Este fato demonstra o potencial das imagens videográficas aéreas multiespectrais no delineamento de zonas de manejo, em áreas de culturas de grãos. 


\section{CONCLUSÕES}

Para as condições em que o trabalho foi desenvolvido conclui-se que:

- Os mapas de superfície criados para o IAF, altura de plantas e número de plantas por metro linear, apresentam elevada correlação entre si;

- Os valores de NDVI e IAF apresentam correlação, mas os valores referentes a esta correlação são considerados baixos;

- A imagem NDVI apresenta uma melhor relação com a estimativa de produtividade de culturas de grãos, quando comparada com as imagens das bandas espectrais individualizadas, do vermelho e do infravermelho próximo;

- As imagens aéreas digitais multiespectrais obtidas por videografia são eficientes na estimativa de produtividade de grãos quando existe heterogeneidade nas imagens produzidas (elevado CV) e as mesmas não apresentam valores discrepantes;

- As imagens videográficas aéreas digitais multiespectrais proporcionam informações importantes ao delineamento de zonas de manejo. 


\section{REFERÊNCIAS BIBLIOGRÁFICAS}

ADAMSEN, F.J.; PINTER, P.J.; BARNES, E.M.; KIMBALL, B.A. Measuring wheat senescence with a digital camera. Crop Science, v.39, n.2, p.719724, 1999.

AMARAL, G. Introdução ao sensoriamento remoto e suas aplicações. 2.ed. Campinas: UNICAMP/IG, 1992. 124p.

ANDERSON, G.L.; YANG, C. Multispectral videography and geographic information systems for site-specific farm management. In: INTERNATIONAL CONFERENCE ON PRECISION AGRICULTURE, 3., Wisconsin, 1996. Proceedings. Wisconsin: ASA; CSSA; SSSA, 1996. p.681-692.

ANDERSON, J.; DELOACH, S.; WATERS, D.; HOWARD, P. Comparative field and image-derived metrics for forecasting yields in cotton. In: INTERNATIONAL CONFERENCE ON GEOESPATIAL INFORMATION IN AGRICULTURE AND FORESTRY, 2., Lake Buena Vista, 2000. Proceedings. Lake Buena Vista: Flórida, 2000. p.130-135.

ANTUNIASSI, R.U.; GADANHA JÚNIOR, C.D. Aplicação localizada de produtos fitossanitários. In: ENCONTRO DE AGRICULTURA DE PRECISÃO, 1., Viçosa, 2000. Anais. Viçosa: UFV, 2000. p.181-202. 
ARAUJO, J.C. Correlação entre mapas de produtividade de grãos e fotografias aéreas convencionais $35 \mathrm{~mm}$. Piracicaba, 2000. 58p. Dissertação (Mestrado) - Escola Superior de Agricultura "Luiz de Queiroz", Universidade de São Paulo.

BALASTREIRE, L.A.; ELIAS, A.I.; AMARAL, J.R. Agricultura de precisão, mapeamento e produtividade da cultura do milho. Viçosa: Departamento de Engenharia Agrícola, UFV, 1997. 324p.

BANZATTO, D.A.; KRONKA, S. do. N. Experimentação agrícola. 3.ed. Jaboticabal: FUNEP; UNESP, 1995. 247p.

BARRET, F.; GUYOT, G.; MAJOR, D.J. Crop biomass evaluation using radiometric measurements. Photogrammetric Engineering and Remote Sensing, v.43, n.5, p.241-256, 1989.

BAUER, M.E.; DAUGHTRY, C.S.T.; VANDERBITT, V.C. Spectral agronomic relationships of maize, soybean and wheat canopies. In: INTERNATIONAL COLLOQUIUM ON SPECTRAL SIGNATURES OF OBJECTS IN REMOTE SENSING, 1., Avignon, 1981. Anais. Avignon: SAM, 1981. p.8-11.

BETTING, J. De olho no agronegócio. O Estado de São Paulo. Economia, São Paulo. http://www.estado.com.br. (05 mar. 2004).

BLACKMER, A.M.; SCHEPERS, J.S. Using DGPS to improve corn production and water quality. GPS World, v.2, n.1, p.44-52, 1996. 
BLACKMER, A.M.; WHITE, S.E. Remote sensing to identify spatial patterns in optimal rates of nitrogen fertilization. In: INTERNATIONAL CONFERENCE ON PRECISION AGRICULTURE, 3., Wisconsin, 1996. Proceedings. Wisconsin: ASA; CSSA; SSSA, 1996. p.431-442.

BLACKMORE, S. Precision farm: an introduction. Outlook on Agriculture, v.23, n.4, p.275-280, 1994.

BLACKMORE, S.; LARSCHEID, G. Strategies for managing variability. In: EUROPEAN CONFERENCE ON PRECISION AGRICULTURE, 1997, 1., London, 1997. Proceedings. London: BIOS, 1997. p.851-859.

BURROUGH, P.A.; VAREKAMP, C.; SKIDMORE, A.K. Using public domain geostatistical and GIS software for spatial interpolation. Photogrammetric Engineering and Remote Sensing, v.62, n.7, p.845-854, 1996.

CÂMARA, G. Modelos, linguagens e arquiteturas para bancos de dados geográficos. São José dos Campos, 1995. 208p. Tese (Doutorado) Instituto Nacional de Pesquisas Espaciais.

CAMARGO, E.C.G. Desenvolvimento, implementação e teste de procedimentos geoestatísticos (krigeagem) no sistema de processamento de informações georreferenciadas (spring). São José dos Campos, 1997. 106p. Dissertação (Mestrado) - Instituto Nacional de Pesquisas Espaciais.

CARTER, P.G. Pattern recognition within crop vegetation: A crop anomaly classification system. Purdue, 1999. 146p. Dissertation (Master Science) Purdue University. 
CARTER, P.G.; JOHANNSEN, C.J. Crop vegetation anomaly identification from observed patterns found within remote sensing data. In: INTERNATIONAL CONFERENCE ON GEOESPATIAL INFORMATION IN AGRICULTURE AND FORESTRY, 2., Lake Buena Vista, 2000. Proceedings. Lake Buena Vista: Flórida, 2000. p.152-155.

CASTRO, C. Boro e estresse hídrico na nutrição e produção do girassol em casa de vegetação. Piracicaba, 1999. 120p. Tese (Doutorado) - Escola Superior de Agricultura "Luiz de Queiroz", Universidade de São Paulo.

CHOUDHURY, B.J. Relationships between vegetation indices, radiation and net photosynthesis evaluated by a sensitivity analysis. Remote Sensing of Environment, v.22, n.2, p.209-234, 1987.

COLVIN, T.S.; JAYMES, D.D.B.; KARLEN, D.L.; LAIRD, D.A.; AMBUEL, J.R. Six year yield variability within a central lowa field. In: INTERNATIONAL CONFERENCE OF THE AMERICAN SOCIETY OF AGRONOMY, 1., Minneapolis, 1996. Proceedings. Minneapolis: ASA; CSS; SSSA, 1996. p.863-870.

COSTA, F.A.; SANTOS, M.L. Agricultura de precisão - uma nova revolução tecnológica no campo. Economia Rural, v.2, n.8, p.33-34, 1997.

CROSTA, A.P. Processamento digital de imagens de sensoriamento remoto. 2.ed. Campinas: UNICAMP/IG, 1993. 170p. 
DABERKOW, S.G.; BRENEMAN, V.E.; KIM, C.S. Exploring the economic potential of remotely sensed images: a case study of aerial photography in irrigated corn precision agriculture. In: EUROPEON CONFERENCE ON PRECISION AGRICULTUR CONGRESS CENTRE, 1., Copenhagen, 1999. Proceedings. Copenhagen: SCl Acadamic Press, 1999. p.615-624.

DAUGHTRY, C.S.T.; GALLO, K.P.; BIEHL. L.L.; KANEMASU, E.T.; ASRAR, G.; BLAD, B.L.; NORMAN, J.M.; GARDNER, B.R. Spectral estimative of agronomic characteristics of crops. In: SYMPOSIUM OF MACHINE PROCESSING OF REMOTE SENSED DATA. 1., Lafayette, 1984. Proceedings. Lafayette: Purdue University, 1984. p.348-55.

DELFINER, P.; DELHOMME, J.P. Optimum interpolation by Kriging. In: DAVIS, J. C.; MCCULLAGH, M.J. Display and analysis of spatial data. 2.ed. New York: John Wiley, 1975. 114p.

DIKER, K.; BAUSCH, W.C.; HEERMANN, D.F. Monitoring temporal changes of irrigated corn by aerial images. Transactions of the ASAE, v.23, n.2, p.4548, 2001.

DOEGE, T.A. The evolution of agriculture production. Journal of Production Agriculture. v.3., n.1, p.50-55, 1999.

DUNCAN TECHNOLOGIES INC. MS3100 digital multiespectral camera user's manual. Auburn: Duncan Technologies, 1999. 32p.

EASTMAN, J.R. IDRISI for windows users's guide version 2.0. Tutorial exercise. Worcester: Graduate School of Geography, Clark University, 1997. $192 p$. 
EASTMAN, J.R. IDRISI32, Version 32.11: software de sistemas de informação geográfica (software). Worcester: Clark University, 1998.

EMPRESA BRASILEIRA DE PESQUISA AGROPECUÁRIA - EMBRAPA. http://www.cnpt.embrapa.br/ (23 jun. 2003).

EVERITT, J.H.; ESCOBAR, D.E.; VILLAREAL, R.; NORIEGA, J.R.; DAVIS, M.R. Airborne Vídeo Systems for agriculture Assessment. Remote Sensing of Environment, v.35, n.2, p.231-242, 1991.

FARRET, J.C.; GIOTTO, E. Aplicabilidade do georreferenciamento de aerofotos de pequeno formato na formação de bancos de dados espaciais uma alternativa para o cadastro técnico rural municipal. Ciência Rural, v.27, n.4, p.577-581, 1997.

FIETZ, C.R. Variabilidade espacial do armazenamento de água no solo visando o manejo da irrigação por aspersão. Piracicaba, 1998. 97p. Tese (Doutorado) - Escola Superior de Agricultura "Luiz de Queiroz", Universidade de São Paulo.

FONSECA, L.M.G. Processamento digital de imagens. 1.ed. São José dos Campos: INPE, 2000. 165p.

FONTANA, D.C.; WEBER, E.; DUCATI, J.; FIGUEIREDO, D.C.; BERLATO, M.A.; BERGAMASCHI, H. Previsão da safra de soja no Brasil. In: CONGRESSO BRASILEIRO DE AGROMETEOROLOGIA, 3., Fortaleza, 2001. Anais. Fortaleza: Sociedade Brasileira de Agrometeorologia, 2001. p.585-586. 
FORMAGGIO, A.R. Características agronômicas e espectrais para o sensoriamento remoto de trigo e feijão. Piracicaba, 1989. 161p. Tese (Doutorado) - Escola Superior de Agricultura "Luiz de Queiroz", Universidade de São Paulo.

FLOYD JÚNIOR, F.S. Remote sensing: Principles and interpretation. New York: Freemaned, 1996. 449p.

GAMMA DESIGN SOFTWARE INC. GS+ Geoestatistics for the environmental sciences, version 3.1.8.8 demonstration: software de análise geoestatística (software). Michigan, 1998.

GARCIA Y GARCIA, A. Variabilidade espacial de atributos físicos do solo e resposta espectral da cultura de feijão irrigado, em imagens aéreas digitais. Piracicaba, 1997. 78p. Dissertação (Mestrado) - Escola Superior de Agricultura "Luiz de Queiroz", Universidade de São Paulo.

GOERING, C.E. How much and where. Agricultural Engineering, v.73, n.4, p.13-15, 1992.

GOERING, C.E.; HAN, S. A field information system for SSCM. Warrendale: SAE International, 1993. (Technical Paper Series, 932422).

GOLDEN SOFTWARE INC. Surfer for Windows, version 6.01: software de geração de mapas de contorno e superfícies contínuas (software). Colorado, 1995.

HAN, S.; HUMMEL, J.W.; GOERING, C.E.; CAHN, M.D. Cell size for site specific crop management. Transactions of the ASAE, v.37, n.1, p.19-25, 1994. 
HOAGLIN, D.C.; MOSTELLER, F.; TYKEY, J.W. Análise exploratória de dados: técnicas robustas, um guia. Lisboa: Salamandra, 1983. 446p.

HOLBEN, B.N.; TUCKER, C.J.; FAN, C.J. Spectral assessment of soybean leaf area and leaf biomass. Photogrammetric Engineering and Remote Sensing, v.46, n.5, p.651-656, 1980.

HUETE, A.R.; JACKSON, R.D. Soil and atmosphere influences on the spectra of partial canopies. Remote Sensing of Environment, v.30, n.1, p.43-54, 1989.

HUMPHRIES, E.C. The dependence of photosynthesis on carbohydrate sinks: current conceps. Proceedings of the International Symposium on Tropical Root Crops, v.1, n.2, p.34-45, 1967.

ISAAKS E.H.; SRIVASTAVA R.M. An introduction to applied geostatistics. New York: Oxford University Press, 1989. 560p.

JACKSON, R.D.; HUETE, A.R. Interpreting vegetation indices. Preventive Veterinary Medicine, v.11, n.2, p.185-200, 1991.

JAKOB, A.A.E.; ROCHA, J.V.; LAMPARELLI, R.A.C. Estudo da correlação entre mapas de variabilidade de propriedades do solo e mapas de produtividade para fins de agricultura de precisão (Compact disc). In: CONGRESSO E FEIRA PARA USUÁRIOS DE GEOPROCESSAMENTO DA AMÉRICA LATINA. 1., Salvador, 1999. Anais. Salvador: GIS Brasil, 1999. p.28-39. 
KING, D. Airborne multiespectral digital camera and video sensors: a critical review of system design and application. Canadian Journal of Remote Sensing, v.21, p.245-273, 1995.

KOLLER, M.; UPADHYAYA, S.K.; ROSA, U. Application of remote sensing in a tomato production system. California: ASA, 1999. (ASAE Paper, n.99113),.

KÖPPEN, W. Climatología. Con un estudio de los climas de la Tierra. México: Fondo de Cultura Econômica, 1948. 478p.

KRIGE, D.G. A statistical approach to some basic mine evaluation problems on the Witwatersrand. Johannesburg Chemistry Metallurgy Mining Society of South African, v.52, n.6, p.119-139, 1951.

LAJAUNIE, C. A geostatistical approach to air pollution modelling. In: JOURNEL, A.G.; MARECHAL, A. (Ed.). Geostatistics for natural resources characterization. Paris: ENSMP, 1984. p.877-891.

LAMB, D.W.; SPACKMAN, S.; LOUIS, J.; BLACK, S.; MCDWAY, J. Forecasting yield in rice using remote sensing and crop growth models. In: SYMPOSIUM ON AUSTRALIAN RESEARCH AND APPLICATION OF PRECISION AGRICULTURE, 1., Sydney, 2000. Proceedings. Sydney: University of Sydney, 2000. p.33-34.

LANDIS, J.; KOCH, G. The measurement of observer agreement for categorical data. Biometrics, v.33, p.159-174, 1977.

LANGE, A.F. On datums and geoids. Gis World, v.9, n.10, p.62, 1996. 
LI-COR. LAI-2000 plant canopy analyser: Instruction manual. Lincoln: LICOR, 1992. 166p.

LUEDER, D.R. Aerial photographic interpretation: principles and applications. New York: McGraw-Hill, 1959. 462p.

MAACK, R. Geografia física do Estado do Paraná. 1.ed. Curitiba: Banco de Desenvolvimento do Paraná; UFPR, 1968. 242p.

MAKEPEACE, R.J. Benefits and limitations of precision farming. In: BRIGHTON CONFERENCE ON PESTS AND DISEASES, Brighton, 1996. Proceedings. Brighton: EPC, 1996. v.3, p.1235-1242.

MARCHETTI, D.A.B.; GARCIA, G.J. Princípios de fotogrametria e fotointerpretação. São Paulo: Nobel, 1988. p.183-189.

MATHER, P.M. Computer processing of remotely - sensed images: an introduction. New York: John Wiley, 1994. 352p.

MATHERON, G. The theory of regionalized variables and its applications. Paris: Les Cahiers du Centre de Morphologie Mathematique de Fontainebleu, 1971. 211p.

MOLIN, J.P. Agricultura de Precisão: fundamentos e estado atual da arte. In: CÂMARA, G.M. Soja: Tecnologia da produção II. Piracicaba: ESALQ, Departamento de Produção Vegetal, 2000a. p.423-437. 
MOLIN, J.P. Geração e interpretação de mapas de produtividade para a agricultura de precisão. In: BORÉN, A.B.; GIÚDICE, M.P.; QUEIROZ,D.M.; MANTOVANI, E.C.; FERREIRA, L.R.; VALLE, F.X.R.; GOMIDE, R.T. Agricultura de precisão. Viçosa: UFV, 2000b. p.237-258.

MOLIN, J.P.; VETTORAZZI, C.A. Novidades no posicionamento por satélites. A Granja, v.58, n.646, p.33-34, 2002.

MORAN, M.S.; INOUE, Y.; BARNES, E.M. Opportunities and limitations for image based remote sensing in precision crop management. Remote Sensing of Environment, v.61, n.2, p.319-346, 1997.

MOREIRA, M.A. Fundamentos do sensoriamento remoto e metodologias de aplicação. São José dos Campos: INPE, 2001. 250p.

MOTTA, Á. Os determinantes das exportações brasileiras de bens industrializados. Rio de Janeiro, 2001. 108p. Tese (Doutorado) - Pontifícia Universidade Católica do Rio de Janeiro.

MOURA, V. Imagens multitemporais TM/Landsat-5 da época de pré-plantio na estimativa de áreas destinadas a culturas de verão. São José dos Campos, 2000. 112p. Dissertação (Mestrado) - Instituto Nacional de Pesquisas Espaciais.

NOVO, E.M.L. de M. Sensoriamento remoto: princípios e aplicações. 2.ed. São Paulo: Edgard Blücher, 1995. 308p. 
PETERSON, D.L.; SPANNER, M.A.; RUNNING, S.W.; TEUBER, K.B. Relationship of thematic maper simulater data to leaf area index of temperature coniferous forests. Remote Sensing of Environment, v.22, n.3, p.323-341, 1997.

QUEIROZ, D.M. de; DIAS, G.P.; MANTOVANI, E.C. Agricultura de precisão na produção de grãos. In: BORÉM, A.B.; GIÚDICE, M.P.; QUEIROZ, D.M.; MANTOVANI, E.C.; FERREIRA, L.R.; VALLE, F.X.R.; GOMIDE, R.T. Agricultura de precisão. Viçosa:UFV, 2000. p.1-42.

QUINTANILHA, J.A. Processamento de imagens digitais. In: SIMPÓSIO BRASILEIRO DE GEOPROCESSAMENTO. 1., São Paulo, 1990. Anais. São Paulo: EDUSP, 1990. p.37-52.

RICCI, M.; PETRI, S. Princípios de aerofotogrametria e interpretação geológica. São Paulo: Editora São Paulo, 1965. 226p.

RICHARDS, J.A. Remote sensing digital image analysis: an introduction. London: Springer-verlag, 1993. 340p.

RIPPLE, W.J. The GIS applications book: examples in natural resources. Bethesda: American Society for Photogrammetry and Remote Sensing, 1994. 380p.

ROSA, R. Introdução ao sensoriamento remoto. Uberlândia: EDUFU, 1990. $135 p$. 
SANTOS JUNIOR, R.F.; SANTOS, J.M.; RUDORFF, B.F.T.; MARCHIORATO, I.A. Utilização do SR com medidas de espectroradiômetro de campo no visível e infravermelho próximo para detecção de áreas infestadas com Meloidagyne incognita em algodão. In: CONGRESSO BRASILEIRO DE NEMATOLOGIA, 23., Marília, 2001. Anais. Marília: UFSP, 2001a. p.6868.

SANTOS JUNIOR, R.F.; SANTOS, J.M.; RUDORFF, B.F.T.; MARCHIORATO, I.A. Espectrorradiometria de campo no visível e infravermelho próximo para detecção de áreas infestadas com Meloidogyne javanica em soja. In: CONGRESSO BRASILEIRO DE NEMATOLOGIA, 23., Marília, 2001. Anais. Marília: UFSP, 2001b. p.62-62.

SASSAGAWA, H.S.Y. Técnicas de sensoriamento remoto e sistema de informações geográficas (SIG) para o estudo da ocupação do espaço físico e dos tipos florestais da reserva extrativista Chico Mendes, Estado do Acre. São José dos Campos, 1999. 170p. Dissertação (Mestrado) - Instituto Nacional de Pesquisas Espaciais.

SCHEPERS, J.S. What is remote sensing? Lincoln: Fall Press, 1996. 30p.

SCHUELLER, J.K. A review and integrating analysis of spatially - variable crop control of crop production. Fertilizer Research, v.33, p.1-34, 1992.

SCHULER, R.T.; LANGTON, S.J.; WOLKOWSKI, R.P. Remote sensing research in Wiscosin soybean and corn production fields. In: INTERNATIONAL CONFERENCE ON PRECISION AGRICULTURE. 4., Minnesota, 1998. Proceedings. Minnesota: ASA; CSSA; SSSA, 1998. p.1435-1445. 
SEARCY, S.W. Engineering systems for site-specific management: opportunities and limitations. In: INTERNATIONAL MANAGEMENT FOR AGRICULTURAL SYSTEMS, 1., Madison, 1995. Proceedings. Madison: ASA; CSSA; SSSA, 1995. p.603-611.

SHARP, T.; SALVADOR, A.; BAIO, F.H.R. Relações entre NDVI e mensurações físicas das plantas em campos de algodão. In: CONGRESSO BRASILEIRO DE AGRICULTURA DE PRECISÃO, 1., Piracicaba, 2004. Anais. Piracicaba, 2004. p.112.

SILVA, E.A.; SILVA, J.F.V.; MONICO, J.F.G.; HIROMOTO, D.M. Perspectivas no manejo e controle localizado de doenças das culturas: uma abordagem no manejo do nematóide de cisto da soja. In: SIMPÓSIO BRASILEIRO DE AGRICULTURA DE PRECISÃO, 1., Viçosa, 2000. Anais. Viçosa: UFV, 2000. p.453-467.

SIMAKOVA, M.S. Soil mapping by color aerial photography. Jerusalén: S. Monson, 1964. 81p.

SPURR, S.H. Photogrammetric and photointerpretation, whit a section on applications to forestry. New York: Ronald Press, 1960. 472p.

STAGGENBORG, S.A.; FJELL, D.L.; TAYLOR, T. Using infrared images as a corn scouting tool. Agronomic Abstract, v.12, n.2, p.90-116, 2000.

STAR, J.; ESTES, J. Geographic information systems: An introduction. New Jersey: Prentice Hall, 1990. 215p.

STEINER, D. Time dimension for crop surveys from space. Photogrammetric Enginnering, v.36, n.2, p.187-194, 1970. 
STEVEN, M.D.; MILLAR, C. Satellite monitoring for precision farm decision support. Bios, v.1, p.697-703, 1997.

TAYLOR, J.C.; WOOD, G.A.; THOMAS, G. Mapping yield potential with remote sensing. In: EUROPEAN CONFERENCE ON PRECISION AGRICULTURE, 1., London, 1997. Proceedings. London: SCI, 1997. p.713-720.

THOMSON J.F.; STANFORD, J.V.; AMBLER, B. Discovery of harmful herb in cerial crops. Saint Joseph: ASAE, 1990. (Suplement -1, 90) 1629p.

TOZI, F.A. Sistemas de informação geográfica na agricultura. In BALASTREIRE, L.A. (Editora) O Estado-da-arte da agricultura de precisão no Brasil. Piracicaba, 2000. p.187-192.

TRANGMAR, B.B.; YOST, R.S.; WADE, M.K.; UEHARA, G. Applications of geoestatistics to spatial studies of soil properties. Advances in Agronomy, v.38, n.2, p.45-94, 1985.

TUCKER, C.J. Red and photographic linear combinations for monitoring vegetation. Remote Sensing of Environment, v.8, n.2, p.127-150, 1979.

VARNER, V.; LACHOWSKI, H.; MAUS, P.; GOLDEN, M.; JOHNSON, J.; LANDRUM, V.; POWELL, J.; WIRTH, T.; GONZALES, J.S.; BAIN, S. Guidelines for the use of digital imagery for vegetation mapping. Washington: USDA, Forest Service Engineering Staff, 2000. 63p. (EM7140-25).

VEIGA, R.D.; SÁFADI, T. Análise de regressão e séries temporais. Lavras: UFLA, FAEPE, 1999. 57p. 
VELLIDIS, G.; THOMAS, D.; WELLS, T. Cotton yield maps created from aerial photographs. In: INTERNATIONAL MEETING SPONSORED BY ASAE. 1., Toronto, 1997. Proceedings. Toronto: ASAE, 1997. p.35-38.

VETTORAZZI, C.A.; COUTO, H.T.Z.; FERRAZ, S.F.B.; POMPERMAYER, P. Videografia aérea como fonte de dados para a tomada de decisões em agricultura. In SIMPÓSIO BRASILEIRO DE AGRICULTURA DE PRECISÃO, 1., Piracicaba, 2000. Anais. Piracicaba: ESALQ, 2000. p.197200

VIEIRA, S.R. Uso da geoestatística em estudos de variabilidade espacial. In: CURSO DE ATUALIZAÇÃO EM CONSERVAÇÃO DO SOLO, 1995. Apostila. Campinas: IAC, 1995. 61p.

VIEIRA, S.R. Geoestatística aplicada a Agricultura de precisão. In: BORÉM, A.; GIÚDE, M.P.; QUEIRÓZ, D.M.; MANTOVANI, E.C.; FERREIRA, L.R.; VALLE, F.X.R.; GOMIDE, R.L. (Ed.). Agricultura de precisão. Viçosa: Giúdice \& Bóren, 2000. p.93-108.

VIEIRA, S.R.; DE MARIA, I.C.; CASTRO, O.M.; DECHEN, S.C.F.; LOMBARDI NETO, F. Utilização da análise de Fourier no estudo do efeito residual da adubação em uva na crotalária. Revista Brasileira de Ciência do Solo, v.11, n.7, p.7-10, 1987.

VOLL, E. Agricultura de precisão: Manejo de plantas daninhas. In: BÓREM, A.; GIÚDE, M.P.; QUEIRÓZ, D.M.; MANTOVANI, E.C.; FERREIRA, L.R.; VALLE, F.X.R.; GOMIDE, R.L. Agricultura de precisão. Viçosa: Giúdice \& Bóren, 2000. p.203-235. 
XAVIER, A.C. Estimativa da dinâmica do índice de área foliar em uma microbacia hidrográfica por meio de técnicas de sensoriamento remoto. Piracicaba, 2002. 111p. Tese (Doutorado) - Escola Superior de Agricultura "Luiz de Queiróz", Universidade de São Paulo.

WAGNER, L.E.; SCHROCK, M.D. Yield determination using a pivoted auger flow sensor. Transactions of the ASAE, v.32, n.2, p.409-413, 1989.

WIEGAND, G.L.; RICHARDSON, A.J.; ESCOBAR, D.E. Vegetation indices in crop assessment. Remote Sensing of Environment, v.35, n.2, p.105-109, 1991.

YANG, C. Tropical soils and soil survey. Cambridge: Cambridge University Press, 1998. 468p.

YANG, C.; EVERITT, J.H.; BRADFORD, J.M.; ESCOBAR, D.E. Airbone multiespectral digital imagery for detecting plant growth and yield variability for a grain sorghum field. In: INTERNATIONAL CONFERENCE ON GEOESPATIAL INFORMATION IN AGRICULTURE AND FORESTRY, 2., Lake Buena Vista, 2000. Proceedings. Lake Buena Vista: Flórida, 2000. p.477-485.

ZANIN, G.; BERTI, A.; RIELO, L. Incorporation of weed spatial variability into the weed control decisión-making process. Weed Research, v.38, n.2, p.107-118, 1998.

ZHANG, M.; HENDLEY, P.; DROST, D. Corn and soybean yield Indicators using remotely sensed vegetation index. In: CONFERENCE ON PRECISION AGRICULTURE, 4., St. Paul, 1998. Proceedings. St. Paul: Minneapolis, 1998. p.1475-1482. 